\title{
Hierarchically nanostructured transition metal oxides for supercapacitors
}

\author{
Mingbo Zheng, Xiao Xiao, Lulu Li, Peng Gu, Xiao Dai, Hao Tang, Qin Hu, Huaiguo Xue and \\ Huan Pang*
}

\begin{abstract}
Highly efficient, clean, and sustainable electrochemical energy storage technologies have been investigated extensively to counter the shortage of fossil fuels and increasingly prominent environmental problems. Supercapacitors (SCs) have received wide attention as critical devices for electrochemical energy storage because of their rapid charging-discharging capability and long life cycle. Various transition metal oxides (TMOs), such as $\mathrm{MnO}_{2}, \mathrm{NiO}, \mathrm{Co}_{3} \mathrm{O}_{4}$, and $\mathrm{CuO}$, have been extensively studied as electrode materials for SCs. Compared with carbon and conducting polymers, TMO materials can achieve higher specific capacitance. For further improvement of electrochemical performance, hierarchically nanostructured TMO materials have become a hot research area for electrode materials in SCs. The hierarchical nanostructure can not only offer abundant accessible electroactive sites for redox reactions but also shorten the ion diffusion pathway. In this review, we provide an overall summary and evaluation of the recent progress of hierarchically nanostructured TMOs for SCs, including synthesis methods, compositions, structures, and electrochemical performances. Both single-phase TMOs and the composites based on TMOs are summarized. Furthermore, we also prospect the developing foreground of this field. In this view, the important directions mainly include: the nanocomposites of TMOs materials with conductive materials; the cobalt-based materials and the nickel-based materials; the improvement of the volume energy density, the asymmetric SCs, and the flexible all-solid-state SCs.
\end{abstract}

Keywords: hierarchical nanostructure, transition metal oxides, supercapacitors

\section{INTRODUCTION}

With the rapid development of global economy, energy shortage and environmental pollution have become two extremely important issues worldwide. A breakthrough in exploiting highly efficient and clean energy storage technologies is necessary to satisfy future energy requirements [1-6]. The electrochemical energy storage is the most promising approach because of its high efficiency, good reliability, ease of operation, and good ecofriendly character [7-18]. Electrochemical energy storage technologies mainly include batteries and supercapacitors (SCs) $[19,20]$. As a new energy storage approach, SCs combine the advantages of high energy density of rechargeable batteries and high power density of dielectric capacitors [19-29]. SCs have been regarded as highly important candidates for energy storage devices because of their fast charging-discharging capability, long cycle stability $\left(>10^{5}\right.$ cycles), high power density $\left(>10 \mathrm{~kW} \mathrm{~kg}^{-1}\right)$, low cost, environment-friendly nature, low maintenance, and safe operation [30-46]. In certain fields, SCs can partly or fully replace traditional batteries.

SCs can be divided into two categories according to energy storage mechanism: electrical double-layer capacitors (EDLCs) (Fig. 1a) and pseudocapacitors (Fig. 1b) [19-21]. The capacitance of EDLCs is associated with the charge separation and accumulation at the interface between electrode and electrolyte [19-21]. During charging, the electric charges on the surface of electrode attract the ions with opposite charges in the electrolyte. Thus, the electric double layer is formed on the surface of electrode and the energy stroge is realized. The capacitance stored in the electric double layer is proportional to the specific surface area of the electrode. During discharging, ions return to the electrolyte and electrons flow into the external circuit. Nanostructured carbon materials, such as mesoporous carbon, activated carbon, carbon nanotubes,

School of Chemistry and Chemical Engineering, Institute for Innovative Materials and Energy, Yangzhou University, Yangzhou 225009, China

* Corresponding author (emails: huanpangchem@hotmail.com or panghuan@yzu.edu.cn) 


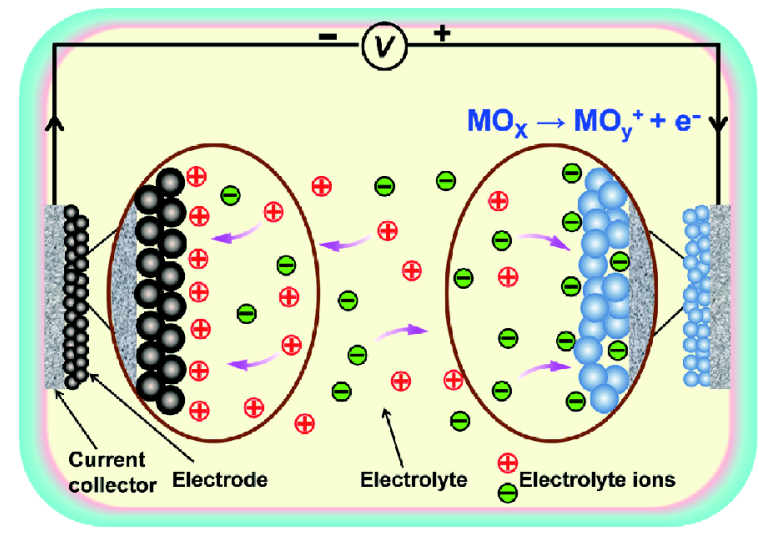

Figure 1 Schematic of the two different mechanisms of SCs: (a) EDLCs and (b) pseudocapacitors.

carbon nanofibers, and graphene, have been widely studied as the electrode materials of EDLCs. The capacitance of pseudocapacitors is derived from the fast and reversible Faradaic process (redox reactions) occurring on the surface or near surface of the electrode materials [1921]. Although the generation process of pseudocapacitance involves redox reactions, it is different from the reaction process of battery. The battery is controlled by the ion diffusion within the crystalline framework of active material; while the pseudocapacitor is not limited by the diffusion process [19]. Therefore, the pseudocapacitor possesses highly dynamic reversibility and is more closer to the characteristics of the capacitor. The electrode materials of pseudocapacitors mainly include transition metal oxides (TMOs) and conductive polymers.

Conventional carbon material-based EDLCs usually exhibit low specific capacitance $[19,20]$. TMOs, which possess multiple oxidation states, could achieve markedly larger specific capacitance than carbon materials $[19,20]$. Early investigations on electrode materials have concentrated on noble TMOs, such as $\mathrm{RuO}_{2}$ and $\mathrm{IrO}_{2} \cdot \mathrm{RuO}_{2}$ with three oxidation states within $1.4 \mathrm{~V}$, indicating a large specific capacitance of $2000 \mathrm{~F} \mathrm{~g}^{-1}[47,48]$. However, the exceedingly high cost and environmentally poisonous nature limit their practical applications. Hence, cheap and high-performance TMOs, such as $\mathrm{MnO}_{2}, \mathrm{NiO}, \mathrm{Co}_{3} \mathrm{O}_{4}$, and $\mathrm{CuO}$, have been extensively studied as the electrode materials for SCs [49-54]. Moreover, multiple-metal TMOs, such as $\mathrm{NiCo}_{2} \mathrm{O}_{4}, \mathrm{NiCoO}_{2}$, and $\mathrm{ZnV}_{2} \mathrm{O}_{4}$, have also attracted considerable interest because these materials can provide better electrochemical performance compared with single-metal TMOs [55-57]. TMOs with a variety of structures and morphologies, such as thin films, nanowires/nanorods, nanotubes, nanosheets, nanoflowers, and hollow nanospheres, have been fabricated via different synthesis routes [49-60]. Moreover, their electrochemical properties have been extensively investigated.

Hierarchically nanostructured materials are self-assembly systems that are assembled from low dimensional nanobuilding blocks, such as nanoparticles (NPs), nanowires, nanorods, nanotubes, and nanosheets $[61,62]$. Recently, hierarchically nanostructured TMO materials have gradually become a research hotspot in SC field because of their unique structures [63-67]. These structures could offer large specific surface area, abundant accessible electroactive sites, and short ion diffusion pathway during the rapid charge-discharge process [63-67]. Hierarchically nanostructured TMOs exhibit higher power properties, larger specific capacitances, and more outstanding cycle stabilities compared with common TMOs. In this review, we mainly expound the topic of hierarchically nanostructured TMO electrode materials for SCs. The synthesis and electrochemical performance of hierarchically nanostructured single- or multiphase TMOs are systematically reviewed. We emphasize on several advanced TMO-based composite materials with excellent electrochemical properties, which mainly originate from advantageous compositional and structural characteristics. In addition, we propose several personal prospects to motivate further development of hierarchically nanostructured TMOs for SCs.

The following sections describe the hierarchically nanostructured TMOs as electrode materials for SCs. The summary mainly is divided into two parts: one is singlephase TMOs, and the other is the composites based on TMOs. Unless otherwise noted, the electrochemical tests are mainly investigated in three-electrode systems. The electrolytes for all works are shown in parentheses.

\section{HIERARCHICALLY NANOSTRUCTURED SINGLE-PHASE TMOs FOR SCs}

\section{Manganese oxides}

Electrochemical SCs based on manganese dioxide $\left(\mathrm{MnO}_{2}\right)$ have attracted considerable interest because of its rich polymorphisms ( $\alpha-, \beta-, \gamma^{-}, \delta$-, $\lambda$-, and $\varepsilon$-type), high theoretical specific capacitance, high natural abundance, and good environmental compatibility [68-75].

Flower-like hierarchical $\alpha-\mathrm{MnO}_{2}$ sub-microspheres were successfully fabricated by Yuan and coworkers via a novel interfacial strategy [76]. The Brunauer-EmmettTeller (BET) specific surface area of the $\alpha-\mathrm{MnO}_{2}$ sample is $216 \mathrm{~m}^{2} \mathrm{~g}^{-1}$. To evaluate electrochemical performance, the hierarchical $\alpha-\mathrm{MnO}_{2}$ material was investigated via cyclic 
a
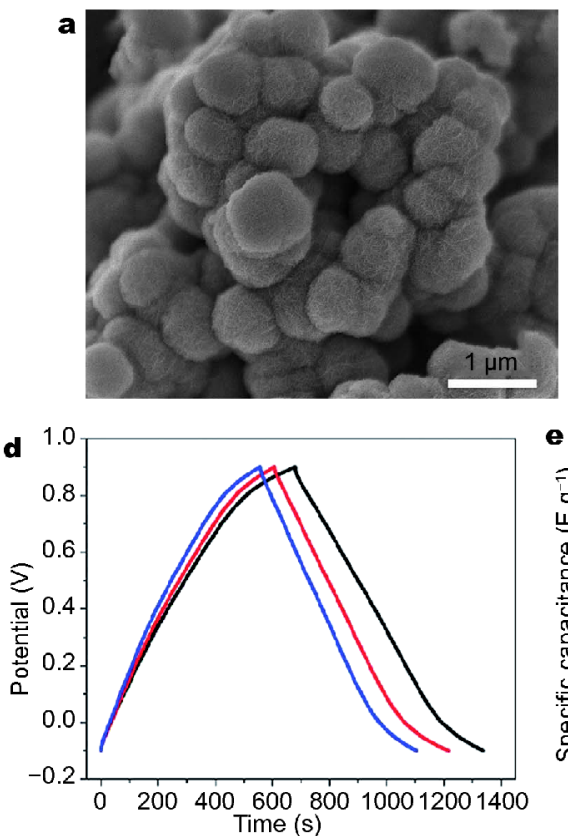
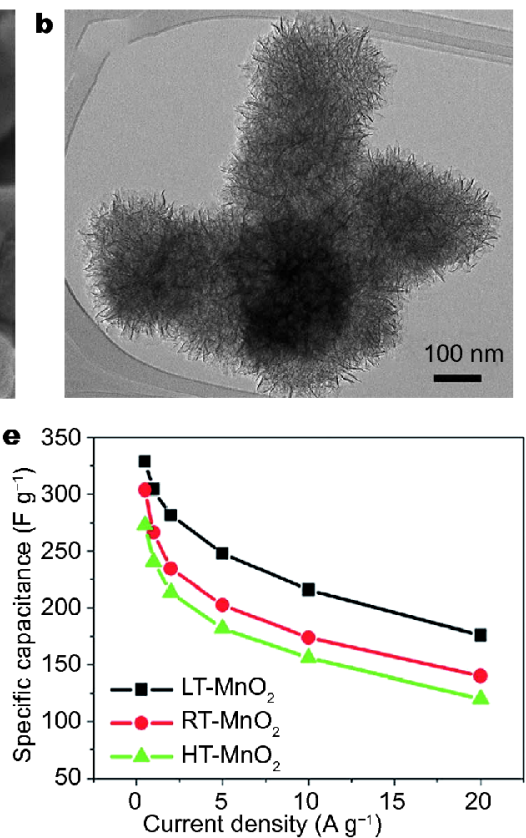
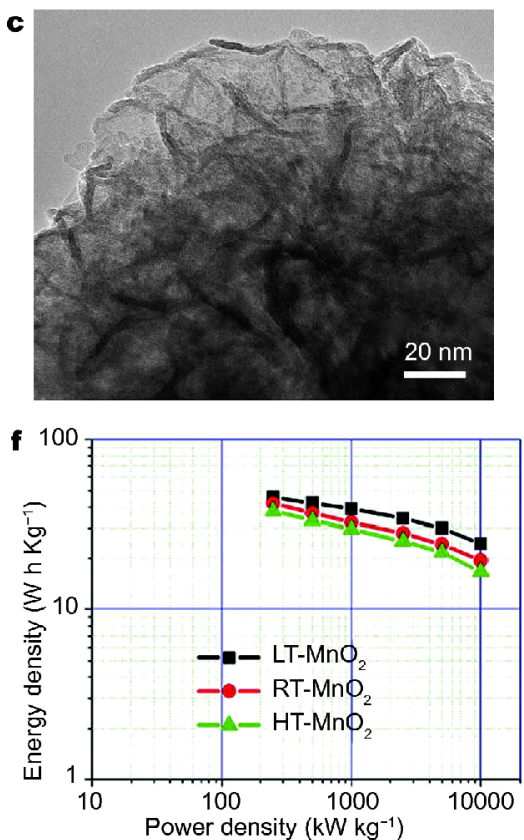

Figure 2 (a) SEM and (b), (c) TEM images of the $\mathrm{LT}-\mathrm{MnO}_{2}$. Electrochemical properties of the three samples; (d) galvanostatic charge-discharge curves at $0.5 \mathrm{~A} \mathrm{~g}^{-1}$; (e) specific capacitances at various current densities; (f) Ragone plots. Reproduced with permission from Ref. [79]. Copyright 2012, the Royal Society of Chemistry.

voltammetry (CV), cyclic chronopotentiometry (CC), and electrochemical impedance spectroscopy in $1 \mathrm{~mol} \mathrm{~L}^{-1}$ $\mathrm{K}_{2} \mathrm{SO}_{4}$. The electrochemical measurement results in high specific capacitances of 298 and $236 \mathrm{~F} \mathrm{~g}^{-1}$ at 0.117 and $2.353 \mathrm{~A} \mathrm{~g}^{-1}$, respectively. Furthermore, the $\alpha-\mathrm{MnO}_{2}$ sample shows $90 \%$ retention after 2,000 cycles at $2 \mathrm{~A} \mathrm{~g}^{-1}$. The good performance is ascribed to the special hierarchical structure and rich $\mathrm{MnO}_{2}$-electrolyte interfaces.

Lee et al. [77] prepared hierarchical nanostructures of hydrated $\alpha-\mathrm{MnO}_{2}$ by one-step synthesis at room temperature. The $\alpha-\mathrm{MnO}_{2}$ sample consists of small ultrathin nanorod-like structures with diameters of $2-4 \mathrm{~nm}$. The $\mathrm{MnO}_{2}$ electrode delivers a high specific capacitance of $356 \mathrm{~F} \mathrm{~g}^{-1}$ at $2 \mathrm{~A} \mathrm{~g}^{-1}\left(1 \mathrm{~mol} \mathrm{~L}^{-1} \mathrm{Na}_{2} \mathrm{SO}_{4}\right)$. After 2,000 cycles of cycling test, no capacitance degradation is observed.

$\beta-\mathrm{MnO}_{2}$ as electrode material in SCs is also investigated. Zhao et al. [78] successfully fabricated hierarchical porous $\beta-\mathrm{MnO}_{2}$ nanoflowers assembled by ultrathin nanoplates at room temperature. The BET specific surface area of the $\beta-\mathrm{MnO}_{2}$ sample is as high as $267 \mathrm{~m}^{2} \mathrm{~g}^{-1}$. The electrochemical measurements demonstrate that the sample possesses a large energy density of $22.6 \mathrm{~W} \mathrm{~h} \mathrm{~kg}^{-1}$ at a high power density of $9.1 \mathrm{~kW} \mathrm{~g}^{-1}$, with a high specific capacitance of $201.5 \mathrm{~F} \mathrm{~g}^{-1}\left(1 \mathrm{~mol} \mathrm{~L}^{-1} \mathrm{Na}_{2}\right.$ $\mathrm{SO}_{4}$ ). Furthermore, at $2 \mathrm{mV} \mathrm{s}^{-1}$, the specific capacitance reaches up to $296.3 \mathrm{~F} \mathrm{~g}^{-1}$, which is evidently superior to those of $\beta-\mathrm{MnO}_{2}$ powders $\left(\sim 7 \mathrm{Fg}^{-1}\right)$ and $\beta-\mathrm{MnO}_{2}$ nanorods $\left(14.9 \mathrm{~F} \mathrm{~g}^{-1}\right)$.

Using a simple and scalable method, Li et al. [79] prepared hierarchical $\mathrm{MnO}_{2}$ nanostructures assembled by ultrathin nanoflakes. The resulting products labeled as LT- $\mathrm{MnO}_{2}, \mathrm{RT}-\mathrm{MnO}_{2}$, and HT- $\mathrm{MnO}_{2}$ (LT, RT, and HT represent low temperature, room temperature, and high temperature, respectively) were synthesized by conducting the reaction in an ice bath, at room temperature, and at $100^{\circ} \mathrm{C}$. Scanning electron microscopy (SEM) and transmission electron microscopy (TEM) images of LT$\mathrm{MnO}_{2}$ are shown in Fig. 2a-c. The $\mathrm{MnO}_{2}$ nanospheres are assembled by small nanoflakes with low crystallinity. The LT- $\mathrm{MnO}_{2}$ displays the largest specific surface area $\left(269.0 \mathrm{~m}^{2} \mathrm{~g}^{-1}\right)$ compared with the RT- $\mathrm{MnO}_{2}$ (173.6 $\left.\mathrm{m}^{2} \mathrm{~g}^{-1}\right)$ and HT- $\mathrm{MnO}_{2}\left(164.6 \mathrm{~m}^{2} \mathrm{~g}^{-1}\right)$. In addition, the LT- $\mathrm{MnO}_{2}$ possesses the highest specific capacitance $\left(176 \mathrm{~F} \mathrm{~g}^{-1}\right)$ at $20 \mathrm{~A} \mathrm{~g}^{-1}\left(1 \mathrm{~mol} \mathrm{~L}^{-1} \mathrm{Na}_{2} \mathrm{SO}_{4}\right)$ compared with the RT- $\mathrm{MnO}_{2}\left(140 \mathrm{~F} \mathrm{~g}^{-1}\right)$ and $\mathrm{HT}-\mathrm{MnO}_{2}\left(120 \mathrm{~F} \mathrm{~g}^{-1}\right)$ (shown in Fig. 2d, e). As shown in Fig. 2f, at a power density of $250 \mathrm{~W} \mathrm{~kg}{ }^{-1}$, the LT- $\mathrm{MnO}_{2}$ also shows the highest energy density of $45.6 \mathrm{~W} \mathrm{~h} \mathrm{~kg}^{-1}$ among the three samples (RT- $\mathrm{MnO}_{2}$ with $42.2 \mathrm{~W} \mathrm{~h} \mathrm{~kg}^{-1}$ and $\mathrm{HT}-\mathrm{MnO}_{2}$ with $37.9 \mathrm{~W} \mathrm{~h} \mathrm{~kg}^{-1}$ ) [76-79].

Raj et al. [80] synthesized hierarchical mesoporous $\delta$ $\mathrm{MnO}_{2}$ via an easy single-step and template-free method. 
This hierarchical mesoporous $\delta-\mathrm{MnO}_{2}$ has a large BET specific surface area of $238 \mathrm{~m}^{2} \mathrm{~g}^{-1}$. The specific capacitance of $\delta-\mathrm{MnO}_{2}$ is $364 \mathrm{~F} \mathrm{~g}^{-1}$ at $1 \mathrm{~A} \mathrm{~g}^{-1}\left(1 \mathrm{~mol} \mathrm{~L}^{-1} \mathrm{Na}_{2}\right.$ $\mathrm{SO}_{4}$ ). Furthermore, the asymmetric SCs device with a large voltage window of $0-2 \mathrm{~V}$ was fabricated by using $\delta$ $\mathrm{MnO}_{2}$ as the cathode and activated carbon as the anode. The device shows a specific capacitance of $86.5 \mathrm{~F} \mathrm{~g}^{-1}$ at $1 \mathrm{~A} \mathrm{~g}^{-1}$ and a capacitance retention of $100 \%$ after 3,000 cycles at $20 \mathrm{~A} \mathrm{~g}^{-1}$. The device exhibits a high energy density of $48.06 \mathrm{~W} \mathrm{~h} \mathrm{~kg}^{-1}$ at a power density of 1.0 $\mathrm{kW} \mathrm{kg}^{-1}$.

\section{Cobalt oxides}

Among TMOs, $\mathrm{Co}_{3} \mathrm{O}_{4}$ is also considered as a highly promising material due to its cost effectiveness, environmental benignancy, and ultrahigh theoretical specific capacitance (3560 $\mathrm{F} \mathrm{g}^{-1}$ ) [81-84]. Cobalt oxides with a variety of structures and morphologies, such as NPs [85], nanowires [86], nanorods [87], nanosheets [88], and porous nanostructures $[89,90]$, have been fabricated via electrochemical and/or chemical routes, and the corresponding electrochemical performance is under intensive investigation.

A hydrothermal strategy based on a self-assembled monolayer polystyrene sphere template was used by Cao et al. [91] for the fabrication of hierarchical porous $\mathrm{Co}_{3} \mathrm{O}_{4}$ film. The $\mathrm{Co}_{3} \mathrm{O}_{4}$ film is approximately $20 \mathrm{~nm}$ thick. The specific capacitances of the $\mathrm{Co}_{3} \mathrm{O}_{4}$ films are 352 and $291 \mathrm{~F} \mathrm{~g}^{-1}$ at 2 and $40 \mathrm{~A} \mathrm{~g}^{-1}\left(2 \mathrm{~mol} \mathrm{~L}^{-1} \mathrm{KOH}\right)$, respectively. These specific capacitances are higher than that of the sample obtained without using a template (325 and $217 \mathrm{~F} \mathrm{~g}^{-1}$ at 2 and $40 \mathrm{~A} \mathrm{~g}^{-1}$ ).

Xiao et al. [92] prepared three-dimensional (3D) enoki mushroom-like $\mathrm{Co}_{3} \mathrm{O}_{4}$ hierarchitectures via an easy reflux method. The primary structure of $\mathrm{Co}_{3} \mathrm{O}_{4}$ hierarchitectures is the nanowire with a diameter of approximately $3.2 \mu \mathrm{m}$. Each $\mathrm{Co}_{3} \mathrm{O}_{4}$ nanowire is made up of numerous $\mathrm{Co}_{3} \mathrm{O}_{4}$ NPs. The $\mathrm{Co}_{3} \mathrm{O}_{4}$ material displays a large specific capacitance of $787 \mathrm{~F} \mathrm{~g}^{-1}$ at $1 \mathrm{~A} \mathrm{~g}^{-1}\left(6 \mathrm{~mol} \mathrm{~L}^{-1} \mathrm{KOH}\right)$, and a capacity retention of $94.5 \%$ after 1,000 cycles at $10 \mathrm{~A} \mathrm{~g}^{-1}$. The asymmetric SCs device (carbon mateials as anode) exhibits an energy density of $23.9 \mathrm{~W} \mathrm{~h} \mathrm{~kg}^{-1}$ at $0.5 \mathrm{~A} \mathrm{~g}^{-1}$, together with a power density of $0.375 \mathrm{~kW} \mathrm{~kg}^{-1}$. The unique 3D enoki mushroom-like hierarchitectures could evidently improve the rate of ion diffusion and the stability of electrodes, which results in considerable electrochemical performances of the $\mathrm{Co}_{3} \mathrm{O}_{4}$ material.

Qu et al. [93] reported that hollow fluffy cages (HFC) of $\mathrm{Co}_{3} \mathrm{O}_{4}$ were prepared by the formation of $\mathrm{Co}(\mathrm{OH})_{2}$ hollow cages and subsequent calcination at different temperature. The $\mathrm{HFC}$ of $\mathrm{Co}_{3} \mathrm{O}_{4}$ was annealed at 250, 300, and $400^{\circ} \mathrm{C}$, respectively. The synthetic scheme for HFC $\mathrm{Co}_{3} \mathrm{O}_{4}$ is shown in Fig. 3a. The TEM image of $\mathrm{Cu}_{2} \mathrm{O}$ template (Fig. 3b) displays a polyhedron structure with a size of $\sim 250 \mathrm{~nm}$. As shown in Fig. $3 \mathrm{c}$, the size of the internal voids of the as-prepared hollow cages is $\sim 250 \mathrm{~nm}$, which is inherited from the dimensions of the $\mathrm{Cu}_{2} \mathrm{O}$ templates. As evidenced in the TEM image (Fig. $3 \mathrm{~d}$ ), the morphology of the HFC-like nanostructure is excellently preserved after annealing at $250^{\circ} \mathrm{C}$. The specific surface area of HFC-250 is approximately 245.5 $\mathrm{m}^{2} \mathrm{~g}^{-1}$, which is substantially higher than those of HFC$300\left(120 \mathrm{~m}^{2} \mathrm{~g}^{-1}\right)$ and HFC-400 $\left(67.3 \mathrm{~m}^{2} \mathrm{~g}^{-1}\right)$. The nearly symmetric charge-discharge curves imply that the HFC250 delivers high coulombic efficiency and low polarization (Fig. 3e). At $1 \mathrm{~A} \mathrm{~g}^{-1}$ (shown in Fig. 3f), the HFC-250 electrode possesses the largest specific capacitance $\left(948.9 \mathrm{~F} \mathrm{~g}^{-1}\right)$, which is markedly larger than those of HFC $\mathrm{Co}(\mathrm{OH})_{2}\left(400.7 \mathrm{~F} \mathrm{~g}^{-1}\right)$, HFC-300 $\left(489.9 \mathrm{~F} \mathrm{~g}^{-1}\right)$, HFC-400 $\left(297 \mathrm{~F} \mathrm{~g}^{-1}\right)$, and $\mathrm{Co}_{3} \mathrm{O}_{4}$-common $\left(151.3 \mathrm{~F} \mathrm{~g}^{-1}\right)$ electrodes $\left(2 \mathrm{~mol} \mathrm{~L}^{-1} \mathrm{KOH}\right)$. Furthermore, the HFC-250 exhibits superior rate performance (Fig. $3 g$ ) and good cycle stability.

\section{Nickel oxides}

Nickel oxides have been widely studied in SCs field because of their high theoretical capacity $\left(2573 \mathrm{~F} \mathrm{~g}^{-1}\right)$, cost effectiveness, and environmental friendliness [94-99]. By an easy hydrothermal method, $\mathrm{Hu}$ et al. [100] designed and synthesized hierarchical $\mathrm{NiO}$ nanosheets/nanowires with $\mathrm{Ni}$ foam substrate. The specific capacitances of the electrodes are 1493 and $867 \mathrm{~F} \mathrm{~g}^{-1}$ at 3 and $50 \mathrm{~A} \mathrm{~g}^{-1}$ $\left(6 \mathrm{~mol} \mathrm{~L}^{-1} \mathrm{KOH}\right)$, respectively, which are superior to those of the mesoporous $\mathrm{NiO}$ nanosheets (1250 and $633 \mathrm{~F} \mathrm{~g}^{-1}$ at 3 and $50 \mathrm{~A} \mathrm{~g}^{-1}$, respectively). Furthermore, the unique hierarchical $\mathrm{NiO}$ nanosheet/nanowire electrodes exhibit good rate performance and good cycling stability.

Using a successive electrode-position method with $\mathrm{ZnO}$ nanorods as template on $\mathrm{Ni}$ foam, Cao et al. [101] synthesized 3D hierarchical $\mathrm{NiO}$ nanotube arrays. Fig. 4a shows the schematic for synthesizing this material. As seen in the SEM and TEM (Fig. 4b, c) images, the sample is consisted of interconnected branch nanoflakes $(\sim 10 \mathrm{~nm})$, and the diameter of nanotube is $\sim 170 \mathrm{~nm}$. Owing to the special hierarchical porous structure, the $\mathrm{NiO}$ nanotube arrays show high specific capacitances of 675 and $569 \mathrm{~F} \mathrm{~g}^{-1}$ at 2 and $40 \mathrm{~A} \mathrm{~g}^{-1}\left(1 \mathrm{~mol} \mathrm{~L}^{-1} \mathrm{Na}_{2} \mathrm{SO}_{4}\right)$ (Fig. 4g), respectively. The pseudocapacitive performance of $\mathrm{NiO}$ nanotube arrays on $\mathrm{Ni}$ foil and $\mathrm{Ni}$ foam were also 

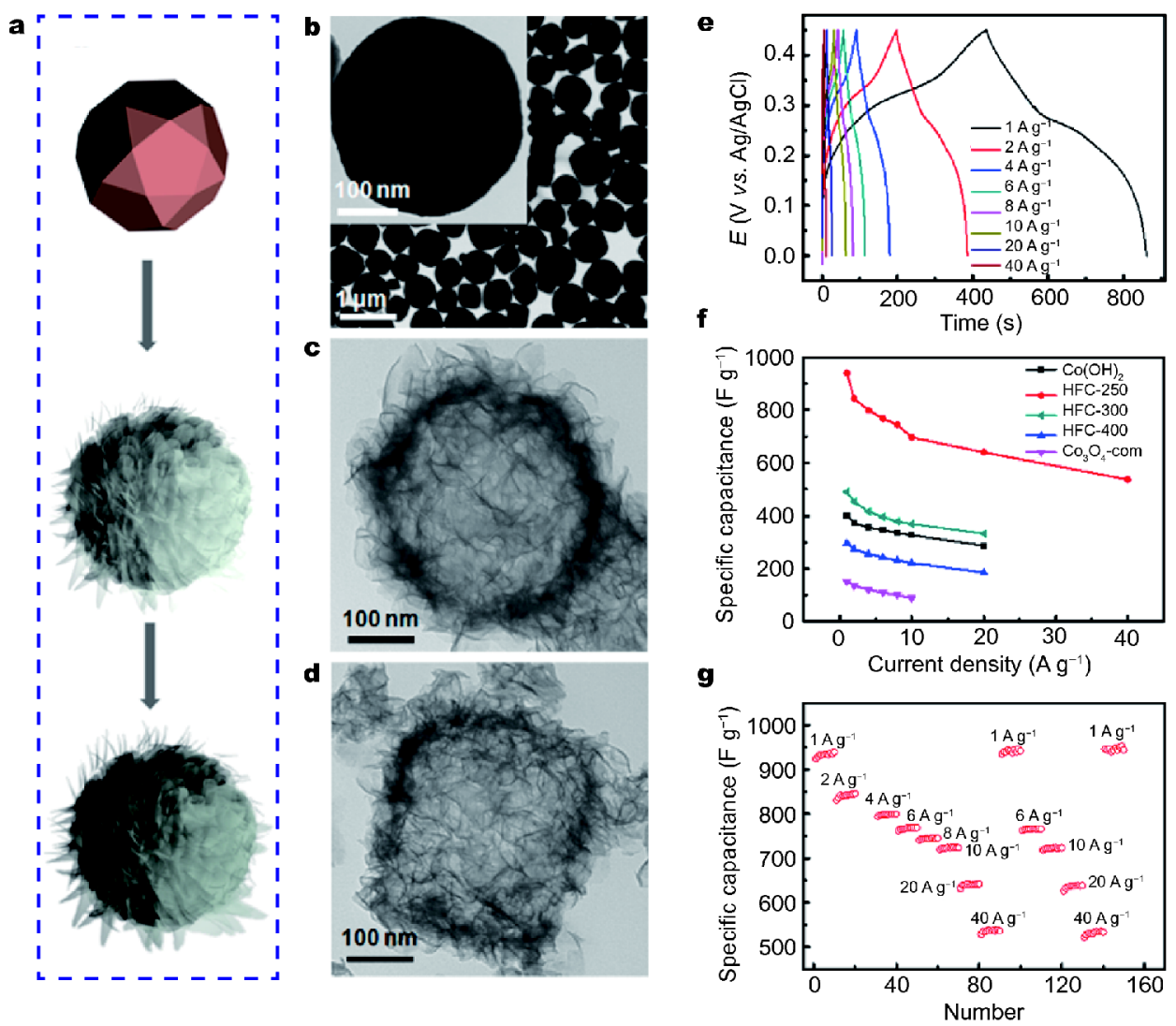

Figure 3 (a) Schematic of the preparation of $\mathrm{Co}(\mathrm{OH})_{2}$ and $\mathrm{Co}_{3} \mathrm{O}_{4}$. TEM images for (b) $\mathrm{Cu}_{2} \mathrm{O}$ template, (c) $\mathrm{Co}(\mathrm{OH})_{2}$, and $(\mathrm{d}) \mathrm{Co}_{3} \mathrm{O}_{4}$. (e) $\mathrm{Charge}$ discharge curves of the HFC-250 electrode. (f) Plots of the specific capacitance of $\mathrm{Co}(\mathrm{OH})_{2}, \mathrm{HFC}-250, \mathrm{HFC}-300, \mathrm{HFC}-400$, and $\mathrm{Co}_{3} \mathrm{O}_{4}$-com. $(\mathrm{g}) \mathrm{Rate}$ capability of the HFC-250 electrode when the current density was progressively varied. Reproduced with permission from Ref. [93]. Copyright 2015, the American Chemical Society.

compared. The specific capacitance of the $\mathrm{NiO}$ on the $\mathrm{Ni}$ foil is $495 \mathrm{~F} \mathrm{~g}^{-1}$ at $2 \mathrm{~A} \mathrm{~g}^{-1}$, which is lower than that of the $\mathrm{NiO}$ on $\mathrm{Ni}$ foam $\left(675 \mathrm{~F} \mathrm{~g}^{-1}\right.$ at $\left.2 \mathrm{~A} \mathrm{~g}^{-1}\right)$. The porous $\mathrm{NiO}$ arrays on $\mathrm{Ni}$ foam electrode demonstrate a low loss of $6.8 \%$ after 10,000 cycles at $2 \mathrm{~A} \mathrm{~g}^{-1}$. This excellent electrochemical performance can be ascribed to the hierarchical porous architecture with large reaction surface area and fast ion transfer. This synthesis method can potentially be applied to the fabrication of other TMO nanotube arrays.

Multi-shell self-assembled hollow structure materials are also investigated in SCs. Zhu et al. [102] designed and prepared single-, double-, and triple-shelled $\mathrm{NiO}$ (S-NiO, $\mathrm{D}-\mathrm{NiO}$, and $\mathrm{T}-\mathrm{NiO}$, respectively) hollow nanospheres by a controllable layer-by-layer self-assembly method with the calcination of $\mathrm{Ni}(\mathrm{OH})_{2} / \mathrm{C}$ precursors. The BET specific surface area of the $\mathrm{D}-\mathrm{NiO}$ is approximately $92.99 \mathrm{~m}^{2} \mathrm{~g}^{-1}$, which is higher than those of $\mathrm{T}-\mathrm{NiO}$ $\left(23.45 \mathrm{~m}^{2} \mathrm{~g}^{-1}\right)$ and $\mathrm{S}-\mathrm{NiO}\left(61.63 \mathrm{~m}^{2} \mathrm{~g}^{-1}\right)$. The average pore sizes for $\mathrm{S}-\mathrm{NiO}, \mathrm{D}-\mathrm{NiO}$, and $\mathrm{T}-\mathrm{NiO}$ are $18.24,7.04$, and $12.30 \mathrm{~nm}$, respectively. The electrochemical measurements indicate that the $\mathrm{D}-\mathrm{NiO}$ possesses the highest specific capacitance of $612.5 \mathrm{~F} \mathrm{~g}^{-1}$ compared with $\mathrm{S}-\mathrm{NiO}$ $\left(432.2 \mathrm{~F} \mathrm{~g}^{-1}\right)$ and $\mathrm{T}-\mathrm{NiO}\left(292.4 \mathrm{~F} \mathrm{~g}^{-1}\right)$ at $0.5 \mathrm{~A} \mathrm{~g}^{-1}$ (2 mol L $\left.{ }^{-1} \mathrm{KOH}\right)$. The $\mathrm{D}-\mathrm{NiO}$ also exhibits good cyclic performance, with capacitance retention exceeding $90 \%$ after 1,000 cycles.

Using a facile, low-cost, and environment-friendly template method, Liu et al. [103] successfully prepared hierarchical mesoporous $\mathrm{NiO}$ nanoarrays (NiOHMNAs). The synthesis process of NiO-HMNAs is shown in Fig. 4d. The edge length of NiO-HMNAs is $1.6 \mu \mathrm{m}$ (shown in Fig. 4e, f). The average thickness of $\mathrm{NiO}-\mathrm{HMNAs}$ is $\sim 10 \mathrm{~nm}$ (Fig. 4f, inset). As a battery-type electrode for hybrid SCs, the specific capacitance of NiOHMNAs is $3114 \mathrm{~F} \mathrm{~g}^{-1}$ at $5 \mathrm{~mA} \mathrm{~cm}^{-2}\left(2 \mathrm{~mol} \mathrm{~L}^{-1} \mathrm{KOH}\right)$. Furthermore, the optimized hybrid SC device demonstrates a high energy density of $67.0 \mathrm{Wh} \mathrm{kg}^{-1}$ at a power 

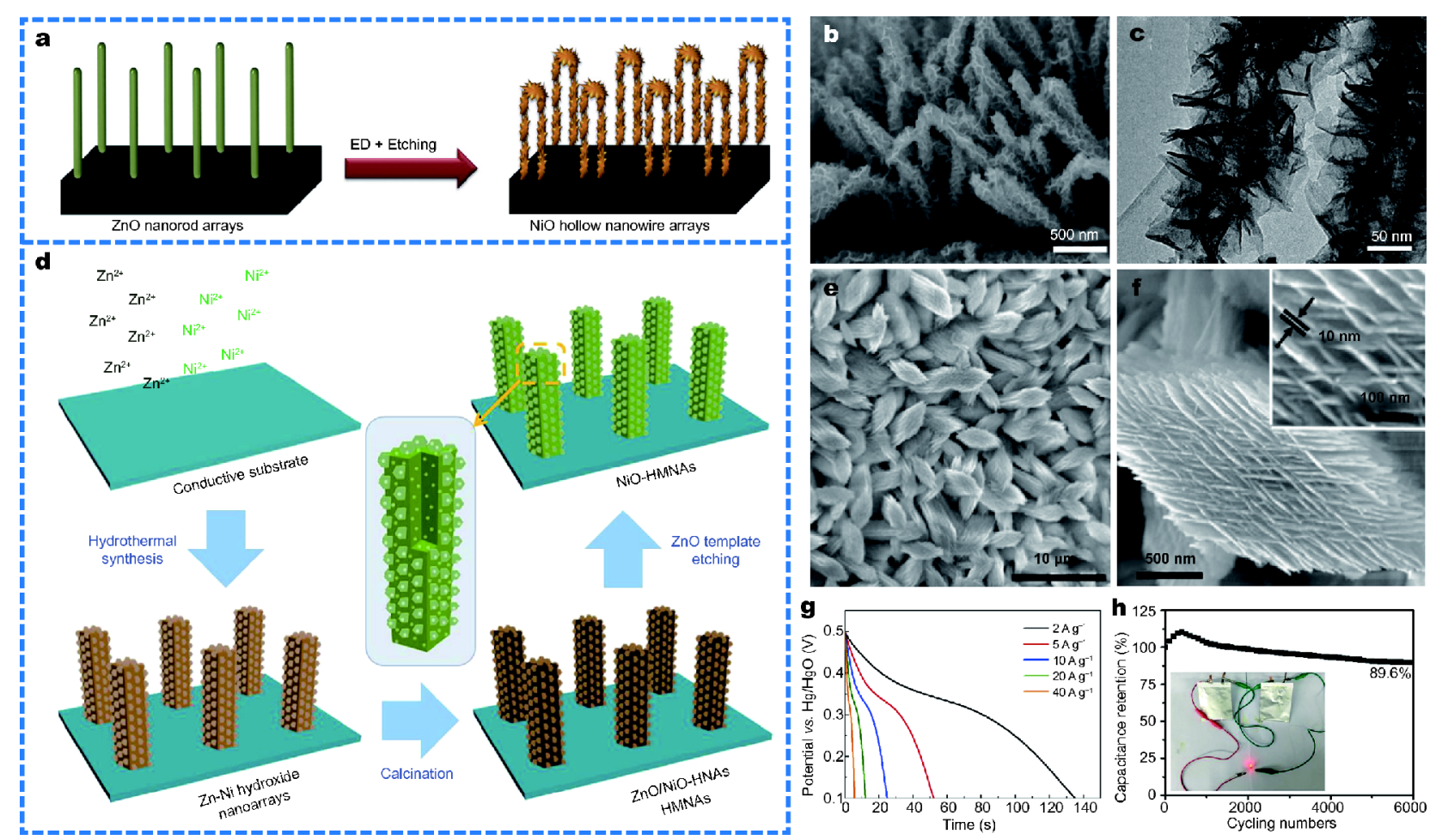

Figure 4 (a) Schematic of the preparation of hierarchical $\mathrm{NiO}$ nanotube arrays on $\mathrm{Ni}$ foam. (b) SEM image of $\mathrm{NiO}$ nanotube arrays on $\mathrm{Ni}$ foam. (c) TEM image of $\mathrm{NiO}$ nanotube. (d) Schematic of the preparation of NiO-HMNAs on Cu foam. (e) and (f) SEM images of NiO-HMNAs. (g) Discharge curves of $\mathrm{NiO}$ nanotube arrays on $\mathrm{Ni}$ foam. (h) Cycling performance of the hybrid SC device based on NiO-HMNAs. Reproduced with permission from Ref. [101]. Copyright 2014, Elsevier. (d-f, h) Reproduced with permission from Ref. [103]. Copyright 2016, Elsevier.

density of $320 \mathrm{~W} \mathrm{~kg}^{-1}$ and a good capacitance retention of $89.6 \%$ after 6,000 cycles (Fig. 4h). The ultrahigh specific capacitance of NiO-HMNAs is ascribed to the unique hierarchical mesoporous architecture.

\section{Copper oxides}

Copper oxide can be considered as another promising candidate for SCs because of its non-toxicity, abundance, and facile preparation $[104,105]$. Through a facile electrochemical process, 3D nanostructured $\mathrm{CuO}$ electrodes were prepared for SCs by Chen et al. (Fig. 5a, b) [106]. Due to its unique nanostructure, the as-prepared $\mathrm{CuO}$ nanoribbon-on-Ni-nanoporous/Ni foam (CNRNP) electrodes show excellent energy storage performance relative to a traditional electrode. $\mathrm{Ni}$ foam and flat $\mathrm{Ni}$ are also respectively used as substrate to fabricate general copper oxide samples. On the $\mathrm{Ni}$ foam, $\mathrm{CuO}$ nanoflakes (CNFNF) form a thick and uniform film, completely covering the $\mathrm{Ni}$ foam framework (Fig. $5 \mathrm{c}$ ). On the flat $\mathrm{Ni}$ plate, the flake-like $\mathrm{CuO}$ (FLC) is formed (Fig. 5d). The specific capacitance of the CNRNP electrode is $800 \mathrm{~F} \mathrm{~g}^{-1}$ at $200 \mathrm{mV} \mathrm{s}^{-1}\left(3 \mathrm{~mol} \mathrm{~L}^{-1} \mathrm{KOH}\right)$, which retains $91 \%$ compared with that at $10 \mathrm{mV} \mathrm{s}^{-1}$ (Fig. 5e, f). By contrast, the CNFNF and FLC electrodes deliver $81 \%$ and $69 \%$ of that at $10 \mathrm{mV} \mathrm{s}^{-1}$, respectively. The symmetric triangular shape of charge-discharge curves indicates that the CNRNP possesses satisfactory pseudocapacitive behavior (Fig. 5g).

An easy and low-cost one-step surface oxidation process was applied by Zhao et al. [107] for the preparation of 3D flower-like $\mathrm{CuO}$ hierarchical structures grown on $\mathrm{Cu}$ foam. Given the innovative synthesis method and 3D connect/quasi-connect structures, this sample gains considerable attention as binder-free electrode material for SCs. The 3D flower-like $\mathrm{CuO} / \mathrm{Cu}$ foam electrode could offer abundant active sites for redox reactions, effectively promote electrolyte penetration, enhance electronic conductivity, and shorten ion diffusion pathway. The specific capacitances of $\mathrm{CuO}$ are calculated to be 1641.4 and $1266.7 \mathrm{mF} \mathrm{cm}^{-2}$ at 2 and $20 \mathrm{~mA} \mathrm{~cm}^{-2}$ $\left(5 \mathrm{~mol} \mathrm{~L}^{-1} \mathrm{NaOH}\right)$, respectively.

By an alkaline solution oxidation, Luo et al. [108] successfully synthesized $\mathrm{CuO}$ nanostructures with different surfactants (sodium dodecyl sulfate (SDS) and poly- 

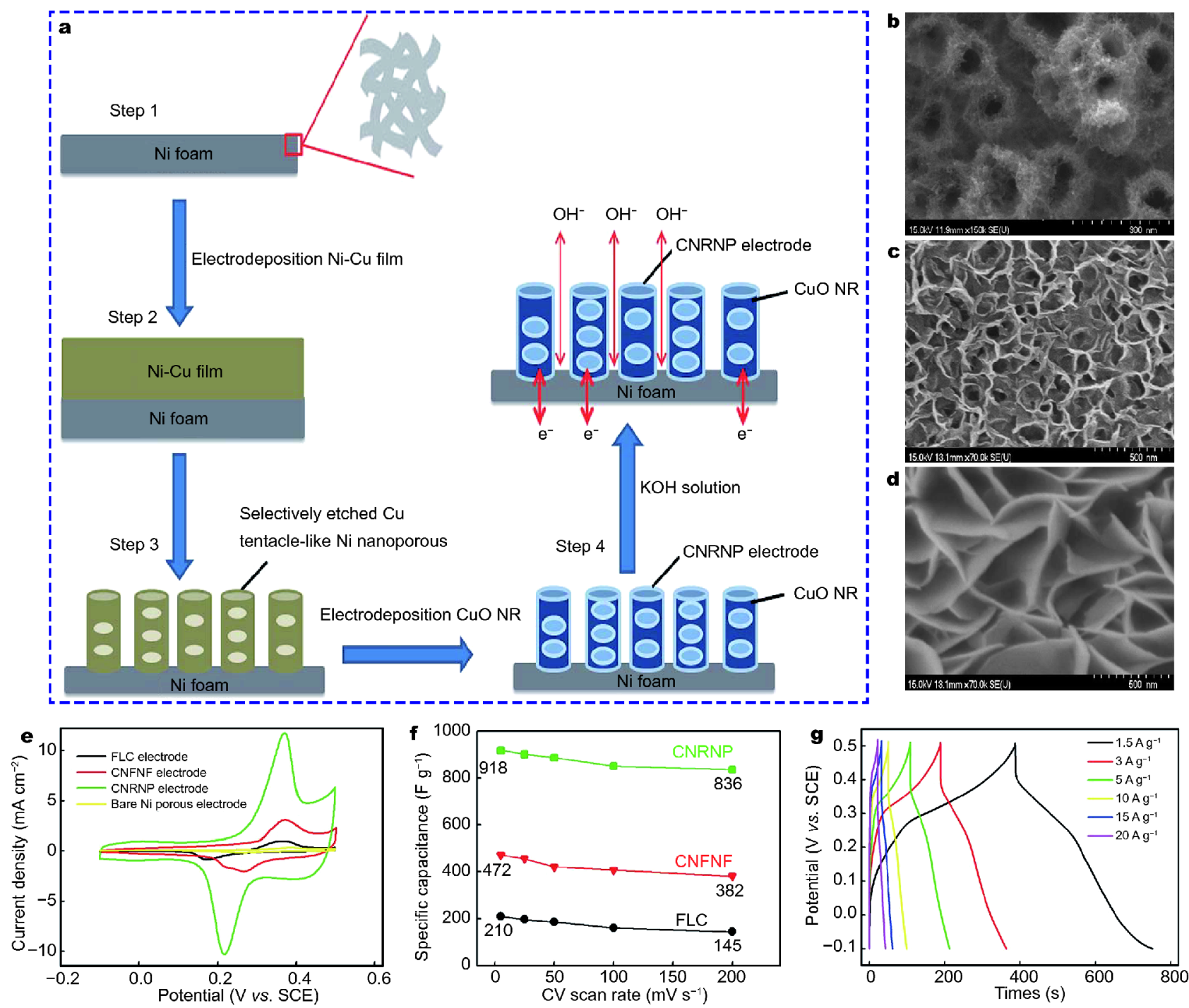

Figure 5 (a) Schematic of the preparation of CNRNP electrode; SEM images of (b) CNRNP, (c) CNFNF, and (d) FLC; (e) CV curves of all samples at $10 \mathrm{mV} \mathrm{s}^{-1}$; (f) specific capacitance of all samples at different scan rates; (g) charge-discharge curves of CNRNP. Reproduced with permission from Ref. [106]. Copyright 2014, the Royal Society of Chemistry.

vinyl alcohol (PVA)). The $\mathrm{CuO}$ electrode obtained with SDS shows superior electrochemical performance because of its ultrathin nanoleaves, which constitute a flowershaped nanostructure, and possesses specific capacitances of 520 and $405 \mathrm{~F} \mathrm{~g}^{-1}$ at 1 and $60 \mathrm{~A} \mathrm{~g}^{-1}\left(1 \mathrm{~mol} \mathrm{~L}^{-1} \mathrm{KOH}\right)$, respectively, and a capacitance retention of $95.2 \%$ after 5,000 cycles at $1 \mathrm{~A} \mathrm{~g}^{-1}$.

\section{Bismuth oxides}

Owing to abundant crystal morphologies and unique physical properties, $\mathrm{Bi}_{2} \mathrm{O}_{3}$ has attracted extensive attention in SC field [109]. $\mathrm{Bi}_{2} \mathrm{O}_{3}$ presents five main polymorphic forms $\left(\alpha-, \beta-, \gamma^{-}, \delta\right.$-, and $\left.\omega-\mathrm{Bi}_{2} \mathrm{O}_{3}\right)$. Among these forms, the high-temperature $\delta$ and low-temperature a phases are stable [110-112]. Gujar et al. first reported that $\mathrm{Bi}_{2} \mathrm{O}_{3}$ thin film, as positive electrode material for SCs, possessed a low specific capacitance of only $98 \mathrm{~F} \mathrm{~g}^{-1}$ but exhibited high electrochemical reversibility [112].

Tong et al. [113] reported that hierarchical rippled $\mathrm{Bi}_{2} \mathrm{O}_{3}$ nanobelts were synthesized via an electrode-position method. The $\mathrm{Bi}_{2} \mathrm{O}_{3}$ nanobelts possess a width of $250-$ $300 \mathrm{~nm}$, a length of $1-5 \mu \mathrm{m}$, and a thickness of $10-30 \mathrm{~nm}$. The intervals between the ripples are approximately $15-30 \mathrm{~nm}$. The BET specific surface area of hierarchical $\mathrm{Bi}_{2} \mathrm{O}_{3}$ nanobelts sample $\left(196 \mathrm{~m}^{2} \mathrm{~g}^{-1}\right)$ is 8 times of that of $\mathrm{Bi}_{2} \mathrm{O}_{3}$ nanobelts sample with smooth surfaces $\left(24 \mathrm{~m}^{2} \mathrm{~g}^{-1}\right)$. 
The specific capacitance of the hierarchical rippled $\mathrm{Bi}_{2} \mathrm{O}_{3}$ nanobelts is $250 \mathrm{~F} \mathrm{~g}^{-1}$ at $100 \mathrm{mV} \mathrm{s}{ }^{-1}\left(1 \mathrm{~mol} \mathrm{~L}^{-1} \mathrm{Na}_{2} \mathrm{SO}_{4}\right)$, which is remarkablely larger than the $\mathrm{Bi}_{2} \mathrm{O}_{3}$ nanobelts with smooth surfaces $\left(61 \mathrm{~F} \mathrm{~g}^{-1}\right)$.

An easy one-step precipitation approach with the addition of diverse surfactants was used by Yuan's group for the synthesis of rod-like $\mathrm{Bi}_{2} \mathrm{O}_{3}$ [114]. The surfactants with various chain structures can effectively regulate and control the morphologies of $\mathrm{Bi}_{2} \mathrm{O}_{3}$ products. The $\mathrm{Bi}_{2} \mathrm{O}_{3}$ sample synthesized using $\mathrm{P} 123$ surfactant as electrode material was investigated. The sample exhibits a large specific capacitance of $1350 \mathrm{~F} \mathrm{~g}^{-1}$ at $0.1 \mathrm{~A} \mathrm{~g}^{-1}\left(6 \mathrm{~mol} \mathrm{~L}^{-1}\right.$ $\mathrm{KOH})$, excellent rate performance $(71.4 \%$ retention from 0.1 to $2 \mathrm{~A} \mathrm{~g}^{-1}$ ), and an outstanding cycle performance (only $2.4 \%$ capacitance fade after 1,000 cycles).

\section{Nickel cobalt oxides}

Bimetallic oxides usually offer higher electrochemical activity than single metal oxides [115-117]. Nickel cobaltite exhibits excellent electrochemical performance because of richer redox reaction between nickel and cobalt ions [118]. A variety of nickel cobaltite materials with different morphologies, such as NPs [119], nanowires $[120,121]$, urchin-like shape [122], and hollow spheres [123], have been studied as electrode materials for SCs.

To shorten the synthesis time, Xiao et al. [124] reported a template-free microwave-assisted heating reflux method to prepare 3D hierarchical flower-shaped $\mathrm{NiCo}_{2}$ $\mathrm{O}_{4}$ microspheres. The $\mathrm{NiCo}_{2} \mathrm{O}_{4}$ microspheres are constituted of numerous flower-shaped nanostructures. The flower-shaped $\mathrm{NiCo}_{2} \mathrm{O}_{4}$ microspheres demonstrate a high specific capacitance of $1006 \mathrm{~F} \mathrm{~g}^{-1}$ at $1 \mathrm{~A} \mathrm{~g}^{-1}\left(6 \mathrm{~mol} \mathrm{~L}^{-1}\right.$ $\mathrm{KOH}$ ) and good cycle performance (retention of $93.2 \%$ after 1,000 cycles at $8 \mathrm{~A} \mathrm{~g}^{-1}$ ).

The design and preparation of novel nanomaterials have gradually become the core research in optimizing pseudocapacitive performance. Li et al. [125] reported that the $\mathrm{NiCo}_{2} \mathrm{O}_{4}$ multiple hierarchical structures (MHSs) composed of two-dimensional (2D) nanosheets and onedimensional (1D) nanowires were directly anchored on $\mathrm{Ni}$ foam (Fig. 6a). First, the $\mathrm{NiCo}_{2} \mathrm{O}_{4}$ nanowires (NCO1) that uniformly covered the substrate were formed by a hydrothermal process followed by annealing treatment. After that, by a second hydrothermal process, the NCO1 was transformed into $\mathrm{NiCo}_{2} \mathrm{O}_{4}$ MHSs, which was named as NCO2. The nanowire was found to be superior over the high-dimensional nanosheet in the growth order; thereby effectively promoting the integration of these different nanostructures into the $\mathrm{NiCo}_{2} \mathrm{O}_{4}$ MHSs. As shown in Fig. $6 \mathrm{~b}, \mathrm{c}$, the $\mathrm{NiCo}_{2} \mathrm{O}_{4}$ MHSs with diameters of about 4-6 $\mu \mathrm{m}$ were obtained. All microspheres possess a $3 \mathrm{D}$ structure, in which the $2 \mathrm{D}$ nanosheets form the skeleton of microspheres, while the $1 \mathrm{D}$ nanowires surround the nanosheet. Given the favorable mesoporous architecture and large specific surface area, the sample $\mathrm{NCO} 2$ $\left(\mathrm{NiCo}_{2} \mathrm{O}_{4} \mathrm{MHSs}\right)$ shows the highest specific capacitance of $2623.3 \mathrm{~F} \mathrm{~g}^{-1}$ at $1 \mathrm{~A} \mathrm{~g}^{-1}\left(3 \mathrm{~mol} \mathrm{~L}^{-1} \mathrm{KOH}\right)$ (Fig. $6 \mathrm{~d}$ ). A capacity retention of $68 \%$ can be achieved from $1 \mathrm{~A} \mathrm{~g}^{-1}$ to $40 \mathrm{~A} \mathrm{~g}^{-1}$. The sample also displays good stability with $94 \%$ retention after 3,000 cycles at $10 \mathrm{~A} \mathrm{~g}^{-1}$.

By a mild solution approach with polymeric nanotubes (PNT) as the template, Yu et al. [126] successfully fabricated hierarchical $\mathrm{NiCoO}_{2}$ nanotubes composed of nanosheets. Fig. 6e displays the SEM image of $\mathrm{NiCoO}_{2}$ nanotubes obtained after calcination of the Ni-precursor@PNT composite at $400^{\circ} \mathrm{C}$. As shown in Fig. 6f, the mesoporous $\mathrm{NiCoO}_{2}$ nanosheet-nanotube structures possess hierarchical external construction and hollow internal structure with a diameter of approximately $100 \mathrm{~nm}$. When tested at 2, 4, 8, 10, 20, and $40 \mathrm{~A} \mathrm{~g}^{-1}$ $\left(2 \mathrm{~mol} \mathrm{~L}^{-1} \mathrm{KOH}\right)$, the $\mathrm{NiCoO}_{2}$ nanotube electrodes show high specific capacitances of 1468, 1352, 1233, 1178, 1020, and $672 \mathrm{~F} \mathrm{~g}^{-1}$, respectively. At $10 \mathrm{~A} \mathrm{~g}^{-1}$, the specific capacitance is $1178 \mathrm{~F} \mathrm{~g}^{-1}$ in the first cycle. The specific capacitance gradually decreases to $1168 \mathrm{~F} \mathrm{~g}^{-1}$ after 3,000 cycles, resulting in only $0.8 \%$ loss of overall capacitance. Furthermore, the $\mathrm{NiCoO}_{2}$ nanotubes show virtually $100 \%$ of the coulombic efficiency during the whole cycle (Fig. $6 \mathrm{~g})$. This excellent performance of the $\mathrm{NiCoO}_{2}$ nanotubes is ascribed to the porous and hierarchical structures, which provide more effective contact areas between the active materials and electrolyte ions. Moreover, the wideopen ends of the $\mathrm{NiCoO}_{2}$ nanotubes provide extra paths for the electrolyte.

\section{Zinc vanadium oxides}

Cao et al. [127] designed a simple and template-free approach to fabricate hierarchical nanospheres (NHNs) of $\mathrm{ZnV}_{2} \mathrm{O}_{4}$. As shown in Fig. 7a, b, these nanospheres are composed of extremely thin nanosheets. Fig. $7 \mathrm{c}$ demonstrates the crystal geometry of spinel oxide $\mathrm{ZnV}_{2} \mathrm{O}_{4}$. Fig. $7 \mathrm{~d}$ shows that the specific capacitances of $\mathrm{ZnV}_{2} \mathrm{O}_{4} \mathrm{NHNs}$ are $385,360,324$, and $272 \mathrm{~F} \mathrm{~g}^{-1}$ at current densities of 0.5 , 1,2 , and $4 \mathrm{~A} \mathrm{~g}^{-1}$, respectively. Furthermore, the $\mathrm{ZnV}_{2} \mathrm{O}_{4}$ NHNs electrode exhibits good cycle stability with $89 \%$ of capacity retention after 1,000 cycles at $1 \mathrm{~A} \mathrm{~g}^{-1}$.

\section{HIERARCHICALLY NANOSTRUCTURED COMPOSITES BASED ON TMOS FOR SCs}

Multiphase composites based on TMOs could effectively 

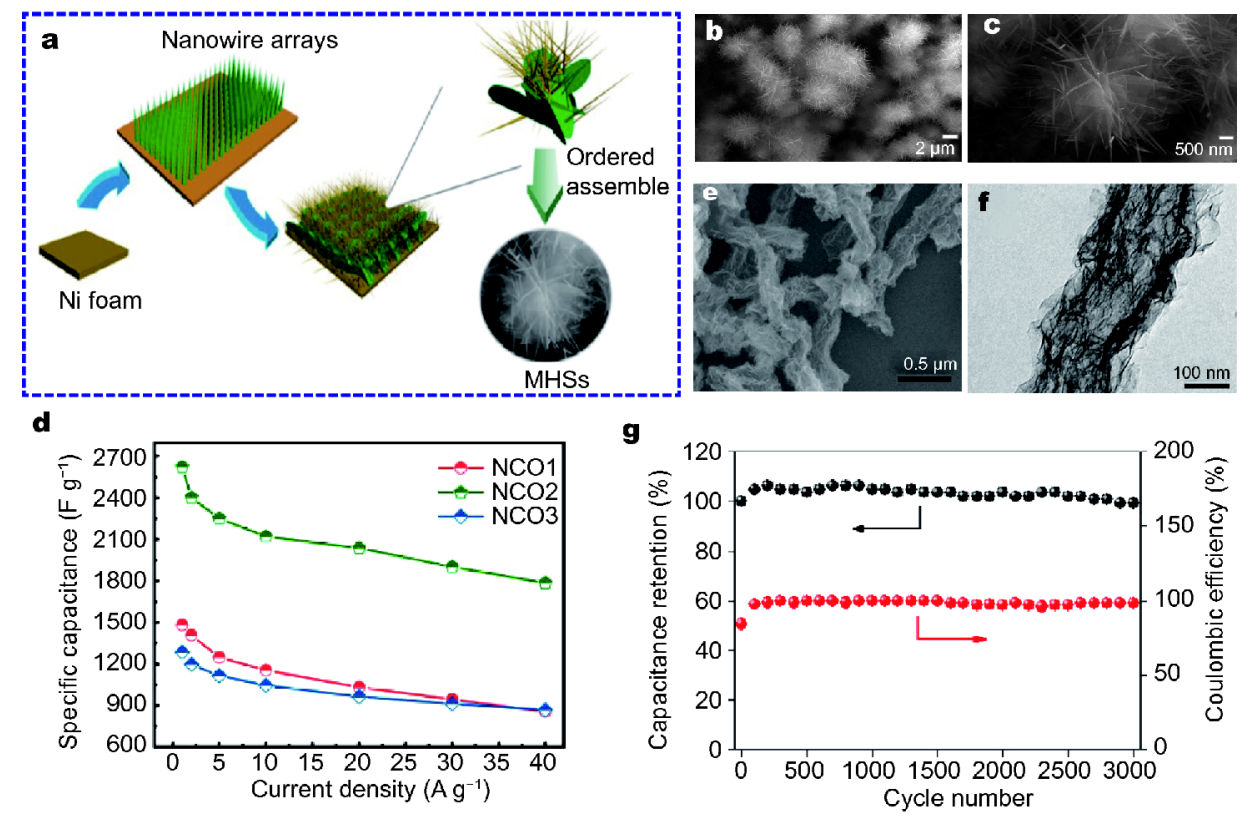

Figure 6 (a) Schematic of the preparation of $\mathrm{NiCo}_{2} \mathrm{O}_{4}$ MHSs; (b and c) FESEM images of the $\mathrm{NiCo}_{2} \mathrm{O}_{4}$ MHSs (NCO2) on Ni foam; (d) specific capacitance obtained from the discharge curves; (e) SEM image and (f) TEM image of the hierarchical $\mathrm{NiCoO}_{2}$ nanosheets; (g) cycling performance of $\mathrm{NiCoO}_{2}$ at $10 \mathrm{~A} \mathrm{~g}^{-1}$. (a, d) Reproduced with permission from Ref. [125]. Copyright 2014, the American chemical Society. (e-g) Reproduced with permission from Ref. [126]. Copyright 2014, Elsevier.
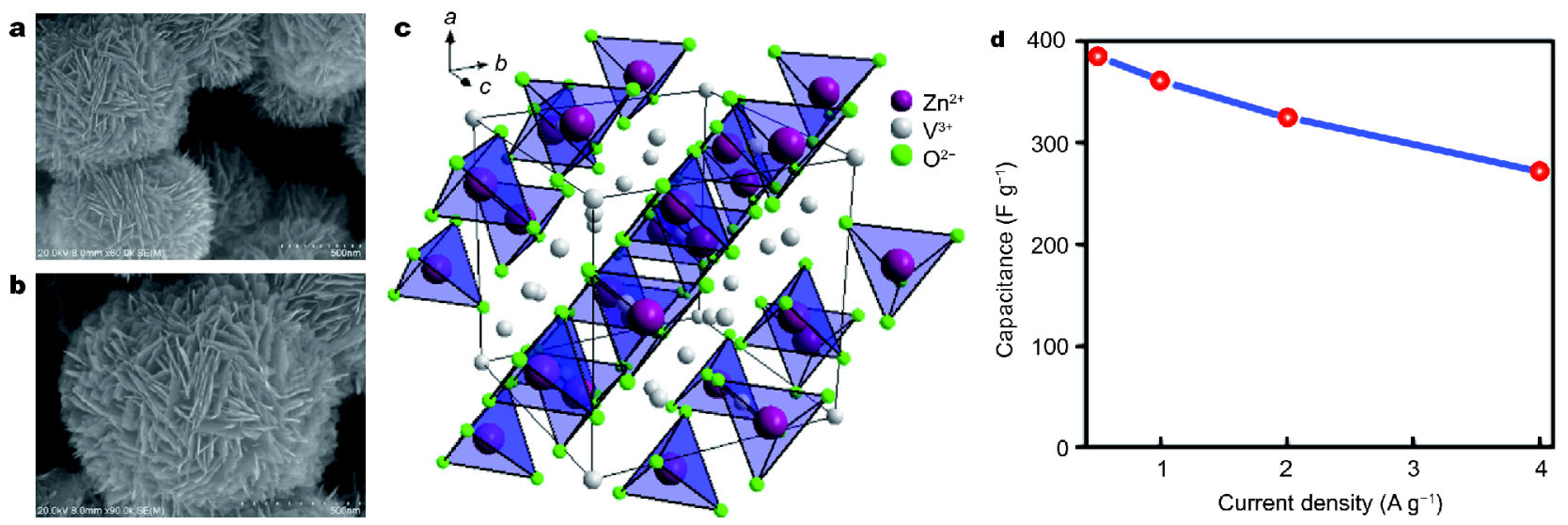

Figure 7 (a and b) SEM images of $\mathrm{ZnV}_{2} \mathrm{O}_{4} \mathrm{NHNs}$; (c) crystal structure of spinel $\mathrm{ZnV}_{2} \mathrm{O}_{4}$ with corresponding atoms; (d) capacitance as a function of current density. Reproduced with permission from Ref. [127]. Copyright 2014, the American Chemical Society.

improve the specific capacitance and cycling performance of the devices compared with single-phase TMOs because of the complex chemical compositions and the synergetic effect of both individual components [128-135]. In the following section, four types of composites were introduced, namely: 1) composites of manganese oxides and other TMOs; 2) composites of gold NP-doped TMOs; 3) composites of carbon materials and TMOs; and 4) other forms of TMOs composites.

\section{Composites of manganese oxides and other TMOs}

Lee et al. [136] designed and synthesized binder-free 3D $\mathrm{CoO} @ \mathrm{MnO}_{2}$ core-shell nanohybrids by using a facile method (shown in Fig. 8a). The 3D CoO@ $\mathrm{MnO}_{2}$ coreshell structure has a diameter of $268 \mathrm{~nm}$ (Fig. 8b). The 3D $\mathrm{CoO} @ \mathrm{MnO}_{2}$ core-shell nanohybrid electrode delivers 

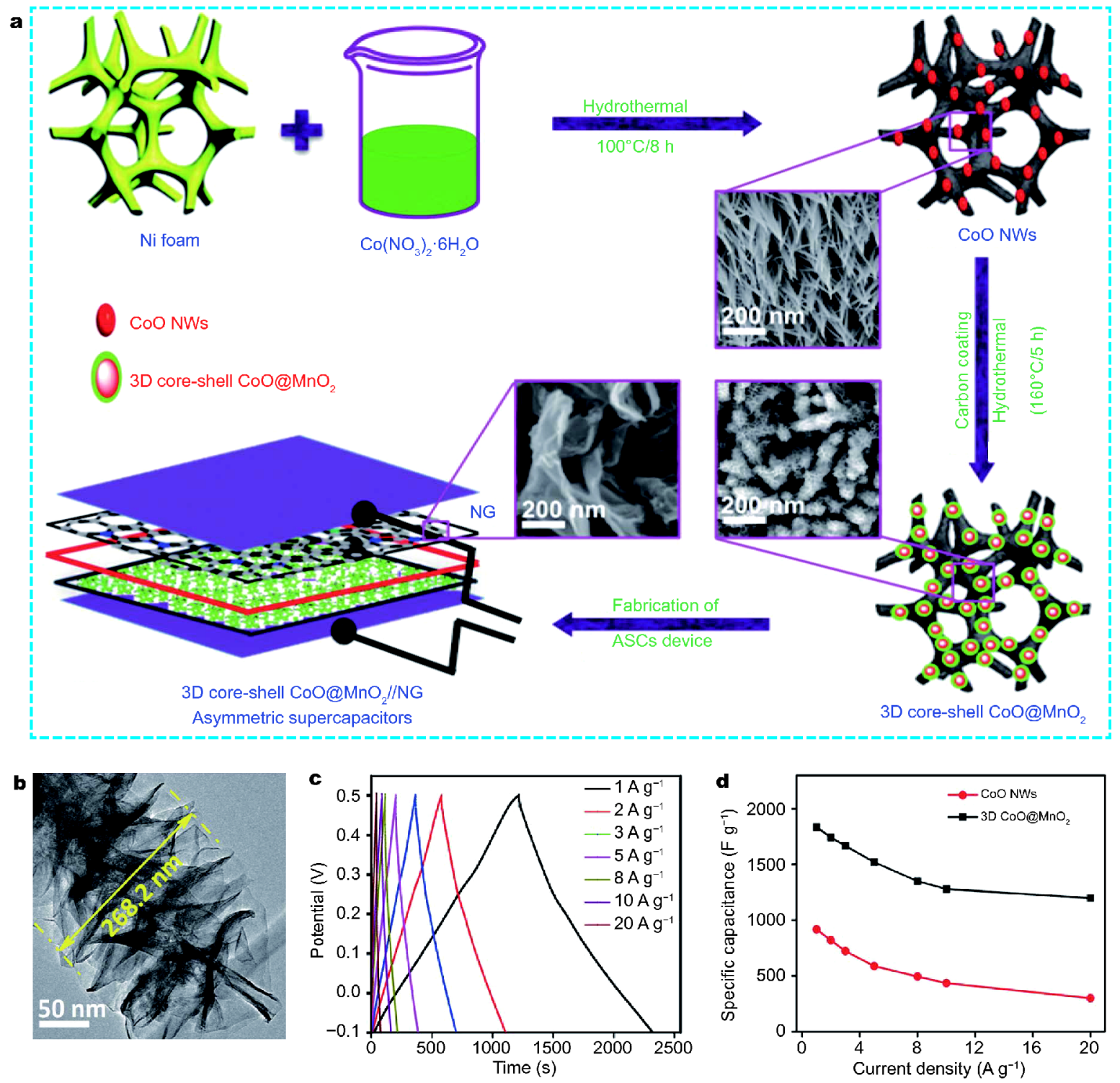

Figure 8 (a) Schematic of the preparation of 3D CoO@ $\mathrm{MnO}_{2}$ nanohybrid; (b) TEM image of the 3D CoO@MnO ${ }_{2}$; (c) charge-discharge curves of the $\mathrm{CoO} @ \mathrm{MnO}_{2}$; (d) cycle stabilities of the 3D CoO@ $\mathrm{MnO}_{2}$ core-shell nanohybrid and $\mathrm{CoO}$ NWs at $5 \mathrm{~A} \mathrm{~g}^{-1}$. Reproduced with permission from Ref. [136]. Copyright 2017, the Royal Society of Chemistry.

good electrochemical performance with high specific capacitances (1835 and $1198 \mathrm{~F} \mathrm{~g}^{-1}$ at 1 and $20 \mathrm{~A} \mathrm{~g}^{-1}$ ) $\left(6 \mathrm{~mol} \mathrm{~L}^{-1} \mathrm{KOH}\right)$ (Fig. 8c, d), and outstanding cycle performance $(97.7 \%$ capacitance retention after 10,000 cycles at $\left.1 \mathrm{~A} \mathrm{~g}^{-1}\right)$. When this 3D $\mathrm{CoO} @ \mathrm{MnO}_{2}$ core-shell nanohybrid was used as cathode and assembled into an asymmetric SCs combined with a $\mathrm{N}$-doped graphene anode, the formed asymmetric SCs device shows a high specific capacitance of $191 \mathrm{~F} \mathrm{~g}^{-1}$ at $1 \mathrm{~A} \mathrm{~g}^{-1}$ and good cycle performance with $86.8 \%$ retention after 10,000 cycles. The device presents an energy density of about $85.9 \mathrm{~W} \mathrm{~h} \mathrm{~kg}^{-1}$ at a power density of $852.4 \mathrm{~W} \mathrm{~kg}^{-1}$.

Meng et al. [137] fabricated hierarchically densely packed porous $\mathrm{MnO}_{2}$ microspheres doped with $\mathrm{Fe}_{3} \mathrm{O}_{4}$ NPs through a one-step low-cost ultrasound-assisted method. The SEM and TEM images (Fig. 9a, b) show that the sample owns a unique hierarchical nanostructure. The microsphere is composed of numerous randomly interconnected nanoflakes. The $\mathrm{Fe}_{3} \mathrm{O}_{4}-\mathrm{MnO}_{2}$ electrode shows a capacitance of $367.4 \mathrm{~F} \mathrm{~g}^{-1}$ at $100 \mathrm{mV} \mathrm{s}^{-1}\left(1 \mathrm{~mol} \mathrm{~L}^{-1}\right.$ 

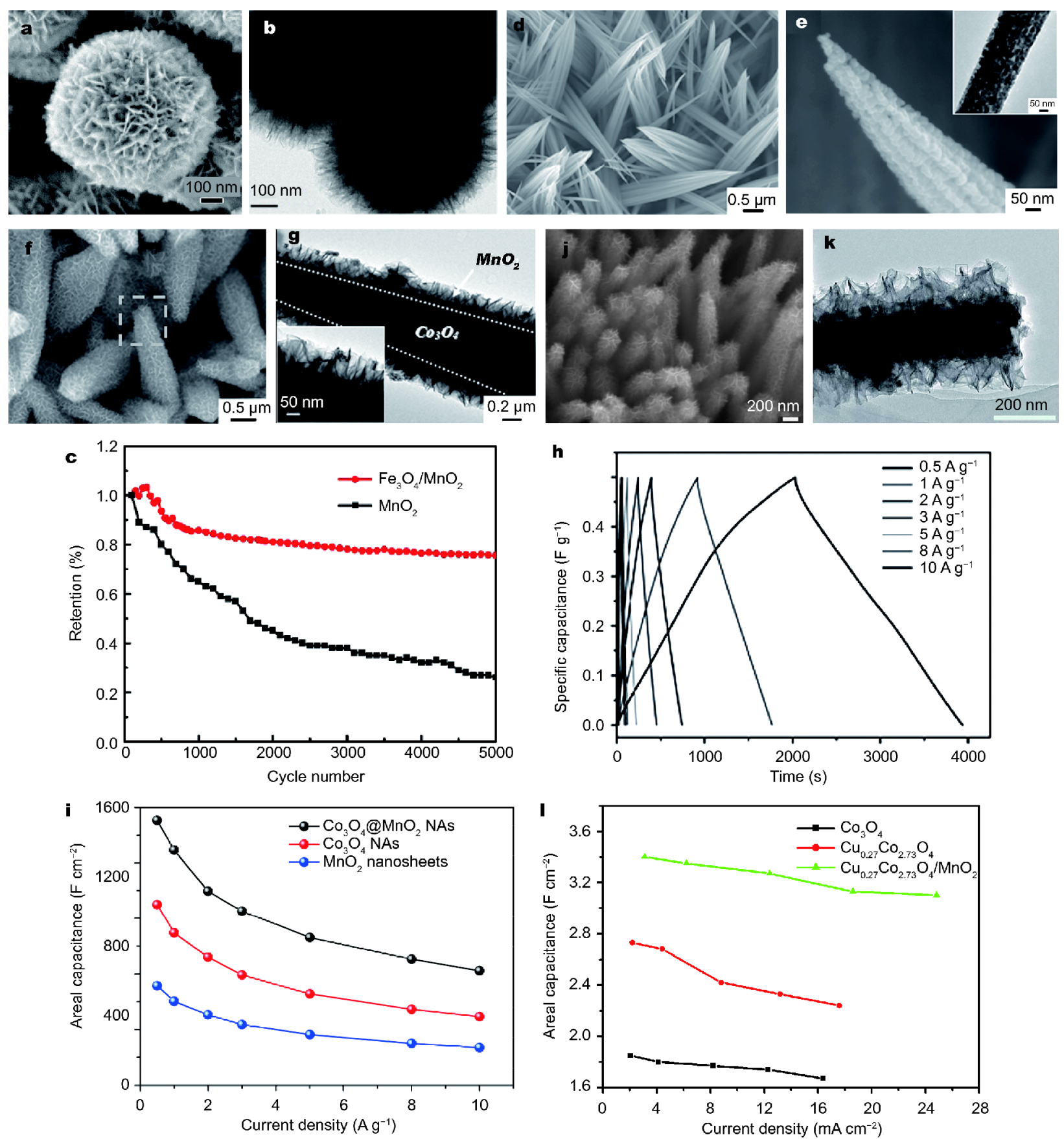

Figure 9 (a) SEM and (b) TEM images of the $\mathrm{Fe}_{3} \mathrm{O}_{4}-\mathrm{MnO}_{2}$ sample; (c) capacitance retention at $5 \mathrm{~A} \mathrm{~g}^{-1}$ over 5,000 cycles; (d, e) SEM images of the $\mathrm{Co}_{3} \mathrm{O}_{4} \mathrm{NAs}$ (the inset shows TEM image of the $\mathrm{Co}_{3} \mathrm{O}_{4} \mathrm{NAs}$ ); (f, g) SEM and TEM images of $\mathrm{Co}_{3} \mathrm{O}_{4} @ \mathrm{MnO}_{2} \mathrm{NAs}$. (h) Charge-discharge curves of the $\mathrm{Co}_{3} \mathrm{O}_{4} @ \mathrm{MnO}_{2}$ composite. (i) Current density dependence of the specific capacitance of the $\mathrm{MnO}_{2}$ nanosheets, $\mathrm{Co}_{3} \mathrm{O}_{4} \mathrm{NAs}$ and $\mathrm{Co}_{3} \mathrm{O}_{4} @ \mathrm{MnO}_{2} \mathrm{NAs}(\mathrm{j}$, k) SEM and TEM images of $\mathrm{Cu}_{0.27} \mathrm{Co}_{2.73} \mathrm{O}_{4} / \mathrm{MnO}_{2}$; (l) the specific capacitances of the three electrodes as a function of current density. (a-c) Reproduced with permission from Ref. [137]. Copyright 2014, the American Chemical Society. (d-i) Reproduced with permission from Ref. [138]. Copyright 2014, Wiley-VCH. (j-l) Reproduced with permission from Ref. [139]. Copyright 2015, the Royal Society of Chemistry.

$\mathrm{Na}_{2} \mathrm{SO}_{4}$ ). The capacitance retention of the $\mathrm{Fe}_{3} \mathrm{O}_{4}-\mathrm{MnO}_{2}$ composite is markedly superior to that of single $\mathrm{MnO}_{2}$ (Fig. 9c). The good electrochemical performance of the
$\mathrm{Fe}_{3} \mathrm{O}_{4}-\mathrm{MnO}_{2}$ sample is attributed to its unique hierarchical nanostructure, in which high-number-density and isolated $\mathrm{Fe}_{3} \mathrm{O}_{4}$ NPs are distributed in the interior of 
$\mathrm{MnO}_{2}$.

Cheng et al. [138] fabricated a hierarchical porous $\mathrm{Co}_{3} \mathrm{O}_{4} @ \mathrm{MnO}_{2}$ nanoneedle arrays $\left(\mathrm{Co}_{3} \mathrm{O}_{4} @ \mathrm{MnO}_{2} \mathrm{NAs}\right)$ on $\mathrm{Ni}$ foam via a hydrothermal method. The synthesis of $\mathrm{Co}_{3} \mathrm{O}_{4} @ \mathrm{MnO}_{2} \mathrm{NAs}$ can be divided into four steps. First, through a modified hydrothermal process, $\mathrm{Co}(\mathrm{OH})_{2} \mathrm{CO}_{3}$ is directly grown on $\mathrm{Ni}$ foam substrate. Further heat treatment enables the formation of porous $\mathrm{Co}_{3} \mathrm{O}_{4}$ nanostructures. Afterward, the porous $\mathrm{Co}_{3} \mathrm{O}_{4}$ nanoneedles are coated with a thin carbon nanolayer. Finally, the $\mathrm{Co}_{3} \mathrm{O}_{4} @ \mathrm{MnO}_{2}$ NAs are obtained via the formation of $\mathrm{MnO}_{2}$ nanosheets through a reaction between $\mathrm{KMnO}_{4}$ and carbon. As shown in Fig. 9d, the $\mathrm{Co}_{3} \mathrm{O}_{4}$ nanoneedles stand on the Ni foam substrate. Each nanoneedle consists of numerous small NPs accumulating with each other, forming a nanoporous structure (shown in Fig. 9e). Fig. 9f, $g$ show the SEM and TEM images of $\mathrm{Co}_{3} \mathrm{O}_{4} @ \mathrm{MnO}_{2}$ NAs. Thin $\mathrm{MnO}_{2}$ nanosheets are covered on the surface of $\mathrm{Co}_{3} \mathrm{O}_{4}$ nanoneedles, forming a core-shell hierarchical nanostructure. The galvanostatic charge-discharge curves of the $\mathrm{Co}_{3} \mathrm{O}_{4} @ \mathrm{MnO}_{2}$ NAs investigated at $0.5-10 \mathrm{~A} \mathrm{~g}^{-1}$ $\left(1 \mathrm{~mol} \mathrm{~L}{ }^{-1} \mathrm{LiOH}\right)$ are shown in Fig. $9 \mathrm{~h}$. The sample displays relatively high specific capacitances of 1905.4, $1693.2,1396,1253.4,1062,905.6$, and $823 \mathrm{~F} \mathrm{~g}^{-1}$ at $0.5,1,2$, 3, 5, 8, and $10 \mathrm{~A} \mathrm{~g}^{-1}$, respectively. Fig. 9i shows that the performance of the $\mathrm{Co}_{3} \mathrm{O}_{4} @ \mathrm{MnO}_{2} \mathrm{NAs}$ is obviously better than those of the individual $\mathrm{MnO}_{2}$ nanosheets and $\mathrm{Co}_{3} \mathrm{O}_{4}$ nanoneedles. Furthermore, the $\mathrm{Co}_{3} \mathrm{O}_{4} @ \mathrm{MnO}_{2}$ composite materials possess a high energy density of $66.2 \mathrm{~W} \mathrm{~h} \mathrm{~kg}^{-1}$ at a power density of $0.25 \mathrm{~kW} \mathrm{~kg}^{-1}$.

A hydrothermal and post-heat treatment method was employed by Yin et al. [139] for the preparation of hierarchical $\mathrm{Cu}_{0.27} \mathrm{Co}_{2.73} \mathrm{O}_{4} / \mathrm{MnO}_{2}$ nanorod arrays. The $\mathrm{MnO}_{2}$ nanoflakes homogeneously grow on $\mathrm{Cu}_{0.27} \mathrm{Co}_{2.73} \mathrm{O}_{4}$ nanorods which are grown on $\mathrm{Ni}$ foam, and the average diameter of the composites is approximately 250-300 nm (shown in Fig. 9j, k). The specific capacitances of $\mathrm{Cu}_{0.27}$ $\mathrm{Co}_{2.73} \mathrm{O}_{4}$ and $\mathrm{Cu}_{0.27} \mathrm{Co}_{2.73} \mathrm{O}_{4} / \mathrm{MnO}_{2}$ are $2.24 \mathrm{~F} \mathrm{~cm}^{-2}$ at $17.6 \mathrm{~mA} \mathrm{~cm}^{-2}$ and $3.1 \mathrm{~F} \mathrm{~cm}^{-2}$ at $24.8 \mathrm{~mA} \mathrm{~cm}^{-2}$, respectively (Fig. 9l). The specific capacitance of $\mathrm{Co}_{3} \mathrm{O}_{4}$ at $16.4 \mathrm{~mA} \mathrm{~cm}^{-2}$ is $1.67 \mathrm{~F} \mathrm{~cm}^{-2}$, which is markedly lower than those of $\mathrm{Cu}_{0.27} \mathrm{Co}_{2.73} \mathrm{O}_{4}$ and $\mathrm{Cu}_{0.27} \mathrm{Co}_{2.73} \mathrm{O}_{4} / \mathrm{MnO}_{2}$ electrodes. As the current density increases from 2.2 to $17.6 \mathrm{~mA} \mathrm{~cm}{ }^{-2}$, the capacity of $\mathrm{Cu}_{0.27} \mathrm{Co}_{2.73} \mathrm{O}_{4}$ remains at $\sim 82.1 \%$. For $\mathrm{Cu}_{0.27} \mathrm{Co}_{2.73} \mathrm{O}_{4} / \mathrm{MnO}_{2}$, a better rate capability with approximately $91.2 \%$ capacitance retention can be observed as the current density increases from 3.1 to $24.8 \mathrm{~mA} \mathrm{~cm}^{-2}$. The homogeneously aligned structure of $\mathrm{Cu}_{0.27} \mathrm{Co}_{2.73} \mathrm{O}_{4}$ nanorods with planar tips and a rough surface can effectively control the aggregation of active materials and shorten the pathway for ion transportation, further resulting in large areal capacitance and superior rate capability. These results demonstrate the opportunity of the potential candidate as binder-free electrodes applied in SCs and show great potential in exploring higher areal capacitance for miniaturized devices.

Liu et al. [140] prepared hierarchical $\mathrm{NiCo}_{2} \mathrm{O}_{4} @ \mathrm{MnO}_{2}$ core-shell nanosheet array composites on $\mathrm{Ni}$ foam by a two-step hydrothermal method. Owing to the unique nanoarchitecture, the $\mathrm{NiCo}_{2} \mathrm{O}_{4} @ \mathrm{MnO}_{2}$ core-shell nanosheet arrays display a high areal capacitance of $2.39 \mathrm{~F} \mathrm{~cm}^{-2}, \quad\left(1595.1 \mathrm{~F} \mathrm{~g}^{-1}\right)$ at $3 \mathrm{~mA} \mathrm{~cm}^{-2} \quad\left(1 \mathrm{~mol} \mathrm{~L}^{-1}\right.$ $\mathrm{NaOH})$. However, the areal capacitance of pure $\mathrm{NiCo}_{2} \mathrm{O}_{4}$ nanosheet arrays was calculated to be only $1.50 \mathrm{~F} \mathrm{~cm}^{-2}$ at $3 \mathrm{~mA} \mathrm{~cm}{ }^{-2}$. The $\mathrm{NiCo}_{2} \mathrm{O}_{4} @ \mathrm{MnO}_{2}$ sample also exhibits good cycle performance $(92.6 \%$ retention after $2000 \mathrm{cy}-$ cles at $40 \mathrm{~mA} \mathrm{~cm}^{-2}$ ), which is superior to that of the pristine $\mathrm{NiCo}_{2} \mathrm{O}_{4}$ nanosheet sample. The results show that the growth of $\mathrm{MnO}_{2}$ nanosheets on $\mathrm{NiCo}_{2} \mathrm{O}_{4}$ nanosheets is a viable approach to increase the capacitive properties of materials and simultaneously improve the cycling performance of SCs.

By a facile two-step electro-deposition process, Zhang et al. [141] successfully synthesized a 3D hierarchical $\mathrm{NiCo}_{2} \mathrm{O}_{4} @ \mathrm{MnO}_{2}$ hybrid nanomaterial grown on stainless steel mesh. The specific capacitance of $\mathrm{NiCo}_{2} \mathrm{O}_{4} @ \mathrm{MnO}_{2}$ at $2 \mathrm{~A} \mathrm{~g}^{-1}$ is $688.4 \mathrm{~F} \mathrm{~g}^{-1}$, which is markedly higher than those of $\mathrm{MnO}_{2}\left(336.6 \mathrm{~F} \mathrm{~g}^{-1}\right)$ and $\mathrm{NiCo}_{2} \mathrm{O}_{4}\left(241 \mathrm{~F} \mathrm{~g}^{-1}\right)$. The $\mathrm{NiCo}_{2} \mathrm{O}_{4} @ \mathrm{MnO}_{2}$ shows a high specific capacitance of 913.6 $\mathrm{F} \mathrm{g}^{-1}$ at $0.5 \mathrm{~A} \mathrm{~g}^{-1}$ and a capacitance retention of $87.1 \%$ after 3,000 cycles. Furthermore, the asymmetric SCs device with a large voltage window of $1.5 \mathrm{~V}$ is assembled by using $\mathrm{NiCo}_{2} \mathrm{O}_{4} @ \mathrm{MnO}_{2}$ sample as the cathode and activated carbon as the anode. The device achieves an energy density of $37.5 \mathrm{~W} \mathrm{~h} \mathrm{~kg}^{-2}$ at a power density of $187.5 \mathrm{~W} \mathrm{~kg}^{-1}$.

\section{Composites of gold NP-doped TMOs}

TMOs doped with Au NPs are highly active and function as selective catalysts for a variety of chemical reactions $[142,143]$. The design of the TMOs composites with Au nanoparticles is demonstrated to be another efficient approach to enhance the electrochemical performance of TMOs as SC electrodes [144]. Wang et al. [145] designed and synthesized an $\mathrm{Au}-\mathrm{NiO}$ composite that exhibited a markedly improved rate performance on SCs. The specific capacitance of the $\mathrm{Au}-\mathrm{NiO}$ electrode at $20 \mathrm{~A} \mathrm{~g}^{-1}$ is $619 \mathrm{~F} \mathrm{~g}^{-1}$, which is markedly higher than that of pure $\mathrm{NiO}$ electrode $\left(216 \mathrm{~F} \mathrm{~g}^{-1}\right)$.

You et al. [146] successfully synthesized mono- 

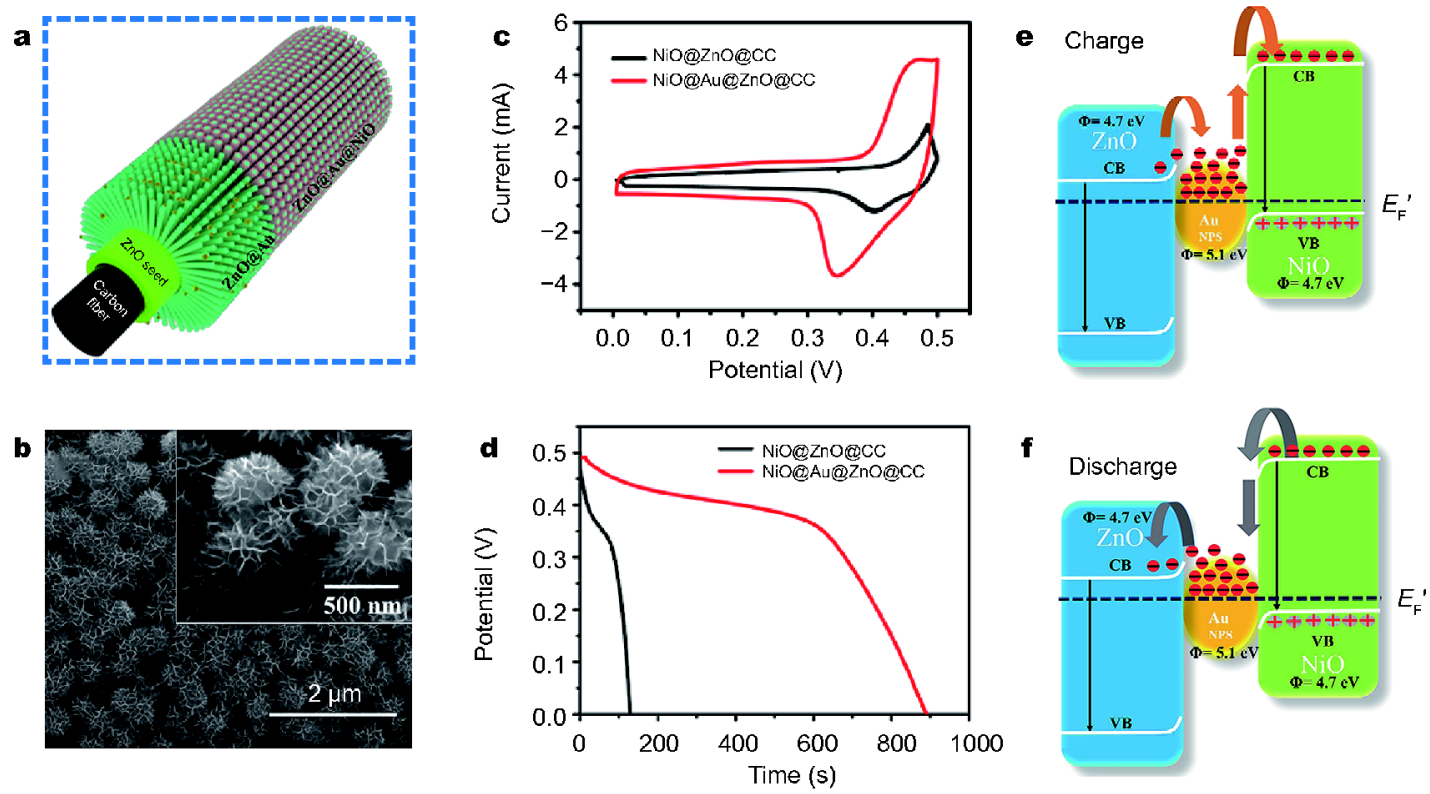

Figure 10 (a) Schematic illustration for the fabrication of hierarchical ZnO@Au@NiO nanocomposite; (b) SEM images of ZnO@Au@NiO; (c) CV curves of two samples; (d) discharge curves of two samples; (e and f) energy level diagrams at the interface of $\mathrm{ZnO}-\mathrm{Au}-\mathrm{NiO}$ during charge-discharge process. Reproduced with permission from Ref. [151]. Copyright 2015, the American Chemical Society.

dispersed dumbbell-like $\mathrm{Au}-\mathrm{Fe}_{3} \mathrm{O}_{4}$ NPs with different sizes $\left(5 / 14,5 / 21,7 / 14\right.$, and $\left.7 / 21 \mathrm{~nm} \mathrm{Au}-\mathrm{Fe}_{3} \mathrm{O}_{4} \mathrm{NPs}\right)$. The specific capacitance of $7 / 14 \mathrm{~nm} \mathrm{Au}-\mathrm{Fe}_{3} \mathrm{O}_{4} \mathrm{NPs}$ at $1 \mathrm{~A} \mathrm{~g}^{-1}$ is $464 \mathrm{~F} \mathrm{~g}^{-1}\left(1 \mathrm{~mol} \mathrm{~L}{ }^{-1} \mathrm{KOH}\right)$, which is markedly higher than that of pure $\mathrm{Fe}_{3} \mathrm{O}_{4} \mathrm{NPs}\left(160 \mathrm{~F} \mathrm{~g}^{-1}\right)$. The $7 / 14 \mathrm{~nm}$ $\mathrm{Au}-\mathrm{Fe}_{3} \mathrm{O}_{4}$ composite exhibits a higher capacitance retention of $86.4 \%$ after 1,000 cycles at $10 \mathrm{~A} \mathrm{~g}^{-1}$ than that of pure $\mathrm{Fe}_{3} \mathrm{O}_{4}$ NP electrode $(72.8 \%$ retention of initial capacitance). The above capacitive enhancement can be ascribed to the electron transfer increase induced by gold across the dumbbell-like NPs.

A simple and controllable electrochemical deposition process was employed by Hu's groups to synthesize the $3 \mathrm{D}$ hierarchical heterostructure of $\mathrm{MnO}_{2}$ nanosheets and nanorods directly grown on porous $\mathrm{Au}$-coated $\mathrm{Co}_{3} \mathrm{O}_{4}$ nanowall array, and to assemble a sandwich construction of $\mathrm{Co}_{3} \mathrm{O}_{4} @ \mathrm{Au} @ \mathrm{MnO}_{2}$ [147]. Owing to the unique sandwich construction, each component is efficiently used for energy reaction. The specific capacitance of the $\mathrm{Co}_{3} \mathrm{O}_{4} @$ $\mathrm{Au} @ \mathrm{MnO}_{2}$ nanosheet hierarchical heterostructures $\left(\mathrm{Co}_{3}\right.$ $\mathrm{O}_{4} @ \mathrm{Au} @ \mathrm{MnO}_{2}$ (NSs) HHs) is $1532.4 \mathrm{Fg}^{-1}$ at $1 \mathrm{~A} \mathrm{~g}^{-1}$ $\left(1 \mathrm{~mol} \mathrm{~L}^{-1} \mathrm{LiOH}\right)$, which is higher than those of the $\mathrm{Au}$ coated $\mathrm{Co}_{3} \mathrm{O}_{4}$ nanowall arrays $\left(1046.6 \mathrm{~F} \mathrm{~g}^{-1}\right)$ and $\mathrm{Co}_{3}$ $\mathrm{O}_{4} @ \mathrm{Au} @ \mathrm{MnO}_{2}$ nanorod hierarchical heterostructures $\left(\mathrm{Co}_{3} \mathrm{O}_{4} @ \mathrm{Au} @ \mathrm{MnO}_{2}\right.$ (NRs) HHs) $\left(1292.9 \mathrm{~F} \mathrm{~g}^{-1}\right)$. The $\mathrm{Co}_{3}$ $\mathrm{O}_{4} @ \mathrm{Au} @ \mathrm{MnO}_{2}$ (NSs) HHs also exhibit superior cycling performance (with virtually no degradation after 5,000 cycles). Furthermore, the presented results of the $\mathrm{Co}_{3}$ $\mathrm{O}_{4} @ \mathrm{Au} @ \mathrm{MnO}_{2}$ (NSs) HHs are larger than those of the reported $\mathrm{Co}_{3} \mathrm{O}_{4}$ or $\mathrm{MnO}_{2}$-based heterostructures, such as $\mathrm{MnO}_{2} / \mathrm{Mn} / \mathrm{MnO}_{2}$ nanotube arrays $\left(937 \mathrm{~F} \mathrm{~g}^{-1}\right.$ at $\left.1.5 \mathrm{~A} \mathrm{~g}^{-1}\right)$ [148], $\mathrm{Zn}_{2} \mathrm{SO}_{4} @ \mathrm{MnO}_{2}$ nanorods (642.3 $\mathrm{F} \mathrm{g}^{-1}$ at $1 \mathrm{~A} \mathrm{~g}^{-1}$ ) [149], and $\mathrm{Co}_{3} \mathrm{O}_{4} / \mathrm{NiO}$ nanowire arrays $\left(853 \mathrm{~F} \mathrm{~g}^{-1}\right.$ at $2 \mathrm{~A} \mathrm{~g}^{-1}$ ) [150]. Thus, the $\mathrm{Co}_{3} \mathrm{O}_{4} @ \mathrm{Au} @ \mathrm{MnO}_{2}$ (NSs) HHs could be recognized as promising materials for SCs.

Yan et al. [151] designed and synthesized a hierarchical ZnO@Au@NiO nanocomposite as the electrode of SCs (Fig. 10a,b). First, ZnO nanowires arrays were grown on carbon nanofibers of carbon cloth. Then, a small quantity of $\mathrm{Au}$ nanoparticles was covered on $\mathrm{ZnO}$ nanowires. Subsequently, $\mathrm{NiO}$ nanosheets were uniformly grown on the surface of the $\mathrm{Au}$-modified $\mathrm{ZnO}$ nanowires to obtain the ZnO@Au@NiO composites. The ZnO/Au/ $\mathrm{NiO}$ electrode possesses a larger area in the CV curve, suggesting superior electrochemical performance to that of $\mathrm{ZnO} / \mathrm{NiO}$ nanorods (shown in Fig. 10c). The areal capacitance of the $\mathrm{ZnO@Au@NiO} \mathrm{nanocomposite} \mathrm{is}$ calculated to be $3.50 \mathrm{~F} \mathrm{~cm}^{-2}$ at $2 \mathrm{~mA} \mathrm{~cm}^{-2}\left(1 \mathrm{~mol} \mathrm{~L}^{-1}\right.$ $\mathrm{KOH}$ ), whereas the $\mathrm{ZnO@NiO} \mathrm{electrode} \mathrm{only} \mathrm{shows} \mathrm{an}$ areal capacitance of $0.42 \mathrm{~F} \mathrm{~cm}^{-2}$ under the same condition (Fig. 10d). The ZnO@Au@NiO nanocomposite electrode demonstrates good cyclic stability with approximately $80.3 \%$ capacitance retention after 4,000 continuous cycles at $30 \mathrm{~mA} \mathrm{~cm}{ }^{-2}$. The enhanced electrochemical property is 
mainly ascribed to the decoration of $\mathrm{Au}$ nanoparticles. On one hand, $\mathrm{Au}$ nanoparticles can accelerate electron conduction. On the other hand, electrons can be temporarily trapped and accumulated at the Fermi level $\left(E_{\mathrm{F}}\right)$ due to the localized Schottky barrier at $\mathrm{Au} / \mathrm{NiO}$ interface during charge process until filling the gap between $\mathrm{ZnO}$ and $\mathrm{NiO}$ (Fig. 10e) [151]. Thus, more electrons can be released during discharge process (Fig. 10f).

\section{Composites of carbon materials and TMOs}

For pseudocapacitors, surface oxidation-reduction reaction of metal oxides can result in higher specific capacitances [152]. Nanostructured carbon materials are generally utilized as EDLC electrodes, demonstrating their superior long-term electrochemical stability [153]. Thus, considerable efforts have been made to enhance the SC performance by creating composites of TMOs and carbon materials, such as TMOs/graphene and TMOs/ carbon nanofibers (CFs) [154-167]. The synthesized multi-component composites can maximize the benefits from all components [154-169].

Wang et al. [170] designed and fabricated two types of hierarchical core-shell fiber-based electrodes, including $\mathrm{MnO}_{2} /$ reduced graphene oxide (RGO)/CF and 3D porous graphene hydrogel-wrapped $\mathrm{Cu}$ wire $(\mathrm{GH} / \mathrm{CW})$. The specific areal capacitance and volumetric capacitance of the $\mathrm{MnO}_{2} / \mathrm{RGO} / \mathrm{CF}$ electrode are $205.7 \mathrm{mF} \mathrm{cm}^{-2}$ and 13.7 $\mathrm{F} \mathrm{cm}^{-3}$ at $0.5 \mathrm{~mA} \mathrm{~cm}^{-2}\left(1 \mathrm{~mol} \mathrm{~L}^{-1} \mathrm{Na}_{2} \mathrm{SO}_{4}\right)$, respectively, and both values are considerably larger than those of $\mathrm{MnO}_{2} / \mathrm{CF}\left(178.3 \mathrm{mF} \mathrm{cm}^{-2}\right.$ and $\left.11.8 \mathrm{~F} \mathrm{~cm}^{-3}\right)$ and $\mathrm{RGO} / \mathrm{CF}$ $\left(1.6 \mathrm{mF} \mathrm{cm} \mathrm{cm}^{-3}\right.$ and $\left.0.1 \mathrm{~F} \mathrm{~cm}^{-3}\right)$. The results indicate that the synergistic effect and the interactions between the RGO nanosheets and $\mathrm{MnO}_{2}$ nanoflakes in the $\mathrm{MnO}_{2} /$ $\mathrm{RGO} / \mathrm{CF}$ electrode markedly increase the total capacitive performance. The specific capacitance of the $\mathrm{MnO}_{2} / \mathrm{RGO} /$ $\mathrm{CF}$ electrode remains at $73 \%$ from 13.7 to $10 \mathrm{~F} \mathrm{~cm}^{-3}$. Owing to the synergistic effects of different components in nanohybrid fiber electrodes, the asymmetric SC device with $\mathrm{MnO}_{2}$ /graphene/CF as the cathode and $\mathrm{GH} / \mathrm{CW}$ as the anode shows a high areal energy density of 18.1 $\mu \mathrm{W} \mathrm{h} \mathrm{cm}{ }^{-2}$ and a volumetric energy density of 0.9 $\mathrm{mW} \mathrm{h} \mathrm{cm}{ }^{-3}$ in a voltage range of $0-1.6 \mathrm{~V}$. Moreover, the asymmetric SC also shows an energy density as high as $0.63 \mathrm{~mW} \mathrm{~h} \mathrm{~cm}^{-3}$ at a high power density of $0.2 \mathrm{~W} \mathrm{~cm}^{-3}$. Thus, the fiber-based flexible SCs show excellent flexibility, great rate capability, and good cycle stability, making these SCs a prospective power source for flexible energy storage devices.

Yu et al. [171] fabricated hierarchical graphene/ $\mathrm{MnO}_{2}$ nanostructured sponges by a low-cost "dip and dry" process with commercial sponges as skeletons. The composite can be operated at a high scan rate of $200 \mathrm{~V} \mathrm{~s}^{-1}$ and has superior cycle performance ( $\sim 90 \%$ retention after 10,000 cycles at $10 \mathrm{~A} \mathrm{~g}^{-1}$ ). As calculated using galvanostatic charge-discharge curves, the highest energy density and power density of sponge@RGO@ $\mathrm{MnO}_{2}$ based device are $8.34 \mathrm{Wh} \mathrm{kg}^{-1}$ and $47 \mathrm{~kW} \mathrm{~kg}^{-1}$, respectively, at an operating voltage of $0.8 \mathrm{~V}$. However, the highest energy density and power density are $2.08 \mathrm{~W} \mathrm{~h} \mathrm{~kg}^{-1}$ and $94 \mathrm{~kW} \mathrm{~kg}^{-1}$ for the sponge@RGO under the same condition. The features of low cost, facile preparation, wide operation range, high specific capacitance, high energy and power density, and superior cycling performance could make the as-fabricated SCs as promising devices for commercial production.

Kumar et al. [172] reported an interesting work about the fabrication of 3D hierarchical structure composed of 0D $\mathrm{Co}_{3} \mathrm{O}_{4}$ nanobeads, $1 \mathrm{D}$ carbon nanotubes (CNTs), and $2 \mathrm{D}$ graphenes (GNSs) via an easy ultrafast microwave irradiation method for high performance supercapacitor electrode. In this unique structure, $\mathrm{Co}_{3} \mathrm{O}_{4}$ nanobeads are anchored on CNTs and the CNTs are grown on GNSs, leading to a good electrochemical performance. The electrode possesses a large specific capacitance of $600 \mathrm{~F} \mathrm{~g}^{-1}$ at $0.7 \mathrm{~A} \mathrm{~g}^{-1}$ (30 wt.\% KOH). Furthermore, the electrode also exhibits good cycle stability ( $94.5 \%$ retention after 5,000 cycles at $10 \mathrm{~A} \mathrm{~g}^{-1}$ ).

Flexible solid-state fiber SCs present the advantages of light weight, high power density, good flexibility, low cost, and environmental friendliness. Zhang et al. [173] fabricated a $\mathrm{MnO}_{2} / \mathrm{CF}$ s fiber via electrodepositing ultrathin $\mathrm{MnO}_{2}$ nanosheets on carbon fiber yarns. The specific volumetric and gravimetric capacitances of the single $\mathrm{MnO}_{2} / \mathrm{CFs}$ fiber electrode are calculated to be $58.7 \mathrm{~F} \mathrm{~cm}^{-3}$ and $428 \mathrm{~F} \mathrm{~g}^{-1}$ based on the mass of $\mathrm{MnO}_{2}$. The $\mathrm{MnO}_{2} / \mathrm{CFs}$ electrode demonstrates a large volumetric capacitance because of the synergistic effects of $\mathrm{MnO}_{2}$ and CFs. The assembled flexible solid-state fiber-like SCs (two $\mathrm{MnO}_{2}$ / CFs fiber electrodes as anode and cathode, resepectively) show a high volumetric energy density $\left(3.8 \mathrm{~mW} \mathrm{~h} \mathrm{~cm}^{-3}\right.$ at a power density of $89 \mathrm{~mW} \mathrm{~cm}{ }^{-3}$ ), superior flexibility (CV curves are almost unaltered after 2,000 bending times), and an excellent cycling performance (only $14.2 \%$ capacitance fade after 10,000 cycles).

By a hydrothermal method, $\mathrm{Hu}$ et al. [174] fabricated a hierarchical mesoporous $\mathrm{NiFe}_{2} \mathrm{O}_{4}$ (NFO) nanocone forest that directly grew on carbon textile (CT). In the NFO-CT sample, the compact bundle of fibers possesses an average diameter of approximately $5 \mu \mathrm{m}$. The BET specific surface area of the hierarchical NFO-CT is as 

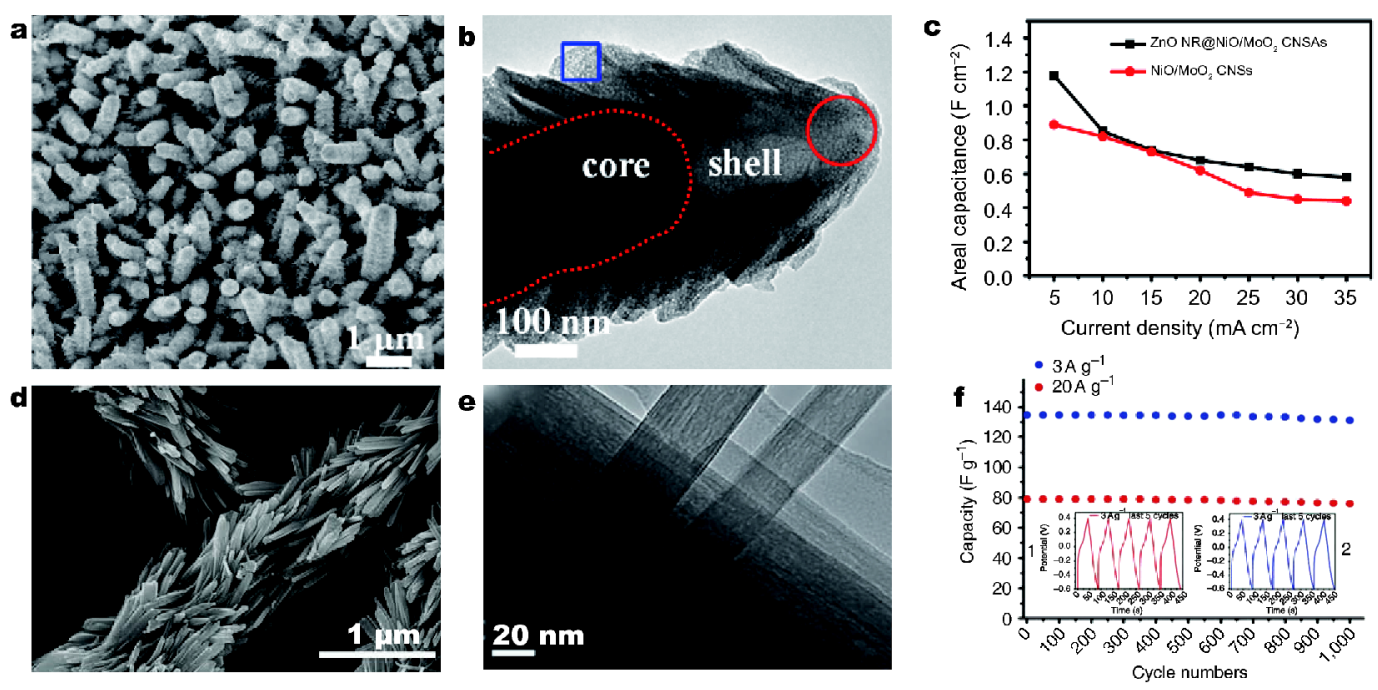

Figure 11 (a) SEM and (b) TEM images of ZnO NR@NiO/MoO ${ }_{2} \mathrm{CNSAs}$; (c) the areal specific capacitances of the two electrodes as a function of current density; (d) SEM image of $\mathrm{MnMoO}_{4} / \mathrm{CoMoO}_{4}$ heterostructured nanowires; (e) TEM image at the heterojunction of the hierarchical MnMoO$/$ $\mathrm{CoMoO}_{4}$ heterostructured nanowires; (f) cycling performance of $\mathrm{MnMoO}_{4} / \mathrm{CoMoO}_{4}$ (3D) electrodes tested at 3 and $20 \mathrm{Ag}^{-1}$ (the inset shows chargedischarge curves cycled at the first and last five cycles at $\left.3 \mathrm{~A} \mathrm{~g}^{-1}\right)$. (a-c) Reproduced with permission from Ref. [176]. Copyright 2014, the American Chemical Society. (d-f) Reproduced with permission from Ref. [177]. Copyright 2011, Nature Publishing Group.

high as $593.60 \mathrm{~m}^{2} \mathrm{~g}^{-1}$. As a binder-free electrode, the NFO-CT exhibits specific capacitances of $697,543.5$, $421.8,355.2$, and $303 \mathrm{~F} \mathrm{~g}^{-1}$ at $5,10,25,50$, and $75 \mathrm{mV} \mathrm{s}^{-1}$ $\left(6 \mathrm{~mol} \mathrm{~L}^{-1} \mathrm{LiCl}\right)$, respectively. Furthermore, the symmetric solid-state SCs device based on NFO-CT demonstrates high capacitance $\left(584 \mathrm{~F} \mathrm{~g}^{-1}\right.$ at $\left.5 \mathrm{mV} \mathrm{s}^{-1}\right)$ and excellent cycle performance $(93.57 \%$ capacitance retention after 10,000 cycles). The energy density is calculated to be $54.9 \mathrm{~W} \mathrm{~h} \mathrm{~kg}^{-1}$ at a power density of $300 \mathrm{~W} \mathrm{~kg}^{-1}$. Even at $1372 \mathrm{~W} \mathrm{~kg}^{-1}$, the NFO-CT electrode still achieves an energy density of $25.5 \mathrm{~W} \mathrm{~h} \mathrm{~kg}^{-1}$, which is substantially higher than those of single/binary metal oxide-based electrodes.

An easy, low-cost, and controllable approach was used by Zhang et al. [175] for the synthesis of corrugated $\mathrm{NiCo}_{2} \mathrm{O}_{4}$ nanosheets on a nitrogen-doped graphene/carbon nanotube (NGN/CNT) film. The $\mathrm{NiCo}_{2} \mathrm{O}_{4} / \mathrm{NGN} /$ CNT film electrode possesses a high volumetric capacitance of $482.7 \mathrm{~F} \mathrm{~cm}^{-3}$ and a gravimetric capacitance of $2292.7 \mathrm{~F} \mathrm{~g}^{-1}$ at $5 \mathrm{~A} \mathrm{~g}^{-1}\left(6 \mathrm{~mol} \mathrm{~L}^{-1} \mathrm{KOH}\right)$. The electrode also exhibits high rate capability and extremely long-term cycle stability. The asymmetric SCs device was fabricated by using $\mathrm{NiCo}_{2} \mathrm{O}_{4} / \mathrm{NGN} / \mathrm{CNT}$ s as the cathode and NGN/ CNTs as the anode. The device exhibits a high gravimetric energy density of $42.71 \mathrm{~W} \mathrm{~h} \mathrm{~kg}^{-1}$ at $775 \mathrm{~W} \mathrm{~kg}^{-1}$ and a high gravimetric power density of $15485 \mathrm{~W} \mathrm{~kg}^{-1}$ at $24.69 \mathrm{~W} \mathrm{~h} \mathrm{~kg}^{-1}$. Thus, this material is better than com- mercially available $\mathrm{Ni}(\mathrm{OH})_{2}$ used in $\mathrm{Ni}-\mathrm{MH}$ battery on power density.

\section{Other forms of TMOs composites}

Via a two-step solution-based approach, Duan et al. [176] synthesized a hierarchical core-shell structure of $\mathrm{ZnO}$ nanorod@NiO/ $/ \mathrm{MoO}_{2}$ composite nanosheet arrays ( $\mathrm{ZnO}$ $\mathrm{NR@NiO/} / \mathrm{MoO}_{2}$ CNSAs) on a $\mathrm{Ni}$ foam substrate. As

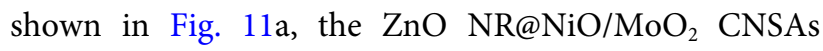
possess a diameter of $\sim 600 \mathrm{~nm}$ and length of $\sim 4 \mu \mathrm{m}$. The nanorod consists of a $\mathrm{ZnO} \mathrm{NR}$ "core" and a $\mathrm{NiO} / \mathrm{MoO}_{2}$ CNS "shell", and the ZnO NRs are well wrapped with ultrathin $\mathrm{NiO} / \mathrm{MoO}_{2} \mathrm{CNSs}$ (shown in Fig. 11b). The unique structure favors the penetration of electrolytes into the interior of the active material. The areal specific

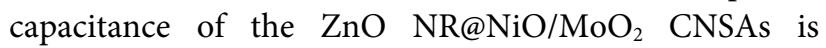
$1.18 \mathrm{~F} \mathrm{~cm}^{-2}$ at $5 \mathrm{~mA} \mathrm{~cm}^{-2}\left(2 \mathrm{~mol} \mathrm{~L}^{-1} \mathrm{KOH}\right.$ ) (shown in Fig. 11c). Moreover, the material also shows a good cycling performance (only $8.3 \%$ loss after 4,000 cycles at $10 \mathrm{~mA} \mathrm{~cm}^{-2}$ ).

Mai et al. [177] synthesized a 3D hierarchical $\mathrm{MnMoO}_{4} / \mathrm{CoMoO}_{4}$ heterostructure by a refluxing approach under mild conditions and $\mathrm{MnMoO}_{4}$ as the backbone material. Fig. 11d shows the morphology and structure of the $\mathrm{MnMoO}_{4} / \mathrm{CoMoO}_{4}$ hierarchical heterostructure. The pure $\mathrm{MnMoO}_{4}$ nanowire backbone materials are approximately $10 \mu \mathrm{m}$ in length and $500 \mathrm{~nm}$ in 
diameter. Furthermore, as shown in Fig. 11e, the Co$\mathrm{MoO}_{4}$ nanorods with diameters of around $50 \mathrm{~nm}$ are obtained. The BET specific surface areas of $\mathrm{MnMoO}_{4}$, $\mathrm{MnMoO}_{4} / \mathrm{CoMoO}_{4}$ nanocomposite, and surface-modified $\mathrm{MnMoO}_{4} / \mathrm{CoMoO}_{4}$ are 3.17, 28.0, and $54.06 \mathrm{~m}^{2} \mathrm{~g}^{-1}$, respectively. The active sites of the electrode can be adequately accessed due to the larger surface area compared with that in a previous report [178] (15 and $25 \mathrm{~m}^{2} \mathrm{~g}^{-1}$, which correspond to $\mathrm{MnMoO}_{4}$ nanorods and $\mathrm{CoMoO}_{4}$ nanorods, respectively). The specific capacitances of the hierarchical $\mathrm{MnMoO}_{4} / \mathrm{CoMoO}_{4}$ heterostructured nanowires is $187.1 \mathrm{~F} \mathrm{~g}^{-1}$ at $1 \mathrm{~A} \mathrm{~g}^{-1}\left(2 \mathrm{~mol} \mathrm{~L}^{-1} \mathrm{NaOH}\right)$, which is evidently higher than those of pure $1 \mathrm{D}$ nanorod $\mathrm{MnMoO}_{4}$ $\left(9.7 \mathrm{~F} \mathrm{~g}^{-1}\right), \mathrm{CoMoO}_{4}\left(62.8 \mathrm{~F} \mathrm{~g}^{-1}\right)$, and the $\mathrm{MnMoO}_{4} / \mathrm{Co}-$ $\mathrm{MoO}_{4}$ nanocomposite $\left(69.2 \mathrm{~F} \mathrm{~g}^{-1}\right)$. Fig. 11f displays excellent reversibility of the hierarchical $\mathrm{MnMoO}_{4} / \mathrm{CoMoO}_{4}$ electrode with high cycling efficiency of up to $98 \%$ after 1,000 cycles.

Through a stepwise hydrothermal method, Mai et al. [179] designed and synthesized 3D self-supported $\mathrm{Co}_{3}$ $\mathrm{O}_{4} @ \mathrm{CoMoO}_{4}$ core-shell architectures that directly grew on $\mathrm{Ni}$ foam. The $\mathrm{Co}_{3} \mathrm{O}_{4} @ \mathrm{CoMoO}_{4}$ shows a high capacitance of $1902 \mathrm{~F} \mathrm{~g}^{-1}$ at $1 \mathrm{~A} \mathrm{~g}^{-1}$ and good cycling stability with $1 \%$ capacitance loss after 5,000 cycles at $5 \mathrm{~A} \mathrm{~g}^{-1}$ ( $2 \mathrm{~mol} \mathrm{~L}^{-1} \mathrm{KOH}$ ). The asymmetric SCs device was fabricated by using $\mathrm{Co}_{3} \mathrm{O}_{4} @ \mathrm{CoMoO}_{4}$ as the cathode and the $\mathrm{CNTs}$ on Ni foam as the anode. The device delivers a high energy density of $45.2 \mathrm{~W} \mathrm{~h} \mathrm{~kg}^{-1}$ at a power density of $400 \mathrm{~W} \mathrm{~kg}^{-1}$ and good cycling performance (capacitance retention of $98.5 \%$ after 3,000 cycles at $\left.0.5 \mathrm{~A} \mathrm{~g}^{-1}\right)$. The good electrochemical performance of $\mathrm{Co}_{3} \mathrm{O}_{4} @ \mathrm{CoMoO}_{4}$ is ascribed to the unique architecture with a large interfacial area and numerous channels for the rapid diffusion of electrolyte ions.

High areal specific capacitance per area is of great importance for the practical application of supercapacitors. To realize this goal, it need to combine high mass-loading of the active material and high utilization ratio of the material. Sun et al. [180] prepared a ternary hierarchical core-shell structure of $\mathrm{Co}_{3} \mathrm{O}_{4} @ \mathrm{Ni}-\mathrm{Co}-\mathrm{O}$ arrays via an easy and cost-effective strategy (Fig. 12a-c). As shown in Fig. 12a, the $\mathrm{Co}_{3} \mathrm{O}_{4}$ microsheet grown on foam Ni substrate is the core, and the aligned slim Ni$\mathrm{Co}-\mathrm{O}$ nanorods (diameter $<20 \mathrm{~nm}$ ) are coated on it. This structure exhibits an excellent electrochemical performance when utilized as a supercapacitor electrode. The electrode with a high areal mass-loading of $12 \mathrm{mg} \mathrm{cm}^{-2}$ possesses a high specific capacitance of $2098 \mathrm{~F} \mathrm{~g}^{-1}$ at $5 \mathrm{~mA} \mathrm{~cm}^{-2}$ (1 mol L$\left.{ }^{-1} \mathrm{KOH}\right)$ (Fig. 12d). Furthermore, Sun et al. [181] also fabricated a hierarchical core-shell structure of $\mathrm{Co}_{3} \mathrm{O}_{4} @ \mathrm{NiO}$ nanowire@nanorod arrays via a similar strategy (Fig. 12e). The $\mathrm{NiO}$ nanorods were in-situ grown on the surface of $\mathrm{Co}_{3} \mathrm{O}_{4}$ nanowire arrays grown on foam Ni substrate (Fig. 12f-i). The electrode with a high mass-loading of $19.5 \mathrm{mg} \mathrm{cm}^{-1}$ delivers a high specific capacitance of $2033 \mathrm{~F} \mathrm{~g}^{-1}$ at $5 \mathrm{~mA} \mathrm{~cm}{ }^{-2}\left(1 \mathrm{~mol} \mathrm{~L}^{-1} \mathrm{KOH}\right)$. The areal capacitance is up to $39.6 \mathrm{~F} \mathrm{~cm}^{-2}$, which is much higher than that of pure $\mathrm{Co}_{3} \mathrm{O}_{4}$ electrode $\left(6.7 \mathrm{~F} \mathrm{~cm}^{-2}\right)$ (Fig. 12j, k). The excellent performance of these core-shell structure arrays is mainly attributed to the special hierarchical structure and the synergistic effect of different components. Based on the above two works, Sun et al. [182] further prepared hierarchical $\mathrm{Co}_{x} \mathrm{Fe}_{3-x} \mathrm{O}_{4}$ arrays directly grown on $\mathrm{Cu}$ foam. Combining the above hierarchical $\mathrm{Co}_{3} \mathrm{O}_{4} @ \mathrm{Ni}-\mathrm{Co}-\mathrm{O}$ arrays as the cathode, an aqueous battery was assembled. The battery shows an energy density of $\sim 2.08 \mathrm{~mW} \mathrm{~h} \mathrm{~cm}^{-2}$ at a power density of $\sim 4.89 \mathrm{~mW} \mathrm{~cm}^{-2}$, and an energy density of $\sim 1.36$ $\mathrm{mW} \mathrm{h} \mathrm{cm}{ }^{-2}$ at a power density of $\sim 42.56 \mathrm{~mW} \mathrm{~cm}^{-2}$ $\left(6 \mathrm{~mol} \mathrm{~L}^{-1} \mathrm{KOH}\right)$. This indicates that hierarchically nanostructured metal oxides also have potential applications in the field of aqueous battery [182].

Iron oxides have been considered to be promising anode materials for supercapacitors due to their low cost, abundance, non-toxicity, and functionality in negative potentials [183-185]. Recently, Lin and co-workers [183] prepared a hierarchical $\mathrm{Fe}_{2} \mathrm{O}_{3}$ nanotube array directly grown on $\mathrm{Ni}$ foam via chemical transformation of $\mathrm{ZnO}$ nanowire. The characterization results show that the walls of nanotube are mainly composed of $\alpha-\mathrm{Fe}_{2} \mathrm{O}_{3}$ nanoparticles mixed with a small quantity of $\mathrm{ZnO}$ nanoparticles. The electrochemical test results indicate that the hierarchical structure electrode exhibits a high reversible capacitance of $300.1 \mathrm{~F} \mathrm{~g}^{-1}$ at $0.75 \mathrm{~A} \mathrm{~g}^{-1}\left(1 \mathrm{~mol} \mathrm{~L}^{-1} \mathrm{Li}_{2} \mathrm{SO}_{4}\right)$.

A comparison of typical hierarchically nanostructured TMOs for SCs is given in Table 1. The morphologies and structures of TMOs are important influential factors for the corresponding electrochemical performance. Moreover, the performance of the reported asymmetric supercapacitors is summarized in Table 2.

\section{CONCLUSIONS AND OUTLOOKS}

In this review, we summarized the recent progress in the field of hierarchically nanostructured TMOs for SCs. Hierarchically nanostructured TMOs with various structures and compositions have been fabricated via different synthesis methods. The primary structure mainly includes spheres, hollow spheres, rods, and tubes at micrometer scale or sub-micrometer scale. The secondary structure is mainly a $2 \mathrm{D}$ nanosheet, which is not only 

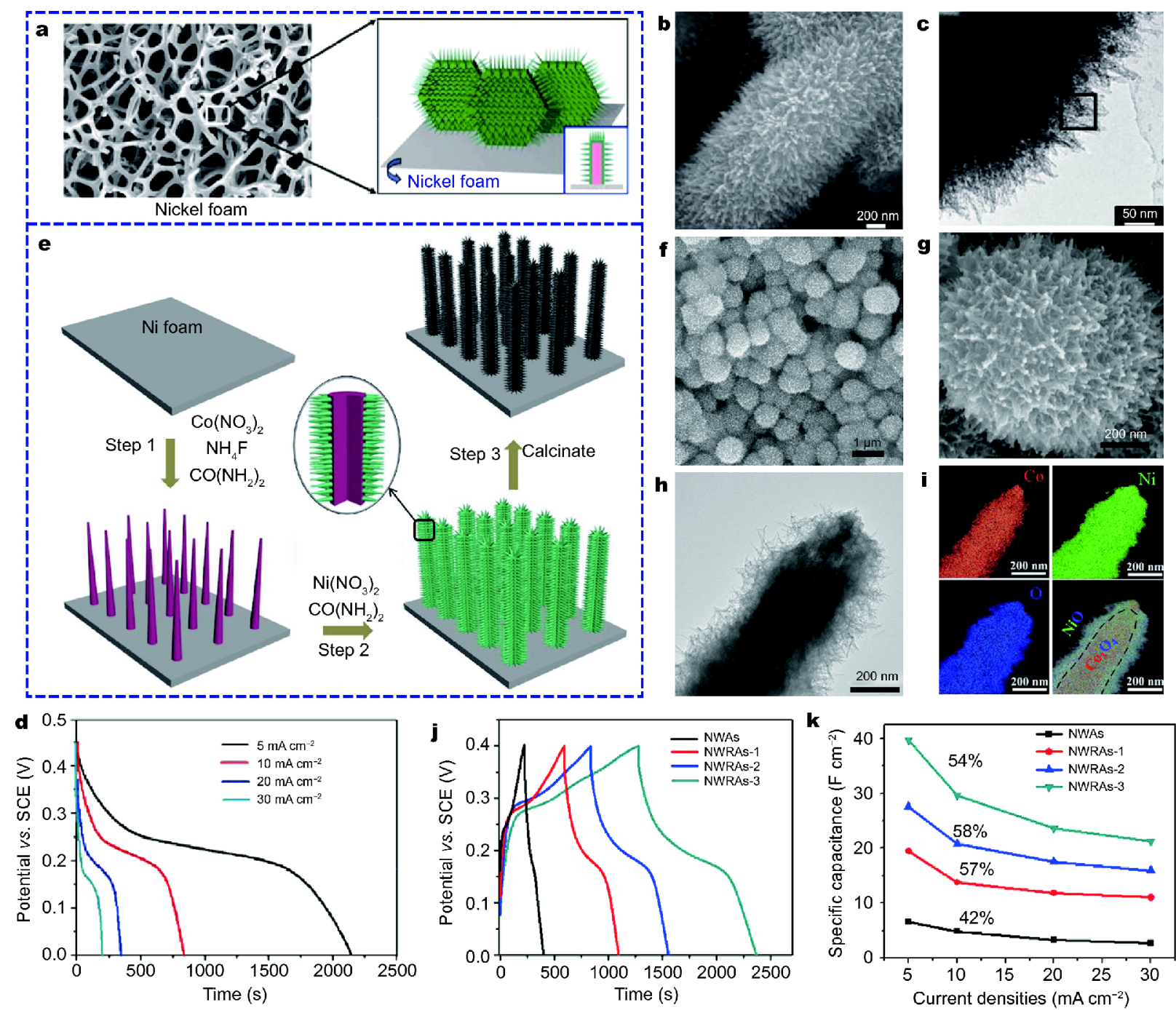

Figure 12 (a) Schematic image for the design of hierarchical core-shell $\mathrm{Co}_{3} \mathrm{O}_{4} @ \mathrm{Ni}-\mathrm{Co}-\mathrm{O}$ nanoarray (the Co $\mathrm{O}_{4}$ nanosheet is shown in pink and the $\mathrm{Ni}-\mathrm{Co}-\mathrm{O}$ nanorod is shown in green); (b, c) SEM and TEM images of the hierarchical $\mathrm{Co}_{3} \mathrm{O}_{4} @ \mathrm{Ni}-\mathrm{Co}-\mathrm{O}$ arrays; (d) galvanostatic discharge curves of the hierarchical $\mathrm{Co}_{3} \mathrm{O}_{4} @ \mathrm{Ni}-\mathrm{Co}-\mathrm{O}$ arrays at various current densities; (e) schematic image for the design of hierarchical core-shell Co $\mathrm{O}_{4} @ \mathrm{NiO}$ arrays (in this work, three samples were fabricated by adding 1,2 , and $3 \mathrm{mmol} \mathrm{Ni}\left(\mathrm{NO}_{3}\right)_{2} \cdot 6 \mathrm{H}_{2} \mathrm{O}$ during the synthesis process. These three samples were denoted as NWRAs-1, NWRAs-2, and NWRAs-3, respectively. $\mathrm{Co}_{3} \mathrm{O}_{4}$ nanowire arrays sample was denoted as NWAs); (f, g) SEM images of NWRAs3 at different magnifications; $(\mathrm{h}, \mathrm{i})$ TEM and EDS mapping images of NWRAs-3; $(\mathrm{j})$ galvanostatic charge and discharge curves at $10 \mathrm{~mA} \mathrm{~cm}^{-2}$; $(\mathrm{k})$ plots of areal specific capacitance versus current density. (a-d) Reproduced with permission from Ref. [180]. Copyright 2012, Springer. (e-k) Reproduced with permission from Ref. [181]. Copyright 2014, Elsevier.

beneficial to the stability of the hierarchical structure but also conducive to electrochemical reaction. Single-metal oxides, bimetallic oxides, the composites of different metal oxides, and the composites of metal oxides with carbon nanomaterials or noble metal NPs have been studied extensively for the compositions of hierarchically nanostructured TMOs. In general, bimetallic oxides or composites with different metal oxides exhibit higher electrochemical activities compared with single-metal oxides because of the complex chemical compositions and the synergetic effect of the individual components.

For further improvement in the performance of SCs, the development of new types of hierarchically nanostructured TMO materials would become the focus of future research. The details can be listed as follows:

(1) The incorporation of TMO materials with various nanostructured carbon materials, such as CNTs, CFs, and graphene, can not only inherit the $1 \mathrm{D}$ or $2 \mathrm{D}$ structures of these carbon materials but also can effectively improve the electrical conductivity of the TMOs. The synthesized 
Table 1 Comparison of typical hierarchically nanostructured TMOs as electrodes of SCs in three-electrode systems

\begin{tabular}{|c|c|c|c|c|c|}
\hline Materials & $\operatorname{SSA}^{\mathrm{a}}\left(\mathrm{m}^{2} \mathrm{~g}^{-1}\right)$ & Electrolyte & Capacitance/current density & Retention $(\%) /$ cycles/current density & Ref. \\
\hline Flower-like $\alpha-\mathrm{MnO}_{2}$ & 216 & $1 \mathrm{~mol} \mathrm{~L}^{-1} \mathrm{~K}_{2} \mathrm{SO}_{4}$ & $298 \mathrm{~F} \mathrm{~g}^{-1} / 0.117 \mathrm{~A} \mathrm{~g}^{-1}$ & $90 / 2000 / 2 \mathrm{~A} \mathrm{~g}^{-1}$ & {$[76]$} \\
\hline$\alpha-\mathrm{MnO}_{2}$ microspheres & I & $1 \mathrm{~mol} \mathrm{~L}^{-1} \mathrm{Na}_{2} \mathrm{SO}_{4}$ & $365 \mathrm{Fg}^{-1} / 2 \mathrm{Ag}^{-1}$ & $100 / 2000 / 2 \mathrm{~A} \mathrm{~g}^{-1}$ & [77] \\
\hline$\beta-\mathrm{MnO}_{2}$ nanoflowers & 267 & $1 \mathrm{~mol} \mathrm{~L}^{-1} \mathrm{Na}_{2} \mathrm{SO}_{4}$ & $296.3 \mathrm{~F} \mathrm{~g}^{-1} / 2 \mathrm{mV} \mathrm{s}^{-1}$ & l & [78] \\
\hline $\mathrm{MnO}_{2} \mathrm{NFs}^{\mathrm{b}}$ & 269 & $1 \mathrm{~mol} \mathrm{~L}^{-1} \mathrm{Na}_{2} \mathrm{SO}_{4}$ & $176 \mathrm{~F} \mathrm{~g}^{-1} / 20 \mathrm{~A} \mathrm{~g}^{-1}$ & $100 / 2000 / 2 \mathrm{Ag}^{-1}$ & [79] \\
\hline$\delta-\mathrm{MnO}_{2}$ microspheres & 238 & $1 \mathrm{~mol} \mathrm{~L}^{-1} \mathrm{Na}_{2} \mathrm{SO}_{4}$ & $364 \mathrm{~F} \mathrm{~g}^{-1} / 1 \mathrm{~A} \mathrm{~g}^{-1}$ & $100 / 6000 / 10 \mathrm{~A} \mathrm{~g}^{-1}$ & [80] \\
\hline $\mathrm{Co}_{3} \mathrm{O}_{4}$ film & 1 & $2 \mathrm{~mol} \mathrm{~L}^{-1} \mathrm{KOH}$ & $352 \mathrm{Fg}^{-1} / 2 \mathrm{~A} \mathrm{~g}^{-1}$ & 1 & [91] \\
\hline Enoki mushroom-like $\mathrm{Co}_{3} \mathrm{O}_{4}$ & I & $6 \mathrm{~mol} \mathrm{~L}^{-1} \mathrm{KOH}$ & $787 \mathrm{~F} \mathrm{~g}^{-1} / 1 \mathrm{~A} \mathrm{~g}^{-1}$ & $94.5 / 1000 / 10 \mathrm{~A} \mathrm{~g}^{-1}$ & [92] \\
\hline $\mathrm{HFC} \mathrm{Co}_{3} \mathrm{O}_{4}{ }^{\mathrm{c}}$ & 245.5 & $2 \mathrm{~mol} \mathrm{~L}^{-1} \mathrm{KOH}$ & $948.9 \mathrm{~F} \mathrm{~g}^{-1} / 1 \mathrm{~A} \mathrm{~g}^{-1}$ & 1 & [93] \\
\hline $\mathrm{NiO} \mathrm{NWs}^{\mathrm{d}}$ & I & $6 \mathrm{~mol} \mathrm{~L}^{-1} \mathrm{KOH}$ & $1493 \mathrm{Fg}^{-1} / 3 \mathrm{Ag}^{-1}$ & $87 / 2000 / 50 \mathrm{mV} \mathrm{s}^{-1}$ & {$[100]$} \\
\hline $\mathrm{NiO} N T A s^{e}$ & 165 & $1 \mathrm{~mol} \mathrm{~L}^{-1} \mathrm{Na}_{2} \mathrm{SO}_{4}$ & $675 \mathrm{~F} \mathrm{~g}^{-1} / 2 \mathrm{~A} \mathrm{~g}^{-1}$ & $93.2 / 10000 / 2 \mathrm{~A} \mathrm{~g}^{-1}$ & {$[101]$} \\
\hline $\mathrm{D}-\mathrm{NiO}^{\mathrm{f}}$ & 92.99 & $2 \mathrm{~mol} \mathrm{~L}^{-1} \mathrm{KOH}$ & $612.5 \mathrm{~F} \mathrm{~g}^{-1} / 0.5 \mathrm{~A} \mathrm{~g}^{-1}$ & $90 / 1000 / 0.5 \mathrm{~A} \mathrm{~g}^{-1}$ & {$[102]$} \\
\hline $\mathrm{NiO}-\mathrm{HMNAs}{ }^{\mathrm{g}}$ & 312.6 & $2 \mathrm{~mol} \mathrm{~L}^{-1} \mathrm{KOH}$ & $3114 \mathrm{~F} \mathrm{~g}^{-1} / 5 \mathrm{~mA} \mathrm{~cm}^{-2}$ & $87.6 / 4000 / 30 \mathrm{~mA} \mathrm{~cm}^{-2}$ & [103] \\
\hline $\mathrm{CNRNP}^{\mathrm{h}}$ & I & $3 \mathrm{~mol} \mathrm{~L}^{-1} \mathrm{KOH}$ & $800 \mathrm{~F} \mathrm{~g}^{-1} / 200 \mathrm{mV} \mathrm{s}^{-1}$ & 1 & [106] \\
\hline Flower-like $\mathrm{CuO}$ & / & $5 \mathrm{~mol} \mathrm{~L}^{-1} \mathrm{NaOH}$ & $1641 \mathrm{mF} \mathrm{cm}^{-2} / 2 \mathrm{~mA} \mathrm{~cm}^{-2}$ & $79 / 10000 / 4 \mathrm{~mA} \mathrm{~cm}^{-2}$ & [107] \\
\hline Flower-shaped $\mathrm{CuO}$ & 119.6 & $1 \mathrm{~mol} \mathrm{~L}^{-1} \mathrm{KOH}$ & $520 \mathrm{Fg}^{-1} / 1 \mathrm{~A} \mathrm{~g}^{-1}$ & $95.2 / 5000 / 1 \mathrm{~A} \mathrm{~g}^{-1}$ & {$[108]$} \\
\hline $\mathrm{Bi}_{2} \mathrm{O}_{3} \mathrm{NBs}^{\mathrm{i}}$ & 196 & $1 \mathrm{~mol} \mathrm{~L}^{-1} \mathrm{Na}_{2} \mathrm{SO}_{4}$ & $250 \mathrm{Fg}^{-1} / 100 \mathrm{mV} \mathrm{s}^{-1}$ & $100 / 1000 / 100 \mathrm{mV} \mathrm{s}^{-1}$ & {$[113]$} \\
\hline Rod-like $\mathrm{Bi}_{2} \mathrm{O}_{3}$ & / & $6 \mathrm{~mol} \mathrm{~L}^{-1} \mathrm{KOH}$ & $1350 \mathrm{Fg}^{-1} / 0.1 \mathrm{~A} \mathrm{~g}^{-1}$ & $97.6 / 1000 / 0.1 \mathrm{~A} \mathrm{~g}^{-1}$ & {$[114]$} \\
\hline $\mathrm{NiCo}_{2} \mathrm{O}_{4}$ microspheres & 148.5 & $6 \mathrm{~mol} \mathrm{~L}^{-1} \mathrm{KOH}$ & $1006 \mathrm{Fg}^{-1} / 1 \mathrm{~A} \mathrm{~g}^{-1}$ & $93.2 / 1000 / 8 \mathrm{~A} \mathrm{~g}^{-1}$ & {$[124]$} \\
\hline $\mathrm{NiCo}_{2} \mathrm{O}_{4} \mathrm{MHSs}^{\mathrm{j}}$ & 118.3 & $3 \mathrm{~mol} \mathrm{~L}^{-1} \mathrm{KOH}$ & $2623 \mathrm{Fg}^{-1} / 1 \mathrm{~A} \mathrm{~g}^{-1}$ & $99.2 / 3000 / 10 \mathrm{~A} \mathrm{~g}^{-1}$ & {$[125]$} \\
\hline $\mathrm{NiCoO}_{2} \mathrm{NTs}^{\mathrm{k}}$ & 98.9 & $2 \mathrm{~mol} \mathrm{~L}^{-1} \mathrm{KOH}$ & $1468 \mathrm{Fg}^{-1} / 2 \mathrm{Ag}^{-1}$ & $99.2 / 3000 / 10 \mathrm{~A} \mathrm{~g}^{-1}$ & {$[126]$} \\
\hline $\mathrm{ZnV}_{2} \mathrm{O}_{4} \mathrm{NHNs}^{1}$ & l & $2 \mathrm{~mol} \mathrm{~L}^{-1} \mathrm{KOH}$ & $385 \mathrm{~F} \mathrm{~g}^{-1} / 0.5 \mathrm{~A} \mathrm{~g}^{-1}$ & $89 / 1000 / 1 \mathrm{~A} \mathrm{~g}^{-1}$ & {$[127]$} \\
\hline $\mathrm{CoO} @ \mathrm{MnO}_{2}$ core-shell & 154.95 & $6 \mathrm{~mol} \mathrm{~L}^{-1} \mathrm{KOH}$ & $1835 \mathrm{~F} \mathrm{~g}^{-1} / 1 \mathrm{~A} \mathrm{~g}^{-1}$ & $97.7 / 10000 / 1 \mathrm{~A} \mathrm{~g}^{-1}$ & {$[136]$} \\
\hline $\mathrm{Fe}_{3} \mathrm{O}_{4}-\mathrm{MnO}_{2}$ microspheres & I & $1 \mathrm{~mol} \mathrm{~L}^{-1} \mathrm{Na}_{2} \mathrm{SO}_{4}$ & $367.4 \mathrm{~F} \mathrm{~g}^{-1} / 100 \mathrm{mV} \mathrm{s}^{-1}$ & $76 / 5000 / 5 \mathrm{~A} \mathrm{~g}^{-1}$ & [137] \\
\hline $\mathrm{Co}_{3} \mathrm{O}_{4} @ \mathrm{MnO}_{2} \mathrm{NAs}^{\mathrm{m}}$ & l & $1 \mathrm{~mol} \mathrm{~L}^{-1} \mathrm{LiOH}$ & $1905.4 \mathrm{~F} \mathrm{~g}^{-1} / 0.5 \mathrm{~A} \mathrm{~g}^{-1}$ & $89.8 / 5000 / 2 \mathrm{~A} \mathrm{~g}^{-1}$ & {$[138]$} \\
\hline $\mathrm{Cu}_{0.27} \mathrm{Co}_{2.73} \mathrm{O}_{4} / \mathrm{MnO}_{2} \mathrm{NRAs}^{\mathrm{n}}$ & l & $6 \mathrm{~mol} \mathrm{~L}^{-1} \mathrm{KOH}$ & $3.1 \mathrm{~F} \mathrm{~cm}^{-2} / 24.8 \mathrm{~mA} \mathrm{~cm}^{-2}$ & 1 & [139] \\
\hline $\mathrm{NiCo}_{2} \mathrm{O}_{4} @ \mathrm{MnO}_{2}$ core-shell & 75.06 & $1 \mathrm{~mol} \mathrm{~L}^{-1} \mathrm{NaOH}$ & $1595.1 \mathrm{~F} \mathrm{~g}^{-1} / 3 \mathrm{~mA} \mathrm{~cm}^{-2}$ & $92.6 / 2000 / 40 \mathrm{~mA} \mathrm{~cm}^{-2}$ & {$[140]$} \\
\hline $\mathrm{NiCo}_{2} \mathrm{O}_{4} @ \mathrm{MnO}_{2}$ nanosheets & / & $1 \mathrm{~mol} \mathrm{~L}^{-1} \mathrm{KOH}$ & $913.6 \mathrm{~F} \mathrm{~g}^{-1} / 0.5 \mathrm{~A} \mathrm{~g}^{-1}$ & $87.1 / 3000 / 0.5 \mathrm{~A} \mathrm{~g}^{-1}$ & {$[141]$} \\
\hline Dumbbell-like Au- $\mathrm{Fe}_{3} \mathrm{O}_{4}$ & I & $1 \mathrm{~mol} \mathrm{~L}^{-1} \mathrm{KOH}$ & $464 \mathrm{~F} \mathrm{~g}^{-1} / 1 \mathrm{~A} \mathrm{~g}^{-1}$ & $86.4 / 1000 / 10 \mathrm{~A} \mathrm{~g}^{-1}$ & {$[146]$} \\
\hline $\mathrm{Co}_{3} \mathrm{O}_{4} @ \mathrm{Au} @ \mathrm{MnO}_{2}(\mathrm{NSs}) \mathrm{HHs}^{\circ}$ & l & $1 \mathrm{~mol} \mathrm{~L}^{-1} \mathrm{LiOH}$ & $1532.4 \mathrm{~F} \mathrm{~g}^{-1} / 1 \mathrm{~A} \mathrm{~g}^{-1}$ & $115 / 5000 / 10 \mathrm{~A} \mathrm{~g}^{-1}$ & [147] \\
\hline ZnO@Au@NiO & l & $1 \mathrm{~mol} \mathrm{~L}^{-1} \mathrm{KOH}$ & $3.5 \mathrm{~F} \mathrm{~cm}^{-2} / 2 \mathrm{~mA} \mathrm{~cm}^{-2}$ & $80.3 / 4000 / 30 \mathrm{~mA} \mathrm{~cm}^{-2}$ & [151] \\
\hline $\mathrm{MnO}_{2} / \mathrm{RGO} / \mathrm{CF}^{\mathrm{p}}$ & I & $1 \mathrm{~mol} \mathrm{~L}^{-1} \mathrm{Na}_{2} \mathrm{SO}_{4}$ & $13.7 \mathrm{~F} \mathrm{~cm}^{-3} / 0.5 \mathrm{~mA} \mathrm{~cm}^{-2}$ & 1 & {$[170]$} \\
\hline $3 \mathrm{D} \mathrm{Co}_{3} \mathrm{O}_{4}-\mathrm{nb} @ \mathrm{CG}^{\mathrm{q}}$ & I & 30 wt.\% KOH & $600.19 \mathrm{~F} \mathrm{~g}^{-1} / 0.7 \mathrm{~A} \mathrm{~g}^{-1}$ & $95.4 / 5000 / 1.1 \mathrm{~A} \mathrm{~g}^{-1}$ & {$[172]$} \\
\hline $\mathrm{NiFe}_{2} \mathrm{O}_{4}-\mathrm{CT}^{\mathrm{r}}$ & l & $6 \mathrm{~mol} \mathrm{~L}^{-1} \mathrm{LiCl}$ & $697 \mathrm{~F} \mathrm{~g}^{-1} / 5 \mathrm{mV} \mathrm{s}^{-1}$ & 1 & {$[174]$} \\
\hline $\mathrm{NiCo}_{2} \mathrm{O}_{4} / \mathrm{NGN} / \mathrm{CNTs}^{\mathrm{s}}$ & l & $6 \mathrm{~mol} \mathrm{~L}^{-1} \mathrm{KOH}$ & $2292.7 \mathrm{~F} \mathrm{~g}^{-1} / 5 \mathrm{~A} \mathrm{~g}^{-1}$ & $125 / 10000 / 30 \mathrm{~A} \mathrm{~g}^{-1}$ & {$[175]$} \\
\hline $\mathrm{ZnO} \mathrm{NR@NiO} / \mathrm{MoO}_{2} \mathrm{CNSAs}^{\mathrm{t}}$ & I & $2 \mathrm{~mol} \mathrm{~L}^{-1} \mathrm{KOH}$ & $1.18 \mathrm{~F} \mathrm{~cm}^{-2} / 5 \mathrm{~mA} \mathrm{~cm}^{-2}$ & $91.7 / 4000 / 10 \mathrm{~mA} \mathrm{~cm}^{-2}$ & {$[176]$} \\
\hline $\mathrm{MnMoO}_{4} / \mathrm{CoMoO}_{4}$ nanowires & 54.06 & $2 \mathrm{~mol} \mathrm{~L}^{-1} \mathrm{NaOH}$ & $187.1 \mathrm{Fg}^{-1} / 1 \mathrm{Ag}^{-1}$ & $98 / 1000 / 20 \mathrm{~A} \mathrm{~g}^{-1}$ & {$[177]$} \\
\hline $\mathrm{Co}_{3} \mathrm{O}_{4} @ \mathrm{CoMoO}_{4}$ core-shell & 61.4 & $2 \mathrm{~mol} \mathrm{~L}^{-1} \mathrm{KOH}$ & $1902 \mathrm{Fg}^{-1} / 1 \mathrm{~A} \mathrm{~g}^{-1}$ & $99 / 5000 / 5 \mathrm{~A} \mathrm{~g}^{-1}$ & {$[179]$} \\
\hline $\mathrm{Co}_{3} \mathrm{O}_{4} @ \mathrm{Ni}-\mathrm{Co}-\mathrm{O} N S R A s^{u}$ & 31.1 & $1 \mathrm{~mol} \mathrm{~L}^{-1} \mathrm{KOH}$ & $2098 \mathrm{~F} \mathrm{~g}^{-1} / 5 \mathrm{~mA} \mathrm{~cm}^{-2}$ & $96 / 1000 / 30 \mathrm{~mA} \mathrm{~cm}^{-2}$ & {$[180]$} \\
\hline $\mathrm{Co}_{3} \mathrm{O}_{4} @ \mathrm{NiO} \mathrm{NWRAs} \mathrm{v}^{\mathrm{v}}$ & 116 & $1 \mathrm{~mol} \mathrm{~L}^{-1} \mathrm{KOH}$ & $2033 \mathrm{~F} \mathrm{~g}^{-1} / 5 \mathrm{~mA} \mathrm{~cm}^{-2}$ & $100 / 1000 / 30 \mathrm{~mA} \mathrm{~cm}^{-2}$ & [181] \\
\hline$\alpha-\mathrm{Fe}_{2} \mathrm{O}_{3}$ nanotubes & 1 & $1 \mathrm{~mol} \mathrm{~L}^{-1} \mathrm{Li}_{2} \mathrm{SO}_{4}$ & $300.1 \mathrm{~F} \mathrm{~g}^{-1} / 0.75 \mathrm{~A} \mathrm{~g}^{-1}$ & 1 & [183] \\
\hline
\end{tabular}

a) SSA: specific surface area. b) $\mathrm{MnO}_{2} \mathrm{NFs}$ : $\mathrm{MnO}_{2}$ nanoflakes; c) $\mathrm{HFC} \mathrm{Co}_{3} \mathrm{O}_{4}$ : hollow fluffy cages $\mathrm{Co}_{3} \mathrm{O}_{4}$; d) NiO NWs: NiO nanowires; e) NiO NTAs: $\mathrm{NiO}$ nanotube arrays; f) D-NiO: double-shelled NiO; g) NiO-HMNAs: hierarchical mesoporous $\mathrm{NiO}$ nanoarrays; h) CNRNP: CuO nanoribbon-onNi-nanoporous/Ni foam; i) $\mathrm{Bi}_{2} \mathrm{O}_{3}$ NBs: $\mathrm{Bi}_{2} \mathrm{O}_{3}$ nanobelts; j) $\mathrm{NiCo}_{2} \mathrm{O}_{4}$ MHSs: $\mathrm{NiCo}_{2} \mathrm{O}_{4}$ multiple hierarchical structures; $\mathrm{k}$ ) $\mathrm{NiCoO}_{2} \mathrm{NTs}$ : $\mathrm{NiCoO}_{2}$

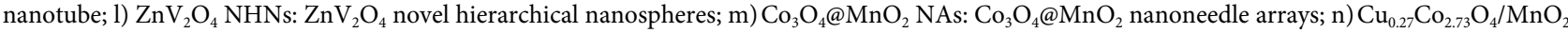
NRAs: $\mathrm{Cu}_{0.27} \mathrm{Co}_{2.73} \mathrm{O}_{4} / \mathrm{MnO}_{2}$ nanorod arrays; o) $\mathrm{Co}_{3} \mathrm{O}_{4} @ \mathrm{Au} @ \mathrm{MnO}_{2}$ (NSs) HHs: $\mathrm{Co}_{3} \mathrm{O}_{4} @ \mathrm{Au} @ \mathrm{MnO}_{2}$ nanosheet hierarchical heterostructures; p) $\mathrm{MnO}_{2} /$ $\mathrm{RGO} / \mathrm{CF}: \mathrm{MnO}_{2}$ /reduced graphene oxide/carbon nanofiber; q) $\mathrm{Co}_{3} \mathrm{O}_{4}$-nb@CG: $\mathrm{Co}_{3} \mathrm{O}_{4}$ nanobeads-CNTs (carbon nanotubes)-GNSs (graphene nanosheets). r) $\mathrm{NiFe}_{2} \mathrm{O}_{4}-\mathrm{CT}$ : $\mathrm{NiFe}_{2} \mathrm{O}_{4}$ nanocone forest on carbon textile; s) $\mathrm{NiCo}_{2} \mathrm{O}_{4} / \mathrm{NGN} / \mathrm{CNTs}: \mathrm{NiCo}_{2} \mathrm{O}_{4}$ nanosheets on nitrogen-doped graphene/ carbon nanotubes; t) ZnO NR@NiO/ $\mathrm{MoO}_{2} \mathrm{CNSAs:} \mathrm{ZnO}$ nanorod@NiO/ $\mathrm{MoO}_{2}$ composite nanosheet arrays; $\left.\mathrm{u}\right) \mathrm{Co}_{3} \mathrm{O}_{4} @ \mathrm{Ni}-\mathrm{Co}-\mathrm{O} \mathrm{NSRAs:} \mathrm{Co}_{3} \mathrm{O}_{4} @ \mathrm{Ni}-$ Co-O nanosheet@nanorod arrays; v) $\mathrm{Co}_{3} \mathrm{O}_{4} @ \mathrm{NiO}$ NWRAs: $\mathrm{Co}_{3} \mathrm{O}_{4} @ \mathrm{NiO}$ nanowire@nanorod arrays. 
Table 2 Typical hierarchically nanostructured TMOs as cathodes of asymmetric SCs

\begin{tabular}{|c|c|c|c|c|c|}
\hline \multirow{2}{*}{ Cathode materials } & \multirow{2}{*}{ Anode materials } & \multirow{2}{*}{ Working voltage } & \multicolumn{2}{|c|}{ Device performance $^{a}$} & \multirow{2}{*}{ Ref. } \\
\hline & & & Energy density & Power density & \\
\hline$\delta$ - $\mathrm{MnO}_{2}$ microspheres & Activated carbon & $0-2 \mathrm{~V}$ & $48.06 \mathrm{~W} \mathrm{~h} \mathrm{~kg}^{-1}$ & $1.0 \mathrm{~kW} \mathrm{~kg}^{-1}$ & {$[80]$} \\
\hline CoO@ $\mathrm{MnO}_{2}$ core-shell & Nitrogen-doped graphene & $0-1.8 \mathrm{~V}$ & $85.9 \mathrm{~W} \mathrm{~h} \mathrm{~kg}^{-1}$ & $852.4 \mathrm{~W} \mathrm{~kg}^{-1}$ & {$[136]$} \\
\hline $\mathrm{NiCo}_{2} \mathrm{O}_{4} @ \mathrm{MnO}_{2}$ nanosheets & Activated carbon & $0-1.5 \mathrm{~V}$ & $37.5 \mathrm{~W} \mathrm{~h} \mathrm{~kg}{ }^{-1}$ & $187.5 \mathrm{~W} \mathrm{~kg}^{-1}$ & [141] \\
\hline $\mathrm{MnO}_{2} / \mathrm{RGO} / \mathrm{CF}^{\mathrm{b}}$ & $\mathrm{GH} / \mathrm{CW}^{\mathrm{c}}$ & $0-1.6 \mathrm{~V}$ & $0.63 \mathrm{~mW} \mathrm{~h} \mathrm{~cm}^{-3}$ & $0.2 \mathrm{~W} \mathrm{~cm}^{-3}$ & {$[170]$} \\
\hline $\mathrm{NiCo}_{2} \mathrm{O}_{4} / \mathrm{NGN} / \mathrm{CNTs}^{\mathrm{d}}$ & NGN/CNTs ${ }^{\mathrm{e}}$ & $0-1.55 \mathrm{~V}$ & $42.7 \mathrm{~W} \mathrm{~h} \mathrm{~kg}^{-1}$ & $775 \mathrm{~W} \mathrm{~kg}^{-1}$ & {$[175]$} \\
\hline $\mathrm{Co}_{3} \mathrm{O}_{4} @ \mathrm{CoMoO}_{4}$ core-shell & $\mathrm{CNTs}^{\mathrm{f}}$ & $0-1.6 \mathrm{~V}$ & $45.2 \mathrm{~W} \mathrm{~h} \mathrm{~kg}^{-1}$ & $400 \mathrm{~W} \mathrm{~kg}^{-1}$ & {$[179]$} \\
\hline
\end{tabular}

a) Device performance: the energy density of the asymmetric SCs device under a certain power density. b) $\mathrm{MnO}_{2} / \mathrm{RGO}^{\mathrm{CF}}$ : $\mathrm{MnO}_{2} / \mathrm{reduced}$ graphene oxide/carbon nanofiber; c) GH/CW: graphene hydrogel-wrapped $\mathrm{Cu}$ wire; d) $\mathrm{NiCo}_{2} \mathrm{O}_{4} / \mathrm{NGN} / \mathrm{CNTs}: \mathrm{NiCo}_{2} \mathrm{O}_{4}$ nanosheets on nitrogen-doped graphene/carbon nanotubes; e) NGN/CNTs: nitrogen-doped graphene/carbon nanotubes; f) CNTs: carbon nanotubes.

multi-component composites can maximize the benefits from all components, thereby making this approach a highly effective method to improve the performance of the TMO materials. Despite several reports on the composites of metal oxides with carbon nanomaterials, these materials still present massive development space in the future.

(2) Compared with general nanostructured TMOs, hierarchically nanostructured TMOs exhibits higher specific capacitance and better rate performance. However, although the hierarchical nanostructure is favorable for the electrochemical reaction of TMO electrode materials, this special structure often leads to the low tap density of the materials. Therefore, new reasonable structures should be designed for hierarchically nanostructured TMOs to endure large volume energy densities.

(3) It is obvious that the specific capacitances of most of the cobalt-based materials and nickel-based materials are much larger than those of other materials. Therefore, these materials are promising for practical applications. The future research of TMOs-based electrode materials can be focused on cobalt-based materials and nickelbased materials.

(4) The asymmetric SCs are a hot spot in the SC field at present. For asymmetric SCs, various negative and positive electrode materials with well-separated potential windows can be combined to maximize the output voltage; thus, the specific energy of SCs will be markedly increased.

(5) The self-supporting flexible electrode in SCs is another important research direction. When self-supporting flexible materials are used as electrodes, the conductive carbon and bonding agent are unnecessary for the assembly of SC device; thus, the energy density of device can be effectively improved. In addition, the self-supporting flexible electrode can enhance the circulation stability of device. Furthermore, the flexible all-solid-state asymmetric SCs device is crucial because of several advantageous properties, such as a wide operating voltage range, high energy densities, excellent flexibility, and superior long term cycling stability.

(6) Aqueous rechargeable batteries, such as $\mathrm{Ni}-\mathrm{Zn}$ battery, Ni-MH battery, and $\mathrm{Ni}-\mathrm{Fe}$ battery, have attracted renewed interest because of their high theoretical energy density, long cycling life, low cost, and safety [186]. Hierarchically nanostructured TMOs reviewed in this paper also can be applied in aqueous batteries [186]. This is also a very important research direction.

\section{Received 7 July 2017; accepted 10 August 2017; \\ published online 17 October 2017}

1 Simon P, Gogotsi Y. Materials for electrochemical capacitors. Nat Mater, 2008, 7: 845-854

2 Wang $\mathrm{X}, \mathrm{Lu} \mathrm{X}$, Liu B, et al. Flexible energy-storage devices: design consideration and recent progress. Adv Mater, 2014, 26: 47634782

3 Xie K, Wei B. Materials and structures for stretchable energy storage and conversion devices. Adv Mater, 2014, 26: 3592-3617

4 Yu D, Goh K, Wang $\mathrm{H}$, et al. Scalable synthesis of hierarchically structured carbon nanotube-graphene fibres for capacitive energy storage. Nat Nanotech, 2014, 9: 555-562

5 Cheng XB, Huang JQ, Zhang Q, et al. Aligned carbon nanotube/ sulfur composite cathodes with high sulfur content for lithiumsulfur batteries. Nano Energ, 2014, 4: 65-72

6 Kim MS, Lim E, Kim S, et al. General synthesis of N-doped macroporous graphene-encapsulated mesoporous metal oxides and their application as new anode materials for sodium-ion hybrid supercapacitors. Adv Funct Mater, 2017, 27: 1603921

7 Zhang J, Zhao XS. On the configuration of supercapacitors for maximizing electrochemical performance. ChemSusChem, 2012, 5: $818-841$

8 Simon P, Gogotsi Y, Dunn B. Where do batteries end and supercapacitors begin? Science, 2014, 343: 1210-1211

9 Lu Z, Wu X, Jiang M, et al. Transition metal oxides/hydroxides nanoarrays for aqueous electrochemical energy storage systems. Sci China Mater, 2014, 57: 59-69 
10 Feng N, He P, Zhou H. Enabling catalytic oxidation of $\mathrm{Li}_{2} \mathrm{O}_{2}$ at the liquid-solid interface: the evolution of an aprotic $\mathrm{Li}-\mathrm{O}_{2}$ battery. ChemSusChem, 2015, 8: 600-602

11 Peng S, Li L, Hu Y, et al. Fabrication of spinel one-dimensional architectures by single-spinneret electrospinning for energy storage applications. ACS Nano, 2015, 9: 1945-1954

12 Jiang J, He P, Tong S, et al. Ruthenium functionalized graphene aerogels with hierarchical and three-dimensional porosity as a free-standing cathode for rechargeable lithium-oxygen batteries. NPG Asia Mater, 2016, 8: e239

13 Tong $\mathrm{S}$, Zheng $\mathrm{M}, \mathrm{Lu} \mathrm{Y}$, et al. Mesoporous $\mathrm{NiO}$ with a singlecrystalline structure utilized as a noble metal-free catalyst for non-aqueous $\mathrm{Li}-\mathrm{O}_{2}$ batteries. J Mater Chem A, 2015, 3: 1617716182

14 Yang S, He P, Zhou H. Exploring the electrochemical reaction mechanism of carbonate oxidation in $\mathrm{Li}$-air/ $/ \mathrm{CO}_{2}$ battery through tracing missing oxygen. Energ Environ Sci, 2016, 9: 1650-1654

15 Zhang S, Zheng M, Lin Z, et al. Activated carbon with ultrahigh specific surface area synthesized from natural plant material for lithium-sulfur batteries. J Mater Chem A, 2014, 2: 15889-15896

16 Li N, Zheng M, Lu H, et al. High-rate lithium-sulfur batteries promoted by reduced graphene oxide coating. Chem Commun, 2012, 48: 4106-4108

17 Zhong Y, Xia X, Shi F, et al. Transition metal carbides and nitrides in energy storage and conversion. Adv Sci, 2016, 3: 1500286

18 Xie D, Xia X, Zhong Y, et al. Exploring advanced sandwiched arrays by vertical graphene and $\mathrm{N}$-doped carbon for enhanced sodium storage. Adv Energ Mater, 2017, 7: 1601804

19 Wang Y, Song Y, Xia Y. Electrochemical capacitors: mechanism, materials, systems, characterization and applications. Chem Soc Rev, 2016, 45: 5925-5950

20 Wang G, Zhang L, Zhang J. A review of electrode materials for electrochemical supercapacitors. Chem Soc Rev, 2012, 41: 797828

21 Liu L, Niu Z, Chen J. Unconventional supercapacitors from nanocarbon-based electrode materials to device configurations. Chem Soc Rev, 2016, 45: 4340-4363

22 Chen S, Xing W, Duan J, et al. Nanostructured morphology control for efficient supercapacitor electrodes. J Mater Chem A, 2013, 1: 2941-2954

23 Cao X, Yin Z, Zhang H. Three-dimensional graphene materials: preparation, structures and application in supercapacitors. Energ Environ Sci, 2014, 7: 1850-1865

24 Qu C, Jiao Y, Zhao B, et al. Nickel-based pillared MOFs for highperformance supercapacitors: design, synthesis and stability study. Nano Energ, 2016, 26: 66-73

25 Dong Y, Xu X, Li S, et al. Inhibiting effect of $\mathrm{Na}^{+}$pre-intercalation in $\mathrm{MoO}_{3}$ nanobelts with enhanced electrochemical performance. Nano Energ, 2015, 15: 145-152

26 Zhang LL, Zhao XS. Carbon-based materials as supercapacitor electrodes. Chem Soc Rev, 2009, 38: 2520-2531

27 Naoi K, Naoi W, Aoyagi S, et al. New generation "nanohybrid supercapacitor". Acc Chem Res, 2013, 46: 1075-1083

$28 \mathrm{Lu} \mathrm{X}, \mathrm{Yu} \mathrm{M}$, Wang G, et al. Flexible solid-state supercapacitors: design, fabrication and applications. Energ Environ Sci, 2014, 7: $2160-2181$

29 Li B, Zheng M, Xue H, et al. High performance electrochemical capacitor materials focusing on nickel based materials. Inorg Chem Front, 2016, 3: 175-202

30 Zhang F, Liu T, Hou G, et al. Hierarchically porous carbon foams for electric double layer capacitors. Nano Res, 2016, 9: 2875-2888

31 Tan Q, Wang P, Liu H, et al. Hollow $\mathrm{MO}_{x}-\mathrm{RuO}_{2}(\mathrm{M}=\mathrm{Co}, \mathrm{Cu}, \mathrm{Fe}$, $\mathrm{Ni}, \mathrm{CuNi}$ ) nanostructures as highly efficient electrodes for supercapacitors. Sci China Mater, 2016, 59: 323-336

32 Nie Z, Wang Y, Zhang $\mathrm{Y}$, et al. Multi-shelled $\alpha-\mathrm{Fe}_{2} \mathrm{O}_{3}$ microspheres for high-rate supercapacitors. Sci China Mater, 2016, 59: $247-253$

33 Kumar R, Singh RK, Kumar Dubey P, et al. Hydrothermal synthesis of a uniformly dispersed hybrid graphene- $\mathrm{TiO}_{2}$ nanostructure for optical and enhanced electrochemical applications. RSC Adv, 2015, 5: 7112-7120

34 Kumar R, Singh RK, Vaz AR, et al. Microwave-assisted synthesis and deposition of a thin $\mathrm{ZnO}$ layer on microwave-exfoliated graphene: optical and electrochemical evaluations. RSC Adv, 2015, 5: 67988-67995

35 Li Z, Ahadi K, Jiang K, et al. Freestanding hierarchical porous carbon film derived from hybrid nanocellulose for high-power supercapacitors. Nano Res, 2017, 10: 1847-1860

36 Shi JL, Du WC, Yin YX, et al. Hydrothermal reduction of threedimensional graphene oxide for binder-free flexible supercapacitors. J Mater Chem A, 2014, 2: 10830-10834

37 Zhai T, Wan L, Sun S, et al. Phosphate ion functionalized $\mathrm{Co}_{3} \mathrm{O}_{4}$ ultrathin nanosheets with greatly improved surface reactivity for high performance pseudocapacitors. Adv Mater, 2017, 29: 1604167

38 Yi J, Qing Y, Wu CT, et al. Lignocellulose-derived porous phosphorus-doped carbon as advanced electrode for supercapacitors. J Power Sources, 2017, 351: 130-137

39 Yu M, Lin D, Feng H, et al. Boosting the energy density of carbon-based aqueous supercapacitors by optimizing the surface charge. Angew Chem Int Ed, 2017, 56: 5454-5459

40 Li Y, Tang F, Wang R, et al. Novel dual-ion hybrid supercapacitor based on a $\mathrm{NiCo}_{2} \mathrm{O}_{4}$ nanowire cathode and $\mathrm{MoO}_{2}-\mathrm{C}$ nanofilm anode. ACS Appl Mater Interfaces, 2016, 8: 30232-30238

41 Lu X, Zhai T, Zhang X, et al. $\mathrm{WO}_{3-x} @ \mathrm{Au} @ \mathrm{MnO}_{2}$ core-shell nanowires on carbon fabric for high-performance flexible supercapacitors. Adv Mater, 2012, 24: 938-944

42 Yan Y, Gu P, Zheng S, et al. Facile synthesis of an accordion-like Ni-MOF superstructure for high-performance flexible supercapacitors. J Mater Chem A, 2016, 4: 19078-19085

43 Amali AJ, Sun JK, Xu Q. From assembled metal-organic framework nanoparticles to hierarchically porous carbon for electrochemical energy storage. Chem Commun, 2014, 50: 1519-1522

44 Liang Q, Ye L, Huang ZH, et al. A honeycomb-like porous carbon derived from pomelo peel for use in high-performance supercapacitors. Nanoscale, 2014, 6: 13831-13837

45 Sun G, Zhang X, Lin R, et al. Weavable, high-performance, solidstate supercapacitors based on hybrid fibers made of sandwiched structure of MWCNT/rGO/MWCNT. Adv Electron Mater, 2016, 2: 1600102

46 Owusu KA, Qu L, Li J, et al. Low-crystalline iron oxide hydroxide nanoparticle anode for high-performance supercapacitors. Nat Commun, 2017, 8: 14264

47 Wu ZS, Wang DW, Ren W, et al. Anchoring hydrous $\mathrm{RuO}_{2}$ on graphene sheets for high-performance electrochemical capacitors. Adv Funct Mater, 2010, 20: 3595-3602

48 Jiang J, Li Y, Liu J, et al. Recent advances in metal oxide-based electrode architecture design for electrochemical energy storage. Adv Mater, 2012, 24: 5166-5180

49 Cao CY, Guo W, Cui ZM, et al. Microwave-assisted gas/liquid 
interfacial synthesis of flowerlike $\mathrm{NiO}$ hollow nanosphere precursors and their application as supercapacitor electrodes. J Mater Chem, 2011, 21: 3204-3209

50 Endut Z, Hamdi M, Basirun WJ. Pseudocapacitive performance of vertical copper oxide nanoflakes. Thin Solid Films, 2013, 528: 213-216

51 Zhong JH, Wang AL, Li GR, et al. $\mathrm{Co}_{3} \mathrm{O}_{4} / \mathrm{Ni}(\mathrm{OH})_{2}$ composite mesoporous nanosheet networks as a promising electrode for supercapacitor applications. J Mater Chem, 2012, 22: 5656-5665

52 Li R, Ren X, Zhang F, et al. Synthesis of $\mathrm{Fe}_{3} \mathrm{O}_{4} @ \mathrm{SnO}_{2}$ core-shell nanorod film and its application as a thin-film supercapacitor electrode. Chem Commun, 2012, 48: 5010-5012

53 Li F, Xing $\mathrm{Y}$, Huang $\mathrm{M}$, et al. $\mathrm{MnO}_{2}$ nanostructures with threedimensional (3D) morphology replicated from diatoms for highperformance supercapacitors. J Mater Chem A, 2015, 3: 78557861

54 Vijayakumar S, Nagamuthu S, Muralidharan G. Supercapacitor studies on $\mathrm{NiO}$ nanoflakes synthesized through a microwave route. ACS Appl Mater Interfaces, 2013, 5: 2188-2196

55 Wang $\mathrm{C}$, Zhang $\mathrm{X}$, Zhang $\mathrm{D}$, et al. Facile and low-cost fabrication of nanostructured $\mathrm{NiCo}_{2} \mathrm{O}_{4}$ spinel with high specific capacitance and excellent cycle stability. Electrochim Acta, 2012, 63: 220-227

56 Wang $\mathrm{C}$, Zhang $\mathrm{X}, \mathrm{Li} \mathrm{C}$, et al. Facile fabrication of nanostructured $\mathrm{NiCO}_{2} \mathrm{O}_{4}$ supported on $\mathrm{Ni}$ foam for high performance electrochemical energy storage. RSC Adv, 2015, 5: 80620-80624

57 Liu X, Liu J, Sun X. $\mathrm{NiCo}_{2} \mathrm{O}_{4} @ \mathrm{NiO}$ hybrid arrays with improved electrochemical performance for pseudocapacitors. J Mater Chem A, 2015, 3: 13900-13905

58 Park S, Nam I, Kim GP, et al. Hybrid $\mathrm{MnO}_{2}$ film with agarose gel for enhancing the structural integrity of thin film supercapacitor electrodes. ACS Appl Mater Interfaces, 2013, 5: 9908-9912

59 Yang P, Ding Y, Lin Z, et al. Low-cost high-performance solidstate asymmetric supercapacitors based on $\mathrm{MnO}_{2}$ nanowires and $\mathrm{Fe}_{2} \mathrm{O}_{3}$ nanotubes. Nano Lett, 2014, 14: 731-736

60 Kai K, Kobayashi Y, Yamada Y, et al. Electrochemical characterization of single-layer $\mathrm{MnO}_{2}$ nanosheets as a high-capacitance pseudocapacitor electrode. J Mater Chem, 2012, 22: 1469114695

61 Chen LH, Li XY, Rooke JC, et al. Hierarchically structured zeolites: synthesis, mass transport properties and applications. J Mater Chem, 2012, 22: 17381-17403

62 Trogadas P, Ramani V, Strasser P, et al. Hierarchically structured nanomaterials for electrochemical energy conversion. Angew Chem Int Ed, 2016, 55: 122-148

63 Choi BG, Huh YS, Hong WH, et al. Electroactive nanoparticle directed assembly of functionalized graphene nanosheets into hierarchical structures with hybrid compositions for flexible supercapacitors. Nanoscale, 2013, 5: 3976-3981

64 Duay J, Sherrill SA, Gui Z, et al. Self-limiting electrodeposition of hierarchical $\mathrm{MnO}_{2}$ and $\mathrm{M}(\mathrm{OH})_{2} / \mathrm{MnO}_{2}$ nanofibril/nanowires: mechanism and supercapacitor properties. ACS Nano, 2013, 7: 1200-1214

65 Li Y, Fu ZY, Su BL. Hierarchically structured porous materials for energy conversion and storage. Adv Funct Mater, 2012, 22: 46344667

66 Yue Y, Liang H. Hierarchical micro-architectures of electrodes for energy storage. J Power Sources, 2015, 284: 435-445

67 Li S, Dong YF, Wang DD, et al. Hierarchical nanowires for highperformance electrochemical energy storage. Front Phys, 2014, 9: 303-322
$68 \mathrm{Ma} \mathrm{Z}$, Shao G, Fan $\mathrm{Y}$, et al. Construction of hierarchical $\alpha-\mathrm{MnO}_{2}$ nanowires@ultrathin $\delta$ - $\mathrm{MnO}_{2}$ nanosheets core-shell nanostructure with excellent cycling stability for high-power asymmetric supercapacitor electrodes. ACS Appl Mater Interfaces, 2016, 8: 9050-9058

69 Zhang X, Miao W, Li C, et al. Microwave-assisted rapid synthesis of birnessite-type $\mathrm{MnO}_{2}$ nanoparticles for high performance supercapacitor applications. Mater Res Bull, 2015, 71: 111-115

70 Zhang X, Sun X, Zhang H, et al. Comparative performance of birnessite-type $\mathrm{MnO}_{2}$ nanoplates and octahedral molecular sieve (OMS-5) nanobelts of manganese dioxide as electrode materials for supercapacitor application. Electrochim Acta, 2014, 132: 315322

71 Zhang X, Sun X, Zhang H, et al. Microwave-assisted reflux rapid synthesis of $\mathrm{MnO}_{2}$ nanostructures and their application in supercapacitors. ElectroChim Acta, 2013, 87: 637-644

72 Zhang X, Yu P, Zhang H, et al. Rapid hydrothermal synthesis of hierarchical nanostructures assembled from ultrathin birnessitetype $\mathrm{MnO}_{2}$ nanosheets for supercapacitor applications. Electrochim Acta, 2013, 89: 523-529

73 Yu P, Zhang X, Chen Y, et al. Solution-combustion synthesis of $\varepsilon$ $\mathrm{MnO}_{2}$ for supercapacitors. Mater Lett, 2010, 64: 61-64

74 Yu P, Zhang X, Wang D, et al. Shape-controlled synthesis of 3D hierarchical $\mathrm{MnO}_{2}$ nanostructures for electrochemical supercapacitors. Cryst Growth Des, 2009, 9: 528-533

75 Yu P, Zhang X, Chen Y, et al. Preparation and pseudo-capacitance of birnessite-type $\mathrm{MnO}_{2}$ nanostructures via microwave-assisted emulsion method. Mater Chem Phys, 2009, 118: 303-307

76 Yuan C, Hou L, Yang L, et al. Facile interfacial synthesis of flower-like hierarchical a- $\mathrm{MnO}_{2}$ sub-microspherical superstructures constructed by two-dimension mesoporous nanosheets and their application in electrochemical capacitors. J Mater Chem, 2011, 21: 16035-16041

77 Sumboja A, Tefashe UM, Wittstock G, et al. Monitoring electroactive ions at manganese dioxide pseudocapacitive electrodes with scanning electrochemical microscope for supercapacitor electrodes. J Power Sources, 2012, 207: 205-211

78 Yu LL, Zhu JJ, Zhao JT. Beta-manganese dioxide nanoflowers self-assembled by ultrathin nanoplates with enhanced supercapacitive performance. J Mater Chem A, 2014, 2: 9353-9360

79 Jiang $\mathrm{H}$, Sun T, Li C, et al. Hierarchical porous nanostructures assembled from ultrathin $\mathrm{MnO}_{2}$ nanoflakes with enhanced supercapacitive performances. J Mater Chem, 2012, 22: 2751-2756

80 Bag S, Raj CR. Facile shape-controlled growth of hierarchical mesoporous $\delta-\mathrm{MnO}_{2}$ for the development of asymmetric supercapacitors. J Mater Chem A, 2016, 4: 8384-8394

81 Liu B, Zhang X, Shioyama H, et al. Converting cobalt oxide subunits in cobalt metal-organic framework into agglomerated $\mathrm{Co}_{3} \mathrm{O}_{4}$ nanoparticles as an electrode material for lithium ion battery. J Power Sources, 2010, 195: 857-861

82 Yuan C, Yang L, Hou L, et al. Growth of ultrathin mesoporous $\mathrm{Co}_{3} \mathrm{O}_{4}$ nanosheet arrays on $\mathrm{Ni}$ foam for high-performance electrochemical capacitors. Energ Environ Sci, 2012, 5: 7883-7887

83 Zheng M, Cao J, Liao S, et al. Preparation of mesoporous $\mathrm{Co}_{3} \mathrm{O}_{4}$ nanoparticles via solid-liquid route and effects of calcination temperature and textural parameters on their electrochemical capacitive behaviors. J Phys Chem C, 2009, 113: 3887-3894

84 Yang Q, Lu Z, Chang $\mathrm{Z}$, et al. Hierarchical $\mathrm{Co}_{3} \mathrm{O}_{4}$ nanosheet@nanowire arrays with enhanced pseudocapacitive performance. RSC Adv, 2012, 2: 1663-1668 
85 Yuan C, Yang L, Hou L, et al. Large-scale $\mathrm{Co}_{3} \mathrm{O}_{4}$ nanoparticles growing on nickel sheets via a one-step strategy and their ultrahighly reversible redox reaction toward supercapacitors. J Mater Chem, 2011, 21: 18183-18185

86 Xia X, Tu J, Mai Y, et al. Self-supported hydrothermal synthesized hollow $\mathrm{Co}_{3} \mathrm{O}_{4}$ nanowire arrays with high supercapacitor capacitance. J Mater Chem, 2011, 21: 9319-9325

87 Zheng Y, Li Z, Xu J, et al. Multi-channeled hierarchical porous carbon incorporated $\mathrm{Co}_{3} \mathrm{O}_{4}$ nanopillar arrays as $3 \mathrm{D}$ binder-free electrode for high performance supercapacitors. Nano Energ, 2016, 20: 94-107

88 Yadav AA, Chavan UJ. Electrochemical supercapacitive performance of spray deposited $\mathrm{Co}_{3} \mathrm{O}_{4}$ thin film nanostructures. Electrochim Acta, 2017, 232: 370-376

89 Xiong S, Yuan C, Zhang X, et al. Controllable synthesis of mesoporous $\mathrm{Co}_{3} \mathrm{O}_{4}$ nanostructures with tunable morphology for application in supercapacitors. Chem Eur J, 2009, 15: 5320-5326

90 Zhu T, Chen JS, Lou XW. Shape-controlled synthesis of porous $\mathrm{Co}_{3} \mathrm{O}_{4}$ nanostructures for application in supercapacitors. J Mater Chem, 2010, 20: 7015-7020

91 Duan BR, Cao Q. Hierarchically porous $\mathrm{Co}_{3} \mathrm{O}_{4}$ film prepared by hydrothermal synthesis method based on colloidal crystal template for supercapacitor application. Electrochim Acta, 2012, 64: 154-161

92 Luo F, Li J, Lei Y, et al. Three-dimensional enoki mushroom-like $\mathrm{Co}_{3} \mathrm{O}_{4}$ hierarchitectures constructed by one-dimension nanowires for high-performance supercapacitors. Electrochim Acta, 2014, 135: 495-502

93 Zhou X, Shen X, Xia Z, et al. Hollow fluffy $\mathrm{Co}_{3} \mathrm{O}_{4}$ cages as efficient electroactive materials for supercapacitors and oxygen evolution reaction. ACS Appl Mater Interfaces, 2015, 7: 2032220331

94 Qian Y, Liu R, Wang Q, et al. Efficient synthesis of hierarchical $\mathrm{NiO}$ nanosheets for high-performance flexible all-solid-state supercapacitors. J Mater Chem A, 2014, 2: 10917-10922

95 Meher SK, Justin P, Ranga Rao G. Microwave-mediated synthesis for improved morphology and pseudocapacitance performance of nickel oxide. ACS Appl Mater Interfaces, 2011, 3: 2063-2073

96 Huang $\mathrm{ML}, \mathrm{Gu} \mathrm{CD}, \mathrm{Ge} \mathrm{X}$, et al. $\mathrm{NiO}$ nanoflakes grown on porous graphene frameworks as advanced electrochemical pseudocapacitor materials. J Power Sources, 2014, 259: 98-105

$97 \mathrm{Li}$, Zhao W, Huang F, et al. Single-crystalline $\mathrm{Ni}(\mathrm{OH})_{2}$ and $\mathrm{NiO}$ nanoplatelet arrays as supercapacitor electrodes. Nanoscale, 2011, 3: 5103-5109

98 Liu T, Jiang C, Cheng B, et al. Hierarchical flower-like C/NiO composite hollow microspheres and its excellent supercapacitor performance. J Power Sources, 2017, 359: 371-378

99 Lu Z, Chang Z, Liu J, et al. Stable ultrahigh specific capacitance of NiO nanorod arrays. Nano Res, 2011, 4: 658-665

100 An L, Xu K, Li W, et al. Exceptional pseudocapacitive properties of hierarchical $\mathrm{NiO}$ ultrafine nanowires grown on mesoporous NiO nanosheets. J Mater Chem A, 2014, 2: 12799-12804

101 Cao F, Pan GX, Xia XH, et al. Synthesis of hierarchical porous $\mathrm{NiO}$ nanotube arrays for supercapacitor application. J Power Sources, 2014, 264: 161-167

102 Yang Z, Xu F, Zhang W, et al. Controllable preparation of multishelled $\mathrm{NiO}$ hollow nanospheres via layer-by-layer self-assembly for supercapacitor application. J Power Sources, 2014, 246: 24-31

103 Meng G, Yang Q, Wu X, et al. Hierarchical mesoporous NiO nanoarrays with ultrahigh capacitance for aqueous hybrid su- percapacitor. Nano Energ, 2016, 30: 831-839

104 Yang Y, Pei L, Xu X, et al. In-situ growth of self-assembled 3D $\mathrm{Cu}_{2} \mathrm{O} @ \mathrm{Cu}$ foam with enhanced electrochemical properties. Electrochim Acta, 2016, 221: 56-61

105 Dong C, Wang Y, Xu J, et al. 3D binder-free $\mathrm{Cu}_{2} \mathrm{O} @ \mathrm{Cu}$ nanoneedle arrays for high-performance asymmetric supercapacitors. J Mater Chem A, 2014, 2: 18229-18235

106 Deng MJ, Wang CC, Ho PJ, et al. Facile electrochemical synthesis of 3D nano-architectured $\mathrm{CuO}$ electrodes for high-performance supercapacitors. J Mater Chem A, 2014, 2: 12857-12865

107 He D, Xing S, Sun B, et al. Design and construction of threedimensional flower-like $\mathrm{CuO}$ hierarchical nanostructures on copper foam for high performance supercapacitor. Electrochim Acta, 2016, 210: 639-645

108 Lu Y, Yan H, Qiu K, et al. Hierarchical porous $\mathrm{CuO}$ nanostructures with tunable properties for high performance supercapacitors. RSC Adv, 2015, 5: 10773-10781

109 Li L, Zhang X, Zhang Z, et al. A bismuth oxide nanosheet-coated electrospun carbon nanofiber film: a free-standing negative electrode for flexible asymmetric supercapacitors. J Mater Chem A, 2016, 4: 16635-16644

110 Fan HT, Teng XM, Pan SS, et al. Optical properties of $\delta-\mathrm{Bi}_{2} \mathrm{O}_{3}$ thin films grown by reactive sputtering. Appl Phys Lett, 2005, 87: 231916

111 He W, Qin W, Wu X, et al. The photocatalytic properties of bismuth oxide films prepared through the sol-gel method. Thin Solid Films, 2007, 515: 5362-5365

112 Gujar TP, Shinde VR, Lokhande CD, et al. Electrosynthesis of $\mathrm{Bi}_{2} \mathrm{O}_{3}$ thin films and their use in electrochemical supercapacitors. J Power Sources, 2006, 161: 1479-1485

113 Zheng FL, Li GR, Ou YN, et al. Synthesis of hierarchical rippled $\mathrm{Bi}_{2} \mathrm{O}_{3}$ nanobelts for supercapacitor applications. Chem Commun, 2010, 46: 5021-5023

$114 \mathrm{Su} \mathrm{H}, \mathrm{Cao} \mathrm{S}$, Xia N, et al. Controllable growth of $\mathrm{Bi}_{2} \mathrm{O}_{3}$ with rodlike structures via the surfactants and its electrochemical properties. J Appl Electrochem, 2014, 44: 735-740

115 Zhou J, Huang Y, Cao X, et al. Two-dimensional $\mathrm{NiCo}_{2} \mathrm{O}_{4}$ nanosheet-coated three-dimensional graphene networks for highrate, long-cycle-life supercapacitors. Nanoscale, 2015, 7: 70357039

116 Ma FX, Yu L, Xu CY, et al. Self-supported formation of hierarchical $\mathrm{NiCo}_{2} \mathrm{O}_{4}$ tetragonal microtubes with enhanced electrochemical properties. Energ Environ Sci, 2016, 9: 862-866

117 Gao G, Wu HB, Ding S, et al. Hierarchical $\mathrm{NiCo}_{2} \mathrm{O}_{4}$ nanosheets grown on $\mathrm{Ni}$ nanofoam as high-performance electrodes for supercapacitors. Small, 2015, 11: 804-808

118 Yuan C, Li J, Hou L, et al. Ultrathin mesoporous $\mathrm{NiCo}_{2} \mathrm{O}_{4}$ nanosheets supported on ni foam as advanced electrodes for supercapacitors. Adv Funct Mater, 2012, 22: 4592-4597

119 Wei TY, Chen CH, Chien HC, et al. A cost-effective supercapacitor material of ultrahigh specific capacitances: spinel nickel cobaltite aerogels from an epoxide-driven sol-gel process. Adv Mater, 2010, 22: 347-351

120 Zou $\mathrm{R}, \mathrm{Xu} \mathrm{K}$, Wang $\mathrm{T}$, et al. Chain-like $\mathrm{NiCo}_{2} \mathrm{O}_{4}$ nanowires with different exposed reactive planes for high-performance supercapacitors. J Mater Chem A, 2013, 1: 8560-8566

121 Jiang $\mathrm{H}, \mathrm{Ma}$ J, Li C. Hierarchical porous $\mathrm{NiCo}_{2} \mathrm{O}_{4}$ nanowires for high-rate supercapacitors. Chem Commun, 2012, 48: 4465-4467

122 Wang Q, Liu B, Wang X, et al. Morphology evolution of urchinlike $\mathrm{NiCo}_{2} \mathrm{O}_{4}$ nanostructures and their applications as psuedo- 
capacitors and photoelectrochemical cells. J Mater Chem, 2012, 22: $21647-21653$

123 Guo J, Yin Z, Zang X, et al. Facile one-pot synthesis of $\mathrm{NiCo}_{2} \mathrm{O}_{4}$ hollow spheres with controllable number of shells for high-performance supercapacitors. Nano Res, 2017, 10: 405-414

124 Lei $\mathrm{Y}, \mathrm{Li}$ J, Wang $\mathrm{Y}$, et al. Rapid microwave-assisted green synthesis of 3D hierarchical flower-shaped $\mathrm{NiCo}_{2} \mathrm{O}_{4}$ microsphere for high-performance supercapacitor. ACS Appl Mater Interfaces, 2014, 6: 1773-1780

125 Zhou Q, Xing J, Gao Y, et al. Ordered assembly of $\mathrm{NiCo}_{2} \mathrm{O}_{4}$ multiple hierarchical structures for high-performance pseudocapacitors. ACS Appl Mater Interfaces, 2014, 6: 11394-11402

$126 \mathrm{Xu} \mathrm{X,} \mathrm{Zhou} \mathrm{H,} \mathrm{Ding} \mathrm{S,} \mathrm{et} \mathrm{al.} \mathrm{The} \mathrm{facile} \mathrm{synthesis} \mathrm{of} \mathrm{hierarchical}$ $\mathrm{NiCoO} 2$ nanotubes comprised ultrathin nanosheets for supercapacitors. J Power Sources, 2014, 267: 641-647

127 Butt FK, Tahir M, Cao C, et al. Synthesis of novel $\mathrm{ZnV}_{2} \mathrm{O}_{4}$ hierarchical nanospheres and their applications as electrochemical supercapacitor and hydrogen storage material. ACS Appl Mater Interfaces, 2014, 6: 13635-13641

128 Liu J, Zheng M, Shi X, et al. Amorphous FeOOH quantum dots assembled mesoporous film anchored on graphene nanosheets with superior electrochemical performance for supercapacitors. Adv Funct Mater, 2016, 26: 919-930

129 Liu L, Guo H, Liu J, et al. Self-assembled hierarchical yolk-shell structured $\mathrm{NiO@C} \mathrm{from} \mathrm{metal-organic} \mathrm{frameworks} \mathrm{with} \mathrm{out-}$ standing performance for lithium storage. Chem Commun, 2014, 50: 9485-9488

130 Yu L, Zhang G, Yuan C, et al. Hierarchical $\mathrm{NiCo}_{2} \mathrm{O}_{4} @ \mathrm{MnO}_{2}$ coreshell heterostructured nanowire arrays on $\mathrm{Ni}$ foam as high-performance supercapacitor electrodes. Chem Commun, 2013, 49: 137-139

131 Shin DH, Lee JS, Jun J, et al. Fabrication of amorphous carboncoated $\mathrm{NiO}$ nanofibers for electrochemical capacitor applications. J Mater Chem A, 2014, 2: 3364-3371

132 Xia H, Hong C, Li B, et al. Facile synthesis of hematite quantumdot/functionalized graphene-sheet composites as advanced anode materials for asymmetric supercapacitors. Adv Funct Mater, 2015, 25: 627-635

133 Wang K, Yang J, Zhu J, et al. General solution-processed formation of porous transition-metal oxides on exfoliated molybdenum disulfides for high-performance asymmetric supercapacitors. J Mater Chem A, 2017, 5: 11236-11245

134 Zhang Y, Zheng M, Qu M, et al. Core-shell $\mathrm{Co}_{11}\left(\mathrm{HPO}_{3}\right)_{8}(\mathrm{OH})_{6}-$ $\mathrm{Co}_{3} \mathrm{O}_{4}$ hybrids for high-performance flexible all-solid-state asymmetric supercapacitors. J Alloys Compd, 2015, 651: 214-221

135 Zhou M, Lu F, Shen X, et al. One-pot construction of three dimensional $\mathrm{CoMoO}_{4} / \mathrm{Co}_{3} \mathrm{O}_{4}$ hybrid nanostructures and their application in supercapacitors. J Mater Chem A, 2015, 3: 2120121210

136 Li C, Balamurugan J, Thanh $\mathrm{TD}$, et al. 3D hierarchical $\mathrm{CoO} @ \mathrm{MnO}_{2}$ core-shell nanohybrid for high-energy solid state asymmetric supercapacitors. J Mater Chem A, 2017, 5: 397-408

137 Zhu J, Tang S, Xie $\mathrm{H}$, et al. Hierarchically porous $\mathrm{MnO}_{2}$ microspheres doped with homogeneously distributed $\mathrm{Fe}_{3} \mathrm{O}_{4}$ nanoparticles for supercapacitors. ACS Appl Mater Interfaces, 2014, 6: 17637-17646

138 Kong D, Luo J, Wang Y, et al. Three-dimensional $\mathrm{Co}_{3} \mathrm{O}_{4} @ \mathrm{MnO}_{2}$ hierarchical nanoneedle arrays: morphology control and electrochemical energy storage. Adv Funct Mater, 2014, 24: 38153826
139 Ge H, Wang C, Yin L. Hierarchical $\mathrm{Cu}_{0.27} \mathrm{Co}_{2.73} \mathrm{O}_{4} / \mathrm{MnO}_{2}$ nanorod arrays grown on $3 \mathrm{D}$ nickel foam as promising electrode materials for electrochemical capacitors. J Mater Chem A, 2015, 3: 1735917368

140 Bao F, Zhang Z, Guo W, et al. Facile synthesis of three dimensional $\mathrm{NiCo}_{2} \mathrm{O}_{4} @ \mathrm{MnO}_{2}$ core-shell nanosheet arrays and its supercapacitive performance. Electrochim Acta, 2015, 157: 31-40

141 Zhang Y, Wang B, Liu F, et al. Full synergistic contribution of electrodeposited three-dimensional $\mathrm{NiCo}_{2} \mathrm{O}_{4} @ \mathrm{MnO}_{2}$ nanosheet networks electrode for asymmetric supercapacitors. Nano Energ, 2016, 27: 627-637

$142 \mathrm{Zhu}$ J, Xu Z, Lu B. Ultrafine Au nanoparticles decorated $\mathrm{NiCo}_{2} \mathrm{O}_{4}$ nanotubes as anode material for high-performance supercapacitor and lithium-ion battery applications. Nano Energ, 2014, 7: $114-123$

143 Han N, Cao S, Han J, et al. Surface cavities of $\mathrm{Ni}(\mathrm{OH})_{2}$ nanowires can host Au nanoparticles as supported catalysts with high catalytic activity and stability. J Mater Chem A, 2016, 4: 2590-2596

$144 \mathrm{Hu} \mathrm{H}$, Pei Z, Fan $\mathrm{H}$, et al. 3D interdigital $\mathrm{Au} / \mathrm{MnO}_{2} / \mathrm{Au}$ stacked hybrid electrodes for on-chip microsupercapacitors. Small, 2016, 12: 3059-3069

$145 \mathrm{Qu} \mathrm{B}, \mathrm{Hu} \mathrm{L}$, Chen $\mathrm{Y}$, et al. Rational design of $\mathrm{Au}-\mathrm{NiO}$ hierarchical structures with enhanced rate performance for supercapacitors. J Mater Chem A, 2013, 1: 7023-7026

146 Liu S, Guo S, Sun S, et al. Dumbbell-like $\mathrm{Au}-\mathrm{Fe}_{3} \mathrm{O}_{4}$ nanoparticles: a new nanostructure for supercapacitors. Nanoscale, 2015, 7: 4890-4893

$147 \mathrm{Li} \mathrm{W}, \mathrm{Li} \mathrm{G}$, Sun J, et al. Hierarchical heterostructures of $\mathrm{MnO}_{2}$ nanosheets or nanorods grown on $\mathrm{Au}$-coated $\mathrm{Co}_{3} \mathrm{O}_{4}$ porous nanowalls for high-performance pseudocapacitance. Nanoscale, 2013, 5: 2901-2908

$148 \mathrm{Li}$, Wang ZL, Li GR, et al. Design and synthesis of $\mathrm{MnO}_{2} / \mathrm{Mn} /$ $\mathrm{MnO}_{2}$ sandwich-structured nanotube arrays with high supercapacitive performance for electrochemical energy storage. Nano Lett, 2012, 12: 3803-3807

149 Bao L, Zang J, Li X. Flexible $\mathrm{Zn}_{2} \mathrm{SnO}_{4} / \mathrm{MnO}_{2}$ core/shell nanocable -carbon microfiber hybrid composites for high-performance supercapacitor electrodes. Nano Lett, 2011, 11: 1215-1220

150 Xia X, Tu J, Zhang Y, et al. High-quality metal oxide core/shell nanowire arrays on conductive substrates for electrochemical energy storage. ACS Nano, 2012, 6: 5531-5538

151 Zheng X, Yan X, Sun Y, et al. Au-embedded $\mathrm{ZnO} / \mathrm{NiO}$ hybrid with excellent electrochemical performance as advanced electrode materials for supercapacitor. ACS Appl Mater Interfaces, 2015, 7: $2480-2485$

152 Xia X, Tu J, Zhang Y, et al. Porous hydroxide nanosheets on preformed nanowires by electrodeposition: branched nanoarrays for electrochemical energy storage. Chem Mater, 2012, 24: 37933799

153 Fan W, Xia YY, Tjiu WW, et al. Nitrogen-doped graphene hollow nanospheres as novel electrode materials for supercapacitor applications. J Power Sources, 2013, 243: 973-981

154 Peng L, Peng X, Liu B, et al. Ultrathin two-dimensional $\mathrm{MnO}_{2} /$ graphene hybrid nanostructures for high-performance, flexible planar supercapacitors. Nano Lett, 2013, 13: 2151-2157

155 Qu L, Zhao Y, Khan AM, et al. Interwoven three-dimensional architecture of cobalt oxide nanobrush-graphene@ $\mathrm{Ni}_{x} \mathrm{Co}_{2 x}(\mathrm{OH})_{6 x}$ for high-performance supercapacitors. Nano Lett, 2015, 15: 20372044

156 Xia W, Mahmood A, Zou R, et al. Metal-organic frameworks and 
their derived nanostructures for electrochemical energy storage and conversion. Energ Environ Sci, 2015, 8: 1837-1866

157 Zhu G, He Z, Chen J, et al. Highly conductive three-dimensional $\mathrm{MnO}_{2}$-carbon nanotube-graphene-Ni hybrid foam as a binderfree supercapacitor electrode. Nanoscale, 2014, 6: 1079-1085

158 Xie J, Sun X, Zhang N, et al. Layer-by-layer $\beta$-Ni $(\mathrm{OH})_{2} /$ graphene nanohybrids for ultraflexible all-solid-state thin-film supercapacitors with high electrochemical performance. Nano Energ, 2013, 2: 65-74

159 Zhang W, Quan B, Lee C, et al. One-step facile solvothermal synthesis of copper ferrite-graphene composite as a high-performance supercapacitor material. ACS Appl Mater Interfaces, 2015, 7: 2404-2414

160 Kumar R, Dubey PK, Singh RK, et al. Catalyst-free synthesis of a three-dimensional nanoworm-like gallium oxide-graphene nanosheet hybrid structure with enhanced optical properties. RSC Adv, 2016, 6: 17669-17677

161 Kumar R, Savu R, Joanni E, et al. Fabrication of interdigitated micro-supercapacitor devices by direct laser writing onto ultrathin, flexible and free-standing graphite oxide films. RSC Adv, 2016, 6: 84769-84776

162 Kumar R, Singh RK, Dubey PK, et al. Freestanding 3D graphenenickel encapsulated nitrogen-rich aligned bamboo like carbon nanotubes for high-performance supercapacitors with robust cycle stability. Adv Mater Interfaces, 2015, 2: 1500191

163 Singh RK, Kumar R, Singh DP. Graphene oxide: strategies for synthesis, reduction and frontier applications. RSC Adv, 2016, 6: 64993-65011

164 Kumar R, Kim HJ, Park S, et al. Graphene-wrapped and cobalt oxide-intercalated hybrid for extremely durable super-capacitor with ultrahigh energy and power densities. Carbon, 2014, 79: 192-202

165 Kumar R, Singh RK, Savu R, et al. Microwave-assisted synthesis of void-induced graphene-wrapped nickel oxide hybrids for supercapacitor applications. RSC Adv, 2016, 6: 26612-26620

166 Kumar R, Singh RK, Vaz AR, et al. Self-assembled and one-step synthesis of interconnected 3D network of $\mathrm{Fe}_{3} \mathrm{O}_{4} /$ reduced graphene oxide nanosheets hybrid for high-performance supercapacitor electrode. ACS Appl Mater Interfaces, 2017, 9: 88808890

167 Fan L, Tang L, Gong H, et al. Carbon-nanoparticles encapsulated in hollow nickel oxides for supercapacitor application. J Mater Chem, 2012, 22: 16376-16381

168 Huang SZ, Cai Y, Jin J, et al. Hierarchical mesoporous urchin-like $\mathrm{Mn}_{3} \mathrm{O}_{4} /$ carbon microspheres with highly enhanced lithium battery performance by in-situ carbonization of new lamellar manganese alkoxide (Mn-DEG). Nano Energ, 2015, 12: 833-844

169 Zheng M, Qiu D, Zhao B, et al. Mesoporous iron oxide directly anchored on a graphene matrix for lithium-ion battery anodes with enhanced strain accommodation. RSC Adv, 2013, 3: 699703

170 Zhang Z, Xiao F, Wang S. Hierarchically structured $\mathrm{MnO}_{2} /$ graphene/carbon fiber and porous graphene hydrogel wrapped copper wire for fiber-based flexible all-solid-state asymmetric supercapacitors. J Mater Chem A, 2015, 3: 11215-11223

171 Ge J, Yao HB, Hu W, et al. Facile dip coating processed graphene/ $\mathrm{MnO}_{2}$ nanostructured sponges as high performance supercapacitor electrodes. Nano Energ, 2013, 2: 505-513

172 Kumar R, Singh RK, Dubey PK, et al. Self-assembled hierarchical formation of conjugated $3 \mathrm{D}$ cobalt oxide nanobead-CNT-gra- phene nanostructure using microwaves for high-performance supercapacitor electrode. ACS Appl Mater Interfaces, 2015, 7: 15042-15051

173 Zhang J, Zhao X, Huang Z, et al. High-performance all-solid-state flexible supercapacitors based on manganese dioxide/carbon fibers. Carbon, 2016, 107: 844-851

174 Javed MS, Zhang C, Chen L, et al. Hierarchical mesoporous $\mathrm{NiFe}_{2} \mathrm{O}_{4}$ nanocone forest directly growing on carbon textile for high performance flexible supercapacitors. J Mater Chem A, 2016, 4: 8851-8859

175 Yue S, Tong $\mathrm{H}$, Lu L, et al. Hierarchical $\mathrm{NiCo}_{2} \mathrm{O}_{4}$ nanosheets/ nitrogen doped graphene/carbon nanotube film with ultrahigh capacitance and long cycle stability as a flexible binder-free electrode for supercapacitors. J Mater Chem A, 2017, 5: 689-698

176 Hou S, Zhang G, Zeng W, et al. Hierarchical core-shell structure of $\mathrm{ZnO}$ nanorod@NiO/ $\mathrm{MoO}_{2}$ composite nanosheet arrays for high-performance supercapacitors. ACS Appl Mater Interfaces, 2014, 6: 13564-13570

177 Mai LQ, Yang F, Zhao YL, et al. Hierarchical $\mathrm{MnMoO}_{4} / \mathrm{CoMoO}_{4}$ heterostructured nanowires with enhanced supercapacitor performance. Nat Commun, 2011, 2: 381

178 Ding Y, Wan Y, Min YL, et al. General synthesis and phase control of metal molybdate hydrates $\mathrm{MMoO}_{4} \cdot n \mathrm{H}_{2} \mathrm{O}(\mathrm{M}=\mathrm{Co}, \mathrm{Ni}$, Mn, $n=0,3 / 4,1)$ nano/microcrystals by a hydrothermal approach: magnetic, photocatalytic, and electrochemical properties. Inorg Chem, 2008, 47: 7813-7823

179 Wang J, Zhang $\mathrm{X}$, Wei Q, et al. 3D self-supported nanopine forest-like $\mathrm{Co}_{3} \mathrm{O}_{4} @ \mathrm{CoMoO}_{4}$ core-shell architectures for highenergy solid state supercapacitors. Nano Energ, 2016, 19: 222-233

180 Lu Z, Yang Q, Zhu W, et al. Hierarchical $\mathrm{Co}_{3} \mathrm{O}_{4} @ \mathrm{Ni}-\mathrm{Co}-\mathrm{O}$ supercapacitor electrodes with ultrahigh specific capacitance per area. Nano Res, 2012, 5: 369-378

181 Yang Q, Lu Z, Li T, et al. Hierarchical construction of core-shell metal oxide nanoarrays with ultrahigh areal capacitance. Nano Energ, 2014, 7: 170-178

$182 \mathrm{Wu} \mathrm{X}, \mathrm{Lu} \mathrm{Z}$, Zhu W, et al. High-performance aqueous battery with double hierarchical nanoarrays. Nano Energ, 2014, 10: 229234

183 Lin YG, Hsu YK, Lin YC, et al. Hierarchical $\mathrm{Fe}_{2} \mathrm{O}_{3}$ nanotube/ nickel foam electrodes for electrochemical energy storage. Electrochim Acta, 2016, 216: 287-294

$184 \mathrm{Wu} \mathrm{Q}$, Chen $\mathrm{M}$, Chen $\mathrm{K}$, et al. $\mathrm{Fe}_{3} \mathrm{O}_{4}$-based core/shell nanocomposites for high-performance electrochemical supercapacitors. J Mater Sci, 2016, 51: 1572-1580

185 Liu Z, Tian X, Xu X, et al. Capacitance and voltage matching between $\mathrm{MnO}_{2}$ nanoflake cathode and $\mathrm{Fe}_{2} \mathrm{O}_{3}$ nanoparticle anode for high-performance asymmetric micro-supercapacitors. Nano Res, 2017, 10: 2471-2481

$186 \mathrm{Lu} \mathrm{Z}$, Wu X, Lei X, et al. Hierarchical nanoarray materials for advanced nickel-zinc batteries. Inorg Chem Front, 2015, 2: 184187

Acknowledgements This work was supported by the National Natural Science Foundation of China (51202106, 21671170 and 21673203) and New Century Excellent Talents of the University in China (NCET-130645), the Innovation Scientists and Technicians Troop Construction Projects of Henan Province (164200510018), the Plan for Scientific Innovation Talent of Henan Province, the Program for Innovative Research Team (in Science and Technology) in the University of Henan Province (14IRTSTHN004 and 16IRTSTHN003), the Science \& Tech- 
nology Foundation of Henan Province (122102210253 and 13A150019), the Science \& Technology Foundation of Jiangsu Province (BK20150438), the Six Talent Plan (2015-XCL-030), and China Postdoctoral Science Foundation (2012M521115). We also acknowledge the Priority Academic Program Development of Jiangsu Higher Education Institutions and the technical support we received at the Testing Center of Yangzhou University.
Author contributions Zheng M, Xiao X and Li L organized the literatures and wrote the manuscript. Gu P participated in writing and revising the manuscript. Dai $\mathrm{X}$, Tang $\mathrm{H}, \mathrm{Hu} \mathrm{Q}$, and Xue $\mathrm{H}$ revised the manuscript. Pang $\mathrm{H}$ provided the overall concept and revised the manuscript. All authors participated in the general discussion.

Conflict of interest The authors declare that they have no conflict of interest.

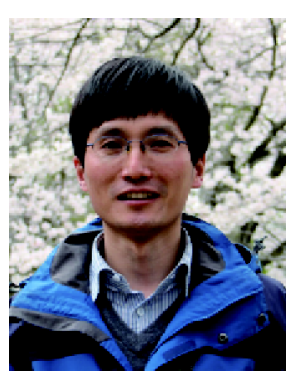

Mingbo Zheng received his $\mathrm{PhD}$ in material processing engineering from Nanjing University of Aeronautics and Astronautics in 2009. He was a postdoctoral researcher at Nanjing University from 2009 to 2012. He was an associate researcher at Nanjing University from 2012 to 2015. He is currently an associate professor at Yanzhou University. His research interests are in the field of materials for electrochemical energy storge, including supercapacitor, lithium-ion battery, and lithium-sulfur battery.

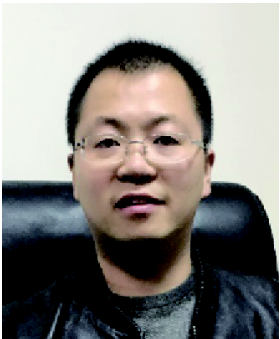

Huan Pang received his PhD degree from Nanjing University in 2011. He then founded his research group in Anyang Normal University where he was appointed as a distinguished professor in 2013. He has now jointed Yangzhou University as a University Distinguished Professor. His research interests include the development of inorganic nanostructures and their applications in flexible electronics with a focus on energy devices.

\section{多级纳米结构过渡金属氧化物作为超级电容器电极材料的应用}

郑明波, 肖潇, 李露露, 顾鹏, 戴晓, 唐浩, 胡钦, 薛怀国, 庞欢 ${ }^{*}$

摘要 为了应对化石燃料短缺与日益严重的环境污染问题, 开发高效、清洁、可持续的电化学储能技术已迫在眉睫. 超级电容器, 由于其 功率密度高、充放电时间短、循环寿命长等特点, 已得到广泛关注. 多种过渡金属氧化物已被作为超级电容器电极材料进行了深入研究. 为了进一步提高性能, 具有多级纳米结构的过渡金属氧化物材料已成为目前超级电容器领域的研究热点. 多级纳米结构不仅可以为电化 学反应提供更多活性位点, 同时还可以缩短离子的传输路径. 本综述对多级纳米结构过渡金属氧化物在超级电容器电极材料方面的应用, 进行了系统的总结与评价, 主要包括: 合成方法、成分、结构和电化学性能. 此外, 对该领域的进一步发展进行了展望. 